\title{
CANTAR CANCIONES ENTRE LOS CUARENTA Y CINCUENTA MESES: UNA HABILIDAD EN GESTACIÓN
}

\author{
MARÍA GABRIELA MÓNACO
}

Tesis presentada para obtener el grado de

Master en Psicología de la Música

Universidad Nacional de La Plata

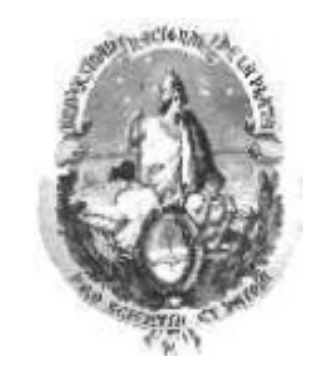

Marzo de 2012

Directora de la Tesis: Dra. SILVIA RAQUEL MALBRÁN

Jurado

Dra SILVIA CRISTINA FURNÓ (UNLP)

Dra. MARIA GUADALUPE SEGALERBA (Universidad de Paris IV)

Prof. MARÍA INÉS FERRERO (UNLP) 
CANTAR CANCIONES ENTRE LOS CUARENTA Y CINCUENTA MESES 2

(C) Copyright María Gabriela Mónaco, 2012

Todos los derechos reservados 
CANTAR CANCIONES ENTRE LOS CUARENTA Y CINCUENTA MESES 3

\section{Agradecimientos}

A la Dra. Silvia Malbrán, directora de esta tesis por su asesoramiento constante, su aliento en los momentos de duda y su vasto conocimiento. Su entusiasmo me ha guiado desde los primeros trabajos de investigación realizados en la Facultad de Bellas Artes.

A la profesora Rosa Torres, vicedirectora del Jardín de Infantes José Manuel Estrada de City Bell, por facilitarme el acceso a la institución y acompañar durante el registro de las voces infantiles.

A los educadores musicales, jueces expertos, que realizaron el análisis de los registros y aportaron sus apreciaciones: Emilia Natali, Rosa Torres y Marina Peña.

A la Dra. Silvia Furnó que asesoró sobre la composición del karaoke y lo grabó en equipos de su propiedad.

A mi familia que apoyó la realización de estos estudios, por su paciencia y comprensión. 


\section{Índice}

Introducción

Capítulos

El Canto Infantil en la Primera Infancia:

1. un objeto de estudio de amplio espectro

1.1 Estudios previos realizados por la autora $\quad$..................... 9

La música y el entorno: visiones de

1.2 la Psicología de la Música

1.3 Naturaleza del problema

Teorías y Modelos Psicológicos:

2. Aportes a una teoría del canto

2.1 Las Ciencias Cognitivas: Teoría y Modelos Psicológicos $\ldots . . .21$

La Psicología de la forma (Gestalt) y

2.1.1 $\quad$ sus aportes a la Teoría Musical. $\quad$................ 21

La Psicología Cultural y sus

2.1.2 aportes a la Teoría Musical. $\quad \ldots \ldots \ldots \ldots \ldots \ldots \ldots \ldots . . \ldots . \ldots 25$

La Teoría de los Esquemas y su

2.1.2.1 vinculación con otros modelos. …............. 28

$\begin{array}{lllll}2.2 & \text { La Psicología Cognitiva y sus aportes a la Teoría Musical } & \ldots & 33\end{array}$

La Psicología Cognitiva de Primera

Generación: una visión avanzada

2.2.1 sobre la pericia musical. $\quad$................. 34

2.2.2 La Psicología Cognitiva de Segunda Generación. ..... 35

2.2.3 La Teoría Ideomotora y la Imitación. $\ldots \ldots \ldots \ldots \ldots . . . . .40$

El Canto infantil en la Primera Infancia: Estado

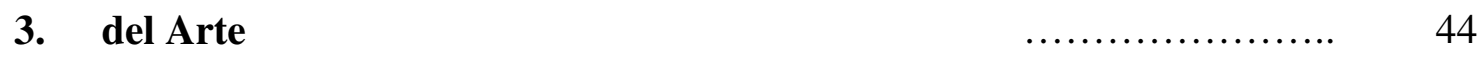

3.1 Música y Lenguaje: algunos paralelismos $\ldots \ldots \ldots \ldots \ldots \ldots . . . \ldots 44$

3.2 El canto como performance infantil f..................... 48

3.2.1 Los esbozos de canto: una iniciativa protomusical. $\quad \ldots \quad 48$

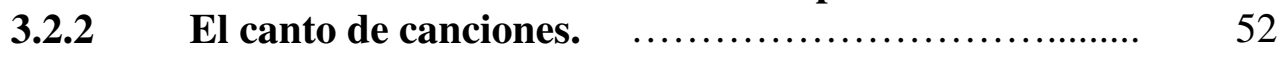

3.2.3 Las improvisaciones cantadas. $\ldots \ldots \ldots \ldots \ldots \ldots \ldots . . . \ldots 54$

3.4 La construcción de la habilidad de cantar f.................. 57

3.4.1 Las habilidades musicales en la primera infancia. $\quad 59$

3.4.2 El canto desde el nacimiento. .................... 62

3.5 El canto infantil en los escritos de pedagogos argentinos $\quad \ldots . . .68$

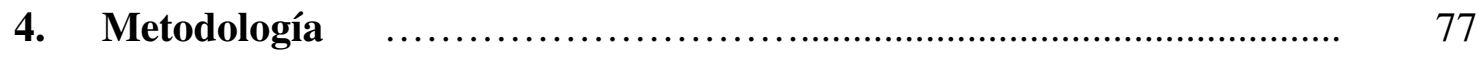

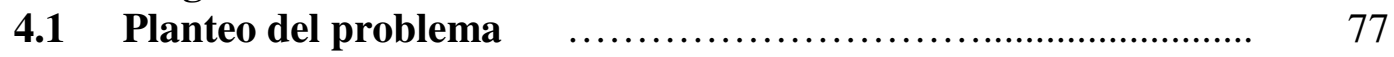

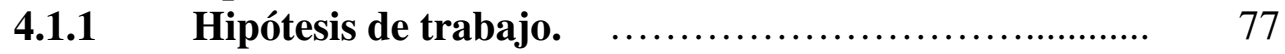

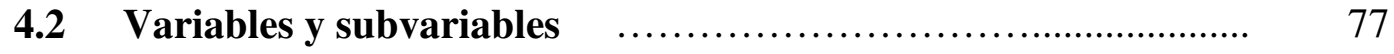

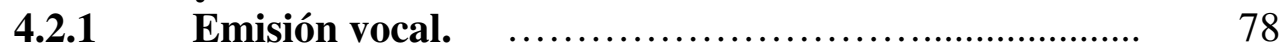

4.2.1.1 Localización de la altura. $\quad$................. 78

4.2.1.2 Contorno melódico. ........................ 78

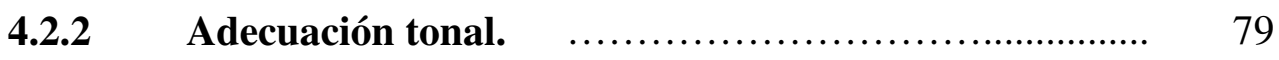


4.2.2.1 Estabilidad tonal. $\quad$........................ 79

4.2.2.2 Apareamiento de la altura. ................ 80

4.2.2.2.1 Altura de comienzo. ........... 80

4.2.2.2.2 Altura de cierre. ............... 80

Vinculaciones entre

las Alturas de

4.2.2.2.3 Comienzo y Cierre. $\quad \ldots \ldots \ldots \ldots . . . . \quad 80$

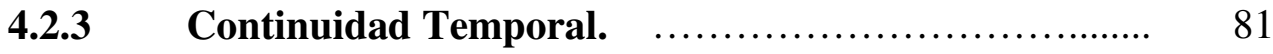

4.2.3.1 Ajuste al tempo. $\quad$......................... 81

4.2.3.2 Réplica del texto literario. $\quad$.................. 81

4.3 Prueba piloto ...................................................... 82

Decisiones adoptadas para la

4.3.1 prueba final (post prueba piloto). …............. 82

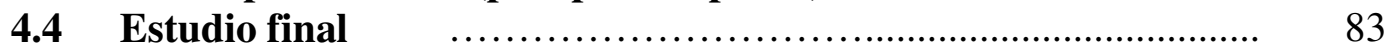

4.4.1 Selección de las canciones. $\quad$............................ 83

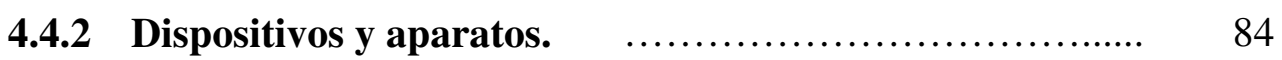

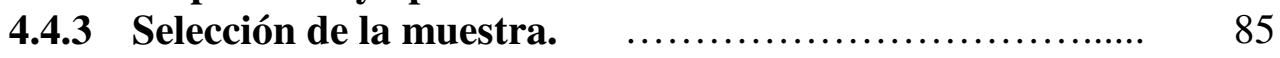

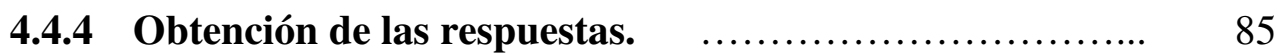

4.4.4.1 Restricciones previas. $\quad . . \ldots \ldots \ldots \ldots \ldots \ldots \ldots . . \ldots \ldots$

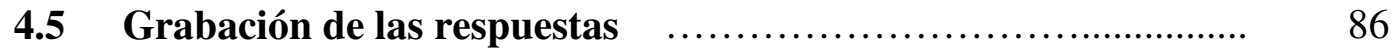

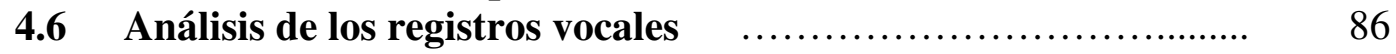

$\begin{array}{llll}4.7 & \text { Escala de puntajes de las respuestas } \ldots \ldots \ldots \ldots \ldots \ldots \ldots \ldots \ldots & 88\end{array}$

4.7.1 Emisión vocal. (............................................. 88

4.7.1.1 Localización de la altura. ..................... 88

4.7.1.2 Contorno melódico. $\quad$.......................... $\quad 88$

4.7.2 Adecuación Tonal. $\quad$....................................... 88

4.7.2.1 Estabilidad tonal. $\quad \ldots \ldots \ldots \ldots \ldots \ldots \ldots \ldots \ldots . . . \ldots \ldots$

4.7.2.2 Apareamiento de la altura. $\quad$.................. 89

4.7.2.2.1 Altura de comienzo. $\quad$................. 89

4.7.2.2.2 Altura de cierre. $\quad$................... 89

Vinculaciones entre

altura de comienzo y

4.7.2.2.3 cierre. $\quad$.................. 89

4.7.3 Continuidad Temporal. $\quad$................................... 89

4.7.3.1 Ajuste al tempo propuesto. $\quad$...................... 89

4.7.3.2 Réplica del texto literario. $\quad$....................... 89

5. Resultados [.......................................................... 91

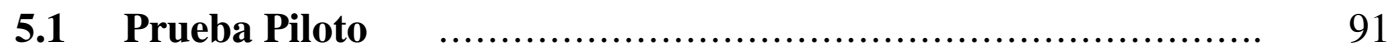

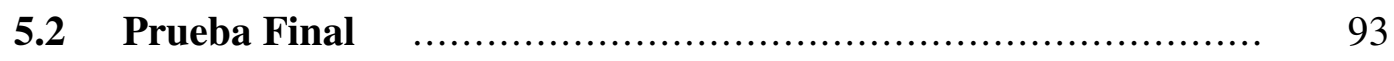

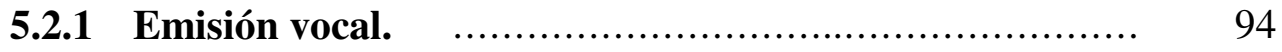

5.2.1.1 Localización de la altura. $\quad$.......................... 94

5.2.1.2 Contorno melódico. ............................. 97

5.2.2 Adecuación tonal. …........................................... 100

5.2.2.1 Estabilidad tonal. .............................. 100

Vinculaciones entre Emisión

$\begin{array}{llll}\text { 5.2.2.1.1 vocal y Estabilidad Tonal. } & \ldots . . & 103 \\ 5.2 .1 .2 & \text { Vinculaciones entre Fidelidad } & \end{array}$

5.2.2.1.2 Vinculaciones entre Fidelidad .... 105 


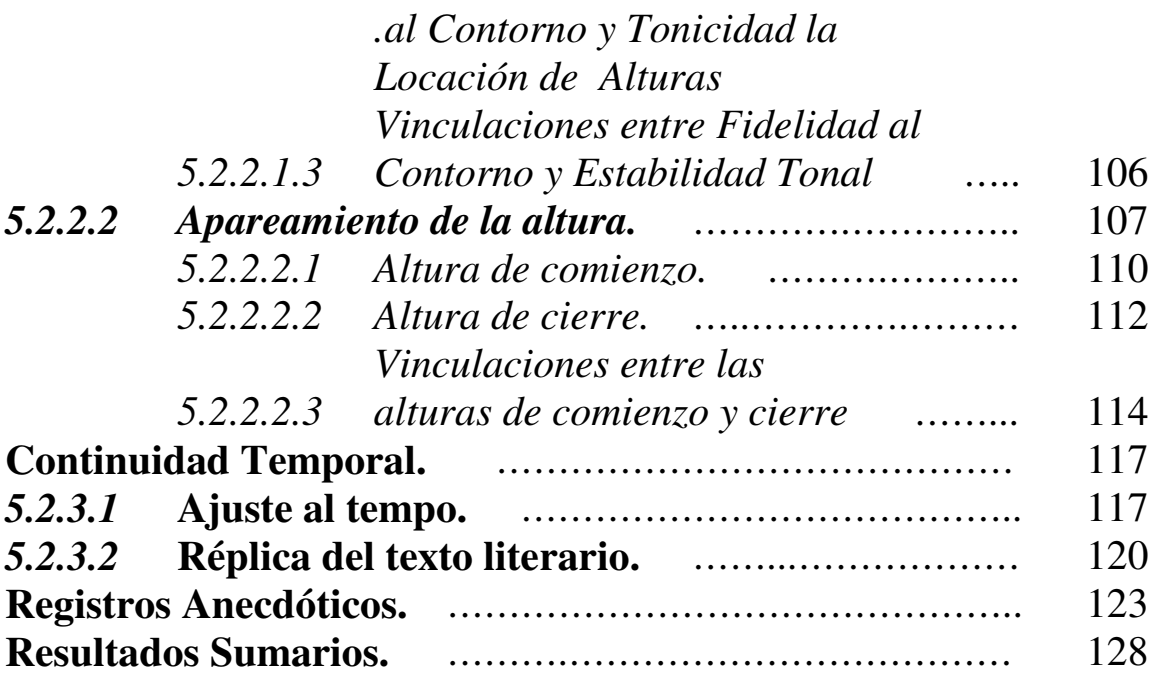

6. Conclusiones y Aportes Potenciales $\quad$.................................... 131

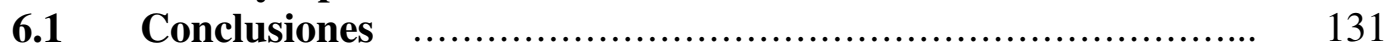

Algunos interrogantes de interés

6.1.1 para investigaciones futuras. $\quad$...................... 141

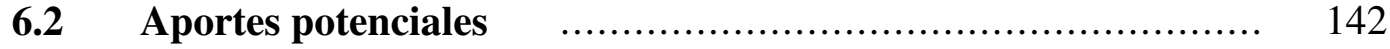

Referencias $\quad$.................................................................. 145 
CANTAR CANCIONES ENTRE LOS CUARENTA Y CINCUENTA MESES 7

\section{Cantar canciones entre los cuarenta y cincuenta meses: una habilidad en gestación}

\section{Introducción}

Cantar es una forma de acercamiento natural al hacer musical al alcance de todos los niños.

Analizar el desarrollo de la habilidad de cantar en edades tempranas es un objeto de estudio de particular interés dada la importancia del canto en el desarrollo expresivo personal y en el rol que cumple en la vida social infantil. Su estudio ha generado diversos interrogantes para los investigadores y motivado importantes trabajos en el área.

Según Welch (2008), el canto es la forma más elemental de hacer música y posible para todos, cualquiera sea su habilidad; además es una actividad poderosamente social que vincula a los individuos con su comunidad.

En el comienzo de la educación sistemática el canto es una de las actividades principales no sólo en las clases de música, sino como acompañamiento expresivo de las tareas habituales. Según Welch (2004, p.19) "la práctica regular del canto puede comunicar sentido de organización, orden y contraste sistemático a la jornada diaria, tal como ocurre con el uso de canciones en el aula". Por lo tanto, el análisis del desarrollo del canto desde edades tempranas se convierte en motivo de interés para la educación en general y particularmente para la educación musical.

Este estudio indaga acerca de las respuestas vocales de niños de entre cuarenta y cincuenta meses, asistentes al primer nivel de la educación inicial. Se intenta analizar la naturaleza y particularidades que caracterizan a los comportamientos vocales infantiles 
CANTAR CANCIONES ENTRE LOS CUARENTA Y CINCUENTA MESES 8

en estas edades, como así también aportar indicios emergentes del trabajo empírico, relativos a la incidencia de la práctica. Los avances obtenidos pueden considerarse aportes potenciales para el aula en el diseño de estrategias susceptibles de ser aplicadas por un maestro de música al abordar la enseñanza del canto en los procesos iniciales. 


\section{Capítulo 1}

\section{El canto infantil en la primera infancia: un objeto de estudio de amplio espectro}

\subsection{Estudios previos realizados por la autora de esta tesis}

Se presentan a continuación sucesivos estudios a cargo de la autora. El recorrido realizado muestra la naturaleza de la indagación a lo largo del tiempo. Cada una de las investigaciones con sus muestras o repertorios señalaron la necesidad de un nuevo estudio repitiendo/variando la muestra de edades y el repertorio.

Las problemáticas que forman parte del presente trabajo, comenzaron en 1993 con investigaciones de carácter transversal y longitudinal, dirigidas a iluminar aspectos que intervienen en el desarrollo del canto y que han permitido delimitar y categorizar las variables aisladas para el presente estudio.

El ejercicio inicial en educación musical de la autora fue en el nivel primario de la enseñanza, es por ello que los primeros trabajos de investigación se refirieron a problemáticas observables en dicho nivel. Durante las clases se podía constatar que los alumnos al cantar utilizaban un registro grave que se suponía fuente de error para la calidad de la entonación y que tal respuesta era tenida insuficientemente en cuenta tanto por los maestros como por los autores de canciones pasibles de cantar en la escuela. Por ello en un primer corpus de investigaciones se abordaron los temas de la tesitura vocal espontánea y las prácticas docentes.

Los resultados de las pruebas suministradas mostraron que los niños empleaban un registro grave y central al cantar espontáneamente, aún en una canción propuesta que tenía una $11^{\text {a }}$ de extensión. Para los maestros de música el análisis de la tonalidad de la canción, su relación con el ámbito de la melodía y el registro en que proponían cantar, 
no parecía ser una variable digna de ser tenida en cuenta para el buen uso de la voz y la eficacia en la entonación.

El segundo grupo de investigaciones fue relativo a la tesitura espontánea al cantar canciones tanto conocidas como enseñadas para los fines del estudio. Nuevamente la muestra fue con niños del nivel inicial, por considerar necesario analizar las características vocales con las que los niños se inician en experiencias de canto colectivo de manera sistemática.

Los resultados mostraron que los niños de 3 y 4 años podían acceder al contorno en cuanto a topografía de ascensos y descensos pero no a los intervalos y que no alcanzaban (en general) el ámbito de 8va., rasgo que por otra parte es la extensión melódica de muchos ejemplares del cancionero habitual en el nivel inicial.

La frecuentación del Himno Nacional Argentino (y obligatoriedad de su enseñanza) en el medio escolar, sugirió utilizarlo para el estudio de las producciones vocales de niños de 7 a 12 años que asistían a escuelas primarias de la zona del gran La Plata. Se trató de registrar el canto espontáneo de la primera frase del himno. El ámbito de dicha sección, abarca la totalidad de las alturas presentes en la obra con una $11^{\mathrm{a}}$ de extensión.

Los resultados mostraron que la mayoría de los niños entrevistados cantaban entre La3 y Fa4, tesitura que resulta reducida y orientada hacia los sonidos graves, lo cual es a todas luces nocivo para la salud vocal y excede la tesitura de cantores no entrenados.

El trabajo amplió su perspectiva local ya que se administró idéntica prueba en otras regiones del país. Los maestros de música realizaron mediciones según el protocolo original (Mónaco, 1998a). Así fueron testeados niños de Paraná (Entre Ríos) 
CANTAR CANCIONES ENTRE LOS CUARENTA Y CINCUENTA MESES 11

que mostraron una tesitura de Sol2-Fa3; Tandil (Buenos Aires) con una tesitura de Sol\#2-Fa\#3 y Mendoza (Capital) con una tesitura de Sol2-Fa\#3 ${ }^{1}$. Los resultados mostraron que en la población infantil de las diferentes regiones (al igual que en la zona del Gran La Plata) la tesitura utilizada es en el registro grave y central sin adoptar el registro medio y agudo. La reducida tesitura usada por los niños procede desde una 6ta. menor (La Plata), una 7ma. menor (Tandil y Paraná) a una 7ma. Mayor (Mendoza) y señalan que la mayoría de los niños de la muestra no están en condiciones de cantar las más frecuentes y sencillas melodías tradicionales. El patrimonio disponible de alturas es tan reducido que por ejemplo si cantan correctamente las alturas más graves de la canción tradicional "Arroz con leche” no pueden cantar las más agudas.

En un trabajo posterior, se estudiaron niños de tres y cuatro años (Mónaco, 2001), respecto de la tesitura espontánea y la nota de comienzo empleada para cantar una canción del repertorio habitual de la institución, que posee un ámbito de 8va. N=48 (24 sujetos de tres años y 24 de cuatro años). Los resultados mostraron que los sonidos empleados por los sujetos para cantar espontáneamente eran en un rango de Do\#4 al Sol\#4 con un $74 \%$ del total de las alturas en los sujetos de tres años y un $76 \%$ para los de cuatro.

De los sonidos más grave y más agudo empleados al cantar, la media fue de Do4-Sol\#4 para los niños de tres años y Do\#4-La4 para los de cuatro años. La tesitura compartida por todos los niños de la muestra, tomados como un solo grupo, fue Re4Fa4 (una 3ra. menor).

Respecto de la nota de comienzo, la media fue Do\#4 para los tres años y Re4 para los cuatro años. La diferencia entre los dos grupos no resultó estadísticamente

\footnotetext{
${ }^{1}$ Se agradece la colaboración de las profesoras: Beatriz Sánchez (+) de Paraná Entre Ríos; Anele Moroder de Tandil y Olga Giacumbo de Mendoza.
} 
significativa, por ello se tomó a ambos grupos como conformando un único grupo. Los resultados mostraron que la tesitura media es de una 6ta menor y que no alcanzan el ámbito de 8va. Por lo tanto se consideró que la canción seleccionada resultaba inadecuada.

La suposición de que el diseño rítmico podía incidir en los resultados motivó un estudio posterior que conciliaba la atención a comportamientos de entonación de las alturas y de organización rítmica.

El trabajo indagó la performance de niños de tres años al cantar una canción y al percutir el pulso más saliente de una microforma musical (Malbrán y Mónaco, 2002). Se analizó para cada sujeto de la muestra $(\mathrm{N}=10)$ la justeza en la entonación, entendida como la emisión de alturas del modelo y la sincronía rítmica, descripta como el acuerdo de fase entre la distribución temporal de acciones en sucesión y un patrón rítmico externo. Los resultados de ambas performances se ordenaron en tres rangos: respuestas más afinadas, intermedias y menos afinadas para el test melódico y respuestas más sincrónicas, intermedias y menos sincrónicas para el test rítmico. Estudios estadísticos mostraron la no correlación entre ambas variables, lo que sugeriría que son habilidades de desarrollo independiente. Los resultados obtenidos indicarían un diferente proceso de desarrollo en ambas ejecuciones y que pueden considerarse habilidades con procesos de configuración y de progreso independiente.

Resultan de interés los resultados del estudio comparativo que se realizaron entre el canto de niños argentinos con sus pares en edad de una institución pre-escolar de Hong Kong ${ }^{2}$. Los resultados fueron similares en cuanto a tesitura y nota de comienzo para cantar la misma canción (Mónaco, 2003). Analizadas las performances más allá del

\footnotetext{
${ }^{2}$ Los registros vocales fueron proporcionados por la profesora Esther Mang.
} 
grado de familiaridad/frecuentación de los niños con la canción seleccionada, la construcción interna de la melodía (El payaso Plinplin - Feliz cumpleaños) excede las posibilidades vocales de los niños. Esto sugirió la necesidad de realizar estudios posteriores sobre la emisión cantada de una canción acorde a los niveles madurativos y de edad de los niños destinatarios.

En otro estudio, Mónaco (1995/publicado en 1999) eligió nuevamente el Himno Nacional Argentino para evaluar la afinación en niños de 7 a 12 años que asistían a coros vocacionales. La elección de sujetos con selección previa y entrenamiento coral, se basó en la suposición de que estos niños ubicarían su voz espontáneamente en el registro agudo; para ello se usó la primera frase de la obra.

El test incluyó tanto el canto espontáneo, como el canto sobre un acompañamiento armónico grabado que se correspondía con el escrito en la partitura. La técnica consistió en que el sujeto escuchara el acompañamiento grabado en piano y cantara sucesivamente en tres tonalidades diferentes.

Si bien el objetivo del trabajo era el estudio de la entonación en una canción muy frecuentada, se consideró de interés indagar en niños con entrenamiento vocal en coros la tonalidad que resultaba más cómoda en el canto con acompañamiento armónico.Las opciones fueron: la tonalidad utilizada habitualmente para su interpretación (la que se toca en actos patrios en Sib, cuyo ámbito es Sib3-Re5) y otros dos propuestos Sol3-Si4 (en la tonalidad de Sol) o Fa3-La4 (en la tonalidad de $\mathrm{Fa}$ ). En el canto con acompañamiento armónico, los niños obtuvieron mejores resultados en la tesitura Sol3Si4.

En cuanto al canto espontáneo la pregunta a responder fue si los niños con entrenamiento coral poseían conciencia de su registro vocal para elegir la tesitura 
CANTAR CANCIONES ENTRE LOS CUARENTA Y CINCUENTA MESES 14

apropiada. Los resultados dieron cuenta del empleo de tonalidades más graves que la original en el $97 \%$ de los sujetos $(\mathrm{N}=30)$, en tesituras que emplearon desde el Fa3 hasta el La4, con una moda estadística para el sonido más grave empleado el Fa\#3 y para el agudo La\#4. No se encontró relación significativa entre la tonalidad elegida para cantar a capella y con acompañamiento, lo que sugiere que los sujetos en el canto espontáneo no eligen la tonalidad más cómoda a su tesitura. Esta conclusión postula que aún en niños coreutas, que cuentan con la conducción de un maestro coral dedicado al problema vocal y que reciben apoyo de técnica vocal, la conciencia de que la afinación y el buen resultado al cantar a capella es dependiente de la tonalidad elegida no ha sido internalizado. Pareciera que los maestros de coro no facilitan suficientemente el tomar conciencia de la importancia de tal elección como así tampoco el que los niños coreutas "registren" en sus representaciones mentales su propia tesitura y puedan exhibir sus mejores rendimientos vocales al momento de cantar a capella.

Ante la comprobación de que tanto los niños sin entrenamiento vocal como aquellos con entrenamiento coral utilizaban al cantar espontáneamente las regiones más graves de la tesitura, se indagó acerca de las acciones de los docentes encargados de la Educación Musical en el nivel inicial y en escuelas primarias de la región, a la hora de seleccionar la tonalidad adecuada para cantar con sus niños (Mónaco, 1998b).

Este nuevo estudio se basó en el supuesto de que la selección del cancionero en términos de la variable ámbito de la melodía, es condición necesaria aunque no suficiente para obtener buenos resultados vocales. La tonalidad a utilizar es la otra variable de incidencia, porque fija los límites de la tesitura.

Se grabó a los maestros de música cantando canciones con sus alumnos usando el acompañamiento de un instrumento armónico. En las pruebas los maestros de música 
CANTAR CANCIONES ENTRE LOS CUARENTA Y CINCUENTA MESES 15

de nivel primario de la escolaridad proponían una tesitura media de La3-La4 para entonar las canciones y los sonidos por debajo del Do central constituían un $11 \%$ del total de sonidos propuestos. En el caso de los maestros del nivel Inicial, la tesitura media propuesta fue de Do central (4) a Do5, y el total de sonidos propuestos para cantar por debajo de Do central fue del $8 \%$. Si bien la $\mathrm{N}=16$, fue pequeña, pareciera que las preocupaciones de los maestros al enseñar a cantar, son ajenas a las variables que intervienen en el desarrollo del canto en el niño; muestra de ello es que en las prácticas de canto colectivo, pareciera fuera de control el análisis del ámbito de la melodía y su relación con la tesitura como elementos determinantes para elegir la tonalidad a proponer y consecuentemente obtener un mejor uso de la voz.

En un trabajo posterior (Mónaco, 1999b) entrevistó veinte maestros de música de pre-escolar para indagar acerca de las experiencias de canto con sus alumnos de cuatro y cinco años: se les solicitó completar un cuestionario con preguntas referidas a la tesitura y tonalidad de las canciones apropiadas para esas edades. Los resultados indicaron que la mayoría de los sonidos propuestos para cantar ocupan el registro grave y central de la tesitura (promedio Do4-La4), sin embargo en las respuestas dadas al cuestionario, los maestros consideran importante el desarrollo del rango más agudo de la tesitura, aunque en la práctica no lo utilizan (opinan que a los cuatro años cantan hasta Do5 y a los cinco años hasta Re5).

La tonalidad de Do Mayor fue la más empleada, aserto comprobado tanto en la práctica como en la opinión de los maestros, quienes utilizan con mayor frecuencia las canciones escritas en dicha tonalidad. Esta práctica sugeriría que la elección de la tonalidad para que los niños canten se vincula con la mayor experiencia de los docentes con la tonalidad de Do Mayor, por ende el nudo de decisión se basaría en la escasa 


\section{CANTAR CANCIONES ENTRE LOS CUARENTA Y CINCUENTA MESES 16}

habilidad del maestro para operar con otras tonalidades en lugar de elegir la tonalidad de ejecución de acuerdo con las posibilidades vocales de los alumnos. Los resultados mostraron que el $43 \%$ de los niños utilizaba un ámbito de Sol3- Sol4, que muestra el uso de alturas ubicadas en el extremo grave de la tesitura.

Se concluyó que, para los maestros de la muestra el análisis de la estructura de la canción, la relación entre el ámbito de la melodía y la tonalidad de ejecución son informaciones desconocidas como factores determinantes para el mejor uso de la voz cantada.

Una posible interpretación de estos resultados es que los maestros utilizan las canciones como repertorio que "cuenta una historia" que facilita la adhesión de los niños y que promueve el desarrollo de interacciones positivas. Si bien dichos beneficios son muy importantes, revelan que los maestros desconocen el uso del repertorio de canciones como herramienta para el desarrollo de la pericia vocal.

El análisis de las respuestas infantiles en las pruebas precedentes sugirió la importancia de analizar las producciones en términos de contorno ya que los resultados indicaban una tendencia a reproducir el contorno global de las canciones más que el diseño intervalar de cada ejemplar.

En un estudio con niños de tres años (Mónaco, 2000) se estudió la fidelidad al contorno y el ajuste interválico al cantar una canción conocida por ellos previamente. La canción seleccionada El payaso Plin plin/Feliz cumpleaños se dividió en sus cuatro unidades formales (chunks). Se analizó en cada chunk la fidelidad al contorno (direccionalidad) y distancia interválica además del nexo intervalar entre chunks. Los chunks uno y dos resultaron los más ajustados, el chunk tres el más difícil de resolver, suponiéndose como causa el salto melódico de 8va. y probablemente el escaso 
incremento de información, pues presenta un sonido más. Este tercer chunk es el que presenta más sonidos aspirados y hablados. En el último chunk la dificultad se ubicó en el nexo entre el chunk tres y cuatro, más que en los intervalos que lo componen. Los resultados permitieron comprobar la habilidad de los niños en la reproducción de ascensos y descensos siguiendo la direccionalidad del contorno, lo que sólo indicaría una primera aproximación a la definición de la topografía melódica sin tomar en cuenta la proporcionalidad en la correspondencia con la interválica original. Esta investigación confirmó estudios previos respecto del análisis de las configuraciones melódicas por segmentación de las frases de la canción tanto como la dificultad presentada por el ejemplar seleccionado, orientando la búsqueda hacia canciones con un ámbito más reducido y de factura melódica más sencilla.

\subsection{La música y el entorno: visiones de la Psicología de la Música}

El aprendizaje de la música constituye una parte importante de la educación por su aporte a la formación integral del ser humano. Su contribución al desarrollo de competencias cognitivas emocionales y sociales ha sido ampliamente aceptada por investigadores del ámbito de la Pedagogía y la Psicología. La concepción tradicional que consideraba a la música una habilidad específica, privilegio de unos pocos especialmente dotados, resulta imposible de sostener. A la luz de de los aportes de la Neurobiología, la Psicología Cognitiva y la Psicología del Desarrollo, hacer música es considerada una actividad natural, mediada por la práctica y a la que todas las personas tienen acceso. Sin duda, "algunos factores genéticos pueden limitar el grado en que una habilidad puede desarrollarse en el curso de una vida, pero desde el punto de vista 
práctico es probable que ese límite biológico no se alcance nunca” (Ibarretxe, 2010, p.46).

Según Welch (1998) la compleja interacción entre la estructura básica del intelecto humano y las oportunidades que proporciona el entorno socio-cultural, determinan la naturaleza y el alcance del desarrollo musical en la temprana infancia y a lo largo de la vida.

Las pioneras investigaciones de Zenatti sobre la percepción musical de los niños $(1969,1990)$, hacen referencia a que las aptitudes musicales no dependen tanto de una formación específica sino que más bien son el resultado de un proceso de enculturación y surgen de los encuentros experienciales del niño con la música de su entorno.

Sloboda (1994) consideró que un individuo será capaz de alcanzar altísimos niveles de capacidad, independientemente de sus dotes innatas, si ha contado con un largo y sostenido proceso de estimulación, refuerzo y entrenamiento, dentro y fuera del ámbito escolar. Identificó cinco indicadores que influyen en el desarrollo de las habilidades musicales: 1) facilitar las experiencias musicales en la infancia; 2) asegurar altos niveles de práctica; 3) contar con un apoyo familiar adecuado; 4) mediar la práctica de los primeros años con la acción de profesores capaces de proponer clases divertidas y en un ambiente relajado y 5) brindar oportunidades para experimentar emociones positivas por medio de la música.

Swanwick (1991, p.90) señala "yo sospecho que si los niños viven en un entorno donde se producen encuentros musicales, la secuencia (de desarrollo) se activa... si el entorno es especialmente enriquecedor, la secuencia evolucionará más rápidamente". Sin 
CANTAR CANCIONES ENTRE LOS CUARENTA Y CINCUENTA MESES 19

embargo admite que no está demostrado que estos cambios se manifiesten de manera uniforme.

Estas referencias dan cuenta acerca de la probabilidad de que una persona pueda lograr niveles sobresalientes de realización en una variedad de tareas musicales depende en gran medida de la calidad de la práctica, el sostén de la familia y del entorno cultural.

\subsection{Naturaleza del problema}

Expertos en el área han comprobado que algunos niños cantan antes de hablar (Stadler-Elmer, 2000; Welch, $1994^{3}$ ). La pregunta clave a responder es... ¿qué es lo que "cantan"?

Los estudios previos acerca de las primeras aproximaciones al canto consideradas proto-cantos- indican que los niños en estas performances reproducen el contorno melódico (ver capítulo 2). Según Malbrán y García Malbrán (2010, p.183) "pueden considerarse aproximaciones protomelódicas; si se traza un paralelo con la lengua materna, describen la fase intermedia entre un estado a-melódico y la completa posesión de la melodía".

Hablar y cantar tienen rasgos en común: el texto con alturas discretas para cantar y el texto con "tendencia entonante" para hablar. En el caso del canto se requieren sonidos tónicos que se anclen en las vocales y el uso de la voz ubicándola en un registro más agudo que para el habla (particularmente en la región geográfica argentina). Las canciones, por el tratamiento del texto, se vinculan particularmente con el recitado (hablado) de retahílas y juegos de manos -repertorio característico infantil-

\footnotetext{
${ }^{3}$ Citado por Cohen (2008)
} 
ya que comparten la redundancia emergente de la reiteración de estribillos, palabras u onomatopeyas, la repetición de patrones rítmicos, de contorno y una cierta estabilidad en el tempo.

Un rasgo de importancia que diferencia el canto del habla (ver capítulo 3), es la configuración tonal entendida como el establecimiento de un centro tonal ya sea por secciones o en la totalidad de la obra.

Cuando en sus producciones los niños pequeños comienzan a diferenciar el tipo de emisión de la voz al hablar y al cantar, dicha diferenciación es el insight clave para el comienzo del desarrollo del canto.

La naturaleza del objeto de estudio, nutrida por la indagación de los avances en el área y los sucesivos estudios previos de la autora dan cuenta del especial interés de avanzar en el tema, mediante estudios que provean masa crítica a la construcción de una Teoría del Desarrollo Socio-cognitivo para el canto y en particular su vinculación con la cognición en las edades tempranas. 


\section{Capítulo 2}

Teorías y modelos psicológicos: aportes a una teoría del canto

\subsection{Las Ciencias Cognitivas: Teoría y Modelos psicológicos}

Las Ciencias Cognitivas conforman una miríada de disciplinas que se proponen pesquisar el comportamiento humano en términos biológicos, neurológicos, psicológicos, sociales, corporales y filosóficos. Por ello confluyen en ellas diversas áreas del saber. Sus aportes multifacéticos borran fronteras y límites disciplinarios.

\subsubsection{La Psicología de la Forma (Gestalt) y sus aportes a la Teoría Musical}

Los principios de la Gestalt se basan en leyes que gobiernan la percepción: proximidad, similitud, buena continuación, simplicidad (pregnanz) y cierre. Estos principios conciben la organización perceptual bajo una idea clave: las partes están determinadas por la configuración de la totalidad.

La Psicología de la Gestalt dio origen a la Teoría del Agrupamiento (chunking) aplicada en diversas disciplinas.

La Gramática Generativa de Noam Chomsky de valioso aporte a la lengua, propone que el lenguaje está conformado por componentes estructurales y de superficie. Por otra parte, en el campo de la teoría musical, el modelo armónico de Schenker consideró que las simultaneidades armónicas se basan en una estructura medular 
conformada por los acordes más fuertes de la tonalidad y que los restantes son formas de embellecimiento del material. Con estas vertientes como soporte, Lerdahl y Jackendoff (2003) desarrollaron la Gramática Generativa de la Música Tonal. Estos dos investigadores aunaron sus respectivas especialidades ya que uno es lingüista y el otro músico. El trabajo por ellos realizado es considerado liminar e iluminó asuntos tales como la representación de una obra musical en términos de la segmentación de sus partes articuladas en una jerarquía. Esta segmentación puede identificarse por diversas propiedades que otorgan coherencia e identidad, en particular las regularidades pertenecientes a unidades temporales subyacentes y cadencias o movimientos armónicos hacia la estabilidad con que ellas concluyen: el grado de estabilidad de una cadencia es referencia del nivel jerárquico del grupo.

El modelo de Lerdahl y Jackendoff propone un sistema de reglas basadas en lo que un oyente competente percibe intuitivamente de la organización musical. El reconocimiento y retención de la información le resulta accesible porque se vale de estrategias mentales de segmentación y agrupamiento de componentes locales y globales de la superficie musical. Las reglas se basan en tres de los principios gestálticos: proximidad, similitud y destino común (Gestalt). Proximidad, tendencia a agrupar los elementos cercanos; Buena continuación, tendencia a percibir como unidad los eventos que incluyen los menores cambios e interrupciones; Similitud, tendencia a agrupar los elementos parecidos. Esto es, los perceptores agrupan como unidades perceptuales relaciones sonoras con características físicas similares y que ocurren cercanas en el tiempo.

Diversos estudios previos han mostrado que los principios gestálticos originalmente formulados para investigar la percepción del estímulo visual- y los de los 
modelos lingüístico y armónico pueden ser aplicados a la investigación de patrones melódicos. La Psicología de la Gestalt dio origen a la Teoría del Agrupamiento (chunking) que analiza la morfología de la melodía y su incidencia en la imitación y memorización del discurso melódico. En efecto, ante la percepción de una melodía, o sea la estructura de superficie de una obra, los oyentes enculturalizados de Occidente tienden a agrupar o separar el desarrollo discursivo en unidades más pequeñas. Los psicólogos cognitivistas han probado que estos recursos mentales ahorran esfuerzo a la memoria y facilitan la retención. Los grupos internos que conforman la melodía resultan aislables como unidades significativas (chunks) las que habitualmente son separadas entre sí por características armónicas y temporales como por ejemplo el final de un subgrupo por valor largo o silencio, o porque utiliza un encadenamiento de dos o más grupos más pequeños, sin solución de continuidad. Según Snyder (2000) cada grupo se presenta como autosuficiente separable del siguiente. Para Lerdahl y Jackendoff (2003) la estructura de agrupamiento es el elemento más elemental de la comprensión musical.

Otro recurso frecuente que facilita la segmentación es la redundancia de la información, recurso ante el cual el oyente advierte que se está repitiendo información ya presentada y por lo tanto la reiteración del material conforma otro grupo.

Estos datos explican comportamientos habituales en las personas que comparten la música de la práctica común -tonal y pulsada-. Sin embargo es necesario preguntarse ¿qué tipo de información musical es la que retiene un perceptor en los primeros contactos con una nueva melodía? ¿el ritmo? ¿las alturas? ¿la conjunción de ambos componentes? 
La investigación aplicada ha mostrado que la información que se retiene es un "boceto" de la melodía, similar a un bosquejo a mano alzada de los dibujantes. Lo que sugiere la siguiente pregunta: ¿cómo es dicha estructura?

El boceto replica lo que se ha denominado "metafóricamente" el movimiento sonoro, esto es, las tendencias de las alturas a proceder hacia el registro agudo o hacia el grave. El esquema resultante ha dado en llamarse el contorno de las alturas de la melodía. El constructo contorno melódico es entendido como "la silueta de una melodía cuyo diseño ignora la medida de los intervalos y sólo considera el movimiento de ascenso y descenso de sus patrones" (Cook, 1999) ${ }^{4}$. Patel (2004) se expresa en términos similares al entenderlo como sucesión de perfiles ascendentes y descendentes y secuencia de intervalos de alturas, sin importar la precisión en el tamaño de los mismos; agrega que dichos rasgos asociados al patrón temporal definen el contorno melódico.

En el presente estudio si bien se acepta que el patrón temporal contribuye a la conformación del contorno, el objeto de análisis se centrará en las características distintivas de las performances infantiles en el campo de las alturas.

Huron (1996) analizó 6.251 melodías vocales de la Colección Essen Folksongs y las clasificó en base a nueve contornos-tipo simples: ascendente, descendente, horizontal, cóncavo, convexo, horizontal-ascendente, horizontal-descendente, ascendente-horizontal y descendente-horizontal. Encontró evidencia consistente con la noción de arco melódico: a nivel de la frase, el contorno más frecuente fue el convexo; en cuanto a la combinación de frases advirtió que las frases-antecedente que finalizaban con un contorno de altura ascendente, tendrían a resolver en una frase descendente (o sea un contorno de forma convexa entre frases). También estudió melodías completas y

${ }^{4}$ Citado por Malbrán (2007, p.100) 
observó que el $40 \%$ de las alturas de las frases sucesivas presentaban un contorno convexo o sea que había una clara tendencia a que las frases melódicas intermedias de la melodía presentaran alturas más agudas que las frases inicial y final.

Un valor agregado que nos proporciona la investigación sobre dicho constructo es que la imitación del contorno es la primera aproximación a la imitación de una melodía y que dicho comportamiento es el común en músicos y no músicos siendo funcional en la primera infancia (Malbrán, 2012, en prensa).

En este sentido, el contorno melódico tomado como forma de la melodía es de tal importancia que por ejemplo, sería imposible reconocer una melodía en la cual se cambiara de octava algunas de sus alturas (Dowling, 1994). "El principal impulso del niño sobre las canciones durante los cinco primeros años es el control de los contornos melódicos". Los contornos melódico y rítmico dominan la percepción y producción infantil durante los años de preescolar. (p.147).

En suma: el contorno melódico permite reconocer, reproducir o recordar una melodía ya que representa sus características perceptualmente relevantes. Los datos precedentes justifican variables del objeto de estudio del presente trabajo: el peso del contorno y la adecuación a las reglas tonales en las imitaciones cantadas de los niños.

\subsubsection{La Psicología Cultural y sus aportes a la Teoría Musical}

La Psicología Cultural utiliza metodologías de las Humanidades, las Ciencias Biológicas y Sociales. Es una disciplina que vincula el derrotero histórico de los comportamientos sociales con el cambio individual, subrayando la mediación del 
contexto (Eckensberger, Krewer y Kasper,1984) ${ }^{5}$. Aborda la influencia del entorno en los procesos psicológicos (Price Williams, 1979) ${ }^{6}$ y fundamenta su análisis en acontecimientos de la vida cotidiana.

Los principios fundamentales de la teoría sostienen que los seres humanos moldean y son moldeados por la cultura de pertenencia, rompiendo así con falsas dicotomías del pasado tales como sujeto/objeto; persona/ambiente. Las personas son vistas como agentes activos de su propio desarrollo.

Un sub-set de la Psicología Cultural es la Teoría de los Esquemas que describe el papel del conocimiento anterior en la producción del actual al poner en juego mecanismos mediante los cuales lo conocido con anterioridad se organiza estructuralmente y orienta los procesos de la memoria (Marty, 1992). La autora señala que esta Teoría parte de la aceptación general de que el conocimiento del mundo juega un papel importante en la percepción, el aprendizaje, la memoria y la comprensión: no es posible aislar el sistema de memoria del resto del conocimiento.

Según dicha teoría, los esquemas codifican la secuencia predominante de acontecimientos en una situación particular y sirven de base para predecir cuál es la información que falta o para corregir informaciones erróneas. Son vistos como estructuras organizadas de conocimiento arquetípico, "paquetes o unidades de conocimiento que incluyen tanto conocimiento en sí como información acerca de cómo

\footnotetext{
${ }^{5}$ Citado por Cole (1996)

${ }^{6}$ Citado por Cole (1996)
} 
debe utilizarse tal conocimiento y de los que depende el procesamiento de toda la nueva información” (Rumelhart, 1984) ${ }^{7}$.

Marty (1992) explicita, "en el esquema de un concepto o acontecimiento puede distinguirse entre una parte fija (que contiene características que están siempre o casi siempre presentes en todos los ejemplares del esquema) y una parte variable, cuyos valores no son completamente libres" (p.20). Los sujetos al clasificar objetos, por ejemplo, varían según la función de sus propiedades y también según el contexto en el que el objeto es presentado o imaginado.

Anderson $(1985)^{8}$ señala que en los esquemas que clasifican nuestro conocimiento sobre varias categorías de objetos se podrá observar una "degradación" desde los miembros más típicos a los menos típicos de la categoría.

Otra característica de los esquemas es la de su jerarquización, ya que un esquema contiene sub-esquemas y que a su vez cada sub-esquema se nutre de nuevos sub-esquemas. "Una ventaja funcional de la jerarquización es que permite relacionar adecuadamente las agrupaciones de objetos" (Marty, 1992. p.23).

Los esquemas influyen en procesos psicológicos tales como la percepción, la comprensión, el aprendizaje y la recuperación. Ellos "ayudan a determinar qué es lo que se percibe, (...) y pueden ser utilizados para guiar los procesos de recuperación de la información a largo plazo"... “otro papel clave que juegan los esquemas es la facilitación de la comprensión de acontecimientos complejos” (Marty, 1992, p.27).

Un asunto clave de esta Teoría es cómo se activa el esquema para cumplir su función, o sea, por cuál mecanismo se incorpora a la memoria la información 
esquematizada, necesaria para cada instante. Rumelhart $(1984)^{9}$ menciona dos vías típicas de activación de un esquema: la vía top-down considerada un mecanismo de expectativas: los sub-esquemas activados derivan de una expectativa puesta en marcha por los esquemas de orden superior y la vía bottom-up que sigue el camino inverso: un sub-esquema causa la activación de otros esquemas supra-ordinales de los que él forma parte. Durante el procesamiento de la información ambas vías tienen lugar para que se pueda alcanzar el fin por el cual se activan los esquemas: ayudar a que se completen satisfactoriamente los procesos. Los esquemas no existen en ausencia de la activación relevante, ya sea ésta bottom-up o top-down. Cada experiencia es única como variante específica de la representación esquemática, pero también es general en la medida en que activa correlaciones previas de rasgos y atributos, por lo tanto, se beneficia de los aspectos generales de experiencias pasadas.

\subsubsection{La Teoría de los Esquemas y su vinculación con otros modelos.}

La Teoría de los Esquemas explica el aprendizaje por los procesos de acomodación y asimilación descriptos por Piaget. Mediante la acomodación los esquemas se ajustan a la información nueva entrante, mediante la asimilación, es la información nueva la que se va a reinterpretar y a ajustar a los esquemas existentes. Esta explicación es cuestionada por Mandler $(1985)^{10}$ al considerar que los acontecimientos que no se aplican a esquemas existentes o a esquemas acomodables no podrían ser percibidos, lo cual es absurdo. Ante un acontecimiento sorprendente se producirían, probablemente, intentos de analizar la información extraña mediante los esquemas actuales en busca de una acomodación o asimilación, "pero también será posible tratar

\footnotetext{
${ }^{9}$ Citado por Marty (1992)

${ }^{10}$ Citado por Marty (1992)
} 
la nueva evidencia en forma relativamente no estructurada" (Marty, 1992, p.34). Mandler introduce el concepto de heterarquía en oposición a la jerarquía de los esquemas planteado por Rumelhart (1977), considerando que éstos no están tan claramente ordenados en relaciones super-ordenadas y sub-ordinadas, sino que estas relaciones son flexibles pudiendo cambiar de una condición a otra.

Graesser y sus colaboradores (1980, 1981, y 1985) ${ }^{11}$ dan una explicación del procesamiento y almacenamiento de las acciones insólitas y que no forman parte del esquema, mediante el "esquema genérico con etiquetas", que permite representar los esquemas a través de una vía múltiple: un conjunto de etiquetas que ligan elementos muy típicos, moderadamente típicos y atípicos con representaciones en la memoria (las acciones atípicas no están ligadas al esquema sino directamente al trazo de la memoria por medio de etiquetas). Además estos autores ofrecen una imagen detallada de los procesos de almacenamiento y recuperación en la memoria. Según ellos el reconocimiento, tanto en la información típica como en la atípica, presenta poco decaimiento y lentitud. En el recuerdo de acciones típicas a largo plazo el decaimiento es moderado y lento, mientras que en el recuerdo de acciones atípicas el decaimiento es muy grande y rápido. Esto confirmaría la teoría de la activación de los esquemas por la doble y diferente vía bottom-up y top down.

Un aporte sobre los esquemas bajo la forma de esquemas-imagen lo aporta López Cano (2004). Según dicho autor, el saber consiste en accionar con/en el mundo y surge por una serie de acoplamientos estructurales entre los sujetos y los objetos. La memoria registra ciertos elementos que le permiten actuar de modo similar en

\footnotetext{
${ }^{11}$ Citado por Marty (1992)
} 
situaciones similares futuras, mediante una serie de abstracciones de puntos nodales. Este procedimiento economiza notablemente la carga de información que almacena la memoria y sirve de base para la acción ejecutora de la competencia. Considera que una de estas abstracciones es el esquema que se convierte en una base estructurada de datos, empleados activamente en la comprensión de información de entrada y que guían la ejecución de operaciones de procesamiento. Agrega que el concepto de esquema presenta diversas particularidades, según quien lo emplea (Bartlett, 1932; Neisser 1976; Rumelhart y Norman 1978; Sonesson 1988).

Los esquemas presentan ciertos rasgos comunes. Implican,

- Selección: de la información disponible en un percepto sólo alguna parte se representará en la memoria; el esquema "da instrucciones" para el reconocimiento de objetos y la selección de rasgos pertinentes.

- Abstracción: los detalles se pierden, se esquematizan solamente los puntos nodales de la información.

- Interpretación: como modo de acción se basa en los procesos de inferencia que permiten la suplantación, producción e interconexión de informaciones ausentes o que se presentan de manera parcial en la percepción.

- Integración: se relacionan las informaciones aisladas por medio de inferencias que permiten articularlas.

- Complejidad: los esquemas son unidades complejas con importante monto de información explícita e implícita, a manera de instrucciones simultáneas de acción y operaciones ejecutivas. 
CANTAR CANCIONES ENTRE LOS CUARENTA Y CINCUENTA MESES 31

- Aditividad: los esquemas se unen formando una red de subesquemas lineales o jerarquizados.

Los esquemas pueden entenderse como (Malbrán, 2012, en prensa)

- un tipo de conocimiento empírico que i) almacena los conocimientos anteriores en un formato sincrético, ii) filtra información que resulta perceptivamente menos saliente y iii) conserva la prominente;

- un constructo de aparición temprana y de permanencia a lo largo del ciclo vital;

- una forma del conocer con estado latente en la memoria y que se activa por la expectativa que se pone en marcha por esquemas pre-existentes;

- un modelo de patrones culturales compartidos intersubjetivamente;

- una forma de simplificación del mundo;

- un ordenamiento de estructuras en el que las partes se relacionan entre sí y con el todo;

- una compleja representación que puede incluir tanto objetos y situaciones como secuencias de acontecimientos y de acción.

Los aportes de esta teoría permiten vincular los conceptos precedentes con el canto de canciones ya que los esquemas tonales se adquieren desde la vida intra-uterina ayudando a advertir y a generar familiaridad con los estímulos del mundo exterior. Posteriormente facilitan la interpretación individual de acuerdo a las reglas de la entonación en el marco de la tonalidad y el acoplamiento intersubjetivo al cantar en grupo (Malbrán, 2012, en prensa). 
En el plano formal los esquemas de la tradición musical occidental (la estructura de la melodía) presentan un cierto equilibrio interno: una frase de ocho compases frecuentemente se conforma por dos semi-frases de cuatro y éstas a su vez por motivos de dos compases. Estas modalidades de la morfología de las melodías occidentales forman parte de la enculturación tonal y se manifiestan desde las edades más tempranas. Dicho constructo se denomina cuadratura, el que es también un esquema (Malbrán, 2012, en prensa).

Dowling (1984) sostiene que a los dos años los niños comienzan a cantar espontáneamente en un estilo claramente distinguible del habla y que las regularidades en la estructura de las canciones tradicionales proveen evidencia del esquema mental que controla la producción de canciones. Usa el término esquema para referirse a patrones sistemáticos de conocimiento abstracto que los oyentes tienen acerca de la estructura musical. Lo define como la descripción de regularidades en la estructura de estímulos que se mantienen a través de diferentes ejemplares musicales y considera que el esquema domina la producción de canciones en la infancia temprana.

Los esquemas son vistos también como configuraciones proyectivas que generan planes de acción y la facilitan. En la producción de canciones se trata de planes que muestran el conocimiento que el niño posee en una determinada etapa del desarrollo como esquema, acerca de cómo sería construida una canción.

Los datos precedentes justifican variables del objeto de estudio de este trabajo. La teoría de los esquemas fundamenta ciertos indicadores básicos de la pericia al cantar: el agrupamiento de ideas del discurso conforma un esquema de cuadratura que "balancea" la forma interna de una melodía, el esquema tonal posibilita el anclaje en un centro tonal con alturas de segundo orden que se subordinan a las más importantes y el esquema de 
contorno, que funciona como soporte en los primeros acercamientos a los movimientos de ascenso/descenso en el campo de las alturas (Malbrán, 2012, en prensa).

\subsection{La Psicología Cognitiva y sus aportes a la Teoría Musical}

\subsubsection{La Psicología Cognitiva de Primera Generación: una visión avanzada} sobre la pericia musical.

La pericia musical ha sido generalmente entendida como la posibilidad de cantar entonado, ejecutar eficazmente un instrumento o analizar la calidad de una ejecución musical. Tradicionalmente fue considerada portadora de talento, esto es, una habilidad disponible para algunas personas "dotadas". Esta cualidad de naturaleza "misteriosa" dio lugar a estudios tempranos sobre la percepción del ritmo y del sonido por parte de psicólogos de reconocida trayectoria. Los estudios (mayormente experimentales) realizados por los psicólogos pioneros, generaron instrumentos y procedimientos de indagación para examinar la pericia musical. Obtuvieron interesantes progresos como así también interrogantes acerca de la habilidad musical y cómo es construida en la mente.

En el campo de la Psicología de la Música las preocupaciones por la relación música-mente se remontan a los primeros decenios del siglo XX. En 1915 E. Hughes publicó un trabajo sobre la memoria musical en la ejecución pianística. En 1936 K. Heuner dio a conocer en el American Journal of Psychology un estudio sobre los elementos de expresión en la música. Así también J. Jeans en 1937 publicó en la editorial de la Universidad de Cambridge la obra Music and Science un liminar trabajo 
que ejerció poderosa influencia. Posterior fue el libro escrito por Seashore (1938) The Psychology of Music, obra que probablemente dio nacimiento a dicha disciplina. Así también la editorial de la Universidad de Oxford publicó en 1944 un libro de P. Buck titulado Psychology for musicians. ${ }^{12}$

Hay acuerdo general en que el nacimiento de la Ciencia Cognitiva se produjo en 1956 en un encuentro de renombrados científicos en el MIT, encuentro que contó entre otros con la presencia de Chomsky, Miller, Simon (por nombrar algunos pocos). Según Rivière (1991) se trató de un "renacer" porque la presencia de las preocupaciones sobre la cognición son más antiguas.

La inserción de la investigación en Música en el campo de la Psicología Cognitiva pareciera remontarse a 1976, fecha en la que W. D. Ward publicó en el Journal of Psychology and Research un trabajo bajo el título "A cognitive model of musical sight-reading". El itinerario descripto de la década del setenta se vio coronado por la obra de J. Sloboda en 1985 denominada The musical mind. The Cognitive Psychology of Music que iluminó nuevas visiones de la mente y su rol en el comportamiento musical (Malbrán, 2012, en prensa).

Las variables y sub-variables seleccionadas para esta tesis se ven reflejadas en trabajos tempranos aparecidos en las décadas de los sesenta/setenta. Así por ejemplo, en 1963 W. Ward, escribió dos artículos acerca de la altura absoluta en el libro Sound. J. Sloboda en 1978 publicó en la revista Perception un trabajo sobre la percepción del contorno en la lectura musical. En 1979 W. K. Kessen y colaboradores publicaron en Infant Behaviour Development un trabajo acerca de la imitación de las alturas por los niños. En 1981 N. Tan y colaboradores dieron a conocer un interesante artículo acerca

\footnotetext{
${ }^{12}$ Estas referencias históricas han sido extraídas de la obra de John Sloboda "The musical mind. The cognitive psychology of music" (1985). Oxford: Oxford University Press
} 
CANTAR CANCIONES ENTRE LOS CUARENTA Y CINCUENTA MESES 35

de la estructura armónica como determinante de la organización melódica. En el mismo año el investigador estadounidense J. Carlsen escribió en Psychomusicology un trabajo acerca de algunos factores que influencian la expectativa melódica.

Los estudios iniciales de la Psicología Cognitiva de la Música se basaron en "conductas observables" esto es, en acciones susceptibles de ser medidas y dimensionadas. Avances posteriores pusieron en tema de discusión comportamientos fuertemente idiosincráticos que no resultan fáciles de analizar en la acción "observable", es decir, comenzaron a estudiarse comportamientos "encubiertos". Este tema será desarrollado en el apartado "La Psicología Cognitiva de Segunda Generación".

\subsubsection{La Psicología Cognitiva de Segunda Generación.}

La Psicología Cognitiva de Segunda Generación surgió como una revisión de los conceptos psicológicos sustentados hasta ese momento por el cognitivismo clásico y puso en consideración, como ya se ha dicho, en particular los procesos internos del sujeto, más allá de la conducta observable sostenida en los encuadres previos. En los últimos años se han desarrollado modelos que encarnan dicha perspectiva: las Teorías Enactivista y de Cognición Corporizada.

Forma parte de los sustratos de estos nuevos modelos el avance de las Neurociencias y los recursos tecnológicos que permiten acceder a la "lectura" de comportamientos y estructuras del funcionamiento mental que en el pasado podían considerarse conjeturas. En particular el fenómeno de las neuronas espejo (Rizzolati y 
Arbib, 1998) ${ }^{13}$ observado inicialmente en el reino animal y luego verificado en los seres humanos. Las nuevas teorías surgen de la comprobación de que en la observación de un movimiento algunas áreas del cerebro presentan una actividad neuronal similar a la que se tiene cuando se realiza el movimiento como acción efectiva. Los autores denominan a estos comportamientos "simulación ideo-motora" en algunos casos e "imaginación motora" en otros. En esta doble faceta mente/cuerpo los investigadores consideran que una parte del movimiento se realiza en forma efectiva y otra en forma virtual.

La Teoría Enactivista iniciada por Varela $(1988)^{14}$ sostiene que el mundo emerge de la interacción del organismo con su entorno y ninguno de los dos puede faltar en una descripción de éste ni en la especificación de la acción misma, ya que la cognición es acción corporizada. El conocimiento no radica en la mente ni en la sociedad ni en la cultura, sino que se genera por y en la interacción de las tres. Para esta Teoría, según López Cano (2004, p.8)

la percepción no es un registro pasivo de rasgos externos, sino una forma creativa de significación enactiva basada en la historia corporizada del sujeto... La mente forma parte del cuerpo y éste de aquella, el trabajo de cognición involucra todos los recursos del ser humano.

Desde la perspectiva de Bruner la "adquisición de las habilidades motoras genera una serie de hábitos organizados secuencial e irreversiblemente, cuyos esquemas mentalmente representados mantienen unidos entre sí los diferentes componentes motores en que se subdivide la acción"15.

Bases neurológicas y trabajos empíricos fundamentan el paradigma epistemológico de Mark Reybrouck (2005) y su modelo adaptativo procesual de cognición experiencial y corporizada. Se trata de una concepción enactiva de la

\footnotetext{
${ }^{13}$ Citado por Ibarretxe (2010)

${ }^{14}$ Citado por Ibarretxe (2010)

${ }^{15}$ Citado por Domingo Curto, J. (2005)
} 
cognición musical entendida como el fruto de las interacciones del sujeto con el sonido, considerando el rol de quien conoce como el de un actor que construye su propio conocimiento.

Según Reybrouck (2005) la experiencia musical es multifacética. Su modelo atiende a la conjunción de cuerpo, mente y música, entendiendo que la cognición se basa en un cuerpo -con sus capacidades sensoriomotoras- que es embebido en un contexto biológico, psicológico y cultural. El autor considera a la percepción como una conducta guiada por la acción, en la que los procesos sensoriales y motores son fundamentalmente inseparables, mutuamente informativos y estructurados, que operan como basamento de nuestro sistema conceptual.

La cognición y la actividad corporal interactúan en alto grado de tal modo que los fundamentales bloques constructivos de los procesos cognitivos actúan como esquemas de control para los patrones motores, los cuales derivan de las interacciones perceptuales con el entorno (Reybrouck, 2005, p.2).

En sentido similar Todd (1999) ${ }^{16}$ explicitó que las personas exploran el entorno con su propio cuerpo y sus sentidos, correlacionando entradas multisensoriales (inputs) con la experiencia corporal a través de elaborados mecanismos de retroalimentación entre el aparato sensorio-motor y la información temporal.

López Cano (2004) considera que

la competencia produce y promueve un acoplamiento estructural cuando intenta comprender y generar sentido con/en/a partir de la música ... La cognición es una acción corporizada guiada por la percepción en donde las cualidades del objeto musical percibido negocian con la competencia para unificarse en un sólido acoplamiento (p.10). La mente forma parte del entorno, comprender el mundo significa crear un continuo fluido y constante entre la mente y el entorno (p.8).

Según dicho autor no siempre tenemos conciencia de toda la actividad motora que desarrollamos en nuestra percepción y comprensión de la música, como por

\footnotetext{
${ }^{16}$ Citado por Reybrouck (2005)
} 
ejemplo, cuando seguimos el ritmo con los dedos, pies y manos, acciones que sugieren la "coreografía” que asociamos a determinada música.

López Cano (2004) considera que una base de sustentación importante para el enactivismo ha sido la Teoría Ecológica de la Percepción Visual de Gibson (1966, 1979) quien sostuvo que objetos y eventos se relacionan con los organismos perceptuales por medio de "información estructurada" que les posibilita realizar ciertos tipos de acción con ellos. Para Gibson, según López Cano (2004, p.11), Los sistemas perceptivos, incluidos los centros nerviosos de varios niveles hasta el cerebro, "son formas de buscar y extraer información en el ambiente sobre el campo fluctuante de energía ambiental" Asimismo concibe la percepción como "una relación mutua y continua entre organismo y entorno, pues las especies desarrollan unos sistemas perceptivos adecuados para el entorno que habitan"... "al mismo tiempo cada individuo en particular tiene la posibilidad de perfeccionar sus sistemas perceptuales a partir de sus características fisiológicas singulares y la naturaleza de su entorno específico (incluyendo el cultural en el caso de los humanos) y su desarrollo personal"17

De igual modo, otras teorías consideran que el cuerpo y la acción corporal tienen una función primordial en los procesos de cognición y percepción. La Filosofía de la Mente Corporizada de Johnson $(1987)^{18}$, según Ibarretxe (2010, p.52) subraya "la función que desempeñan ciertas metáforas corporales a la hora de conceptualizar y hacer más comprensibles fenómenos abstractos como la música”. Según esta teoría, nuestro pensamiento es sobre todo de naturaleza metafórica, ya que utiliza esquemas básicos, o esquemas encarnados que proceden de la propia experiencia corporal. De este modo, se proyectan metafóricamente las características internas de los esquemas a

\footnotetext{
${ }^{17}$ Citado por López Cano (2004, p.11)

${ }^{18}$ Citado por Ibarretxe (2010)
} 
las del fenómeno o concepto abstracto que se pretende comprender. "En el campo de la Música, esta Teoría de la Metáfora ha supuesto una alternativa a los modelos tradicionales de Análisis Musical, al emplear los esquemas encarnados para analizar repertorios de distintas épocas o aspectos de la Teoría Musical" (Ibarretxe, 2010, p.53).

La proyección metafórica de esquemas corporales permite comprender la correspondencia existente entre las expresiones cinéticas en la música y nuestra vivencia en el espacio real. Por ejemplo: concebir las frecuencias como alturas, donde lo grave se corresponde espacialmente con la ubicación "abajo" y lo agudo con "arriba".

En este marco analizar los componentes motores conscientes e inconscientes a la hora de cantar, cobra una importancia de primer orden. Son conocimientos corporizados acciones tales como: usar los órganos fonadores de diferente modo para cantar que para hablar, manifestar la tensión que provoca un contorno ascendente ya sea de manera encubierta o manifiesta ya que en algunos casos se observa que los sujetos suben la cabeza o los hombros según la tensión melódica. Al respecto los maestros de canto habitualmente enseñan a disociar la expresión de la tensión musical de la tensión muscular ociosa. Una acción importante es aprender a usar el tono muscular apropiado para la ejecución vocal adecuando el impulso de energía en función de la destreza implicada.

Otro comportamiento necesario en el canto es utilizar eficazmente el soplo espiratorio para poder cantar hasta la última altura de cada grupo o frase musical. El modo de inspirar, de regular el aire, de administrarlo a lo largo de la frase, de mantener una posición del torso y los hombros que ayuden a estas destrezas son todos comportamientos que juegan de manera asociada y secuencial. Los cantores intuitivos 
CANTAR CANCIONES ENTRE LOS CUARENTA Y CINCUENTA MESES 40

aprenden estos mecanismos por observación de modelos correctos esencialmente corporales y vocales.

Las acciones descriptas son todas formas de uso del cuerpo como soporte y fuente del conocimiento y también como herramienta dúctil y sutil que demanda el uso de estrategias cognitivas de alto orden tales como flexibilidad, regulación, anticipación de la acción y ejecución controlada (Malbrán, 2012, en prensa).

\subsubsection{La Teoría Ideomotora y la imitación.}

Estudiar los comportamientos típicos en la primera infancia impone atender al rol ancestralmente verificado de la imitación y su contribución al mundo expresivo y comunicacional de los niños.

La conducta imitativa en los primeros años de vida se manifiesta cotidianamente, entre otras acciones, a través del canto y los juegos corporales acompañados de breves canciones y recitados.

La teoría ideomotora concibe la conducta imitativa como una representación somato-sensorio-motriz en que la percepción modula y dispara la acción al poner en juego la imagen de lo que hay que hacer. La intención de expresar evoca respuestas motrices asociadas (Massen y Prinz, 2009).

La imitación puede ser vista como una forma de lenguaje no-verbal que implica la intencionalidad para sí y para el otro y se constituye en un fundamento semántico para el desarrollo del lenguaje (Nadel, 1993). Este mismo autor en 1986 filmó más de 150 niños de diferentes edades. Observó un predominio de la imitación en los intercambios sociales a partir de los ocho meses de edad, con un pico de uso alrededor de los treinta meses. Las imitaciones observadas mostraban rasgos comunes: eran 
CANTAR CANCIONES ENTRE LOS CUARENTA Y CINCUENTA MESES 41

precedidas por rutinas, seguían reglas convencionales, eran recíprocas y habitualmente comprometían un uso referencial de objetos. Asimismo observó que los niños en sus juegos de imitación tomaban turnos, intercambiaban roles, aplicaban reglas convencionales y de este modo se comunicaban e interactuaban. Posteriores observaciones en contextos naturalistas en la edad preescolar permitieron corroborar el cotidiano y efectivo uso de la imitación como modo de comunicación.

El lenguaje imitativo pone en juego componentes cognitivos y meta cognitivos tales como el atribuir intenciones al imitador planear e inducir conductas imitativas, comprender la incitación a imitar y negociar la toma e intercambio de roles (Nadel, 1993).

El modelo like-me hipotetizado por Meltzoff y Gopnik (1993) y sus estudios empíricos obtuvieron evidencias de la imitación del adulto por niños desde los primeros meses de vida, como así también la complacencia del niño cuando el adulto es quien lo imita. Estos intercambios son descriptos como mapeos cross modales de equivalencia entre movimientos sentidos en sí mismo y movimientos realizados por otro.

Estas iniciativas comenzaron en la década del 70 con un trabajo de Maratos ${ }^{19}$ que luego fue continuado por Meltzoff y Moore (1977, 1983). Las observaciones sistemáticas obtenidas han abierto nuevas avenidas de indagación y convergentes investigaciones en el área. Los recién nacidos son hábiles para imitar movimientos faciales tales como la protrusión de la lengua o abrir la boca, como así también lo son para imitar expresiones faciales.

Imitaciones tan avanzadas para la edad de los bebés, producen la reacción emotiva y entusiasta de los adultos; por ello se considera que la imitación es una de las

\footnotetext{
${ }^{19}$ Citado por Nadel (1993)
} 
muestras más tempranas de la contingencia social. Los avances producidos por los autores citados les permiten sugerir que los niños a partir de los cinco meses forman sus primarias representaciones del propio cuerpo. Asimismo hay acuerdo entre diversos expertos en que los niños adoptan un modelo representacional de la mente entre los tres y cinco años de edad (Melzoff, 1995). Según Melzoff (2007) las bases de las preferencias infantiles son la contingencia temporal y la equivalencia estructural.

Ya en 1993 Meltzoff y Gopnik ${ }^{20}$ habían propuesto una provocativa hipótesis: la imitación temprana provee los medios para la elaboración de propiedades esencialmente humanas que lideran una teoría de la mente humana. Los autores han mostrado que el uso de la imitación pre-verbal facilita en los niños el intercambio social al impulsar iniciativas personales y responder a las del otro, esto es, emprendimientos intersubjetivos de comunicación precoz.

En un simple juego de ronda los niños cantan mientras realizan movimientos corporales y observan a sus compañeros para el desarrollo y cumplimiento de las reglas del juego. Convergen en ello percepciones auditivas, corporales y visuales. Recientes investigaciones con infantes han brindado evidencia de que la información sensorialmente redundante y con sincronía temporal a través de dos o más modalidades sensoriales alista la atención y facilita el aprendizaje (Malbrán, 2012, en prensa). Por ende se enfatiza la importancia del uso de estímulos multimodales para el desarrollo de la atención y la percepción durante la infancia temprana (Licklitterm et al., 2001).

En el marco de este trabajo la imitación juega un rol fundamental ya que se aprende a cantar cantando y de acuerdo a modelos. Como todo acto imitativo se mejora por aproximaciones sucesivas (Malbrán, Martínez y Segalerba, 1994). Una teoría del

\footnotetext{
${ }^{20}$ Citado por Nadel (1993).
} 
canto necesita adentrarse en los modos de interacción imitativa del aprendiz tanto con el adulto como con los compañeros, quienes frecuentemente se constituyen en maestros apropiados al momento y la circunstancia de la acción de cantar.

El capítulo ha tratado de presentar las Teorías Psicológicas que fundamentan las hipótesis de trabajo y las variables comprometidas en el presente estudio.

La compleja habilidad de cantar entonado requiere para su estudio una mirada multifacética que atienda a la diversidad de problemáticas comprometidas en su desarrollo. Indudablemente la masa crítica disponible para fundamentar los comportamientos y las prácticas es de amplio espectro. Resta enriquecer dicho universo con las necesarias transferencias y miradas transversales entre los avances científicos vinculados con los comportamientos neuro-psicológicos y las pericias musicales puestas en juego. 


\section{Capítulo3}

\section{El canto en la primera infancia: estado del arte}

\section{1 Música y lenguaje: algunos paralelismos}

El desarrollo del canto y del lenguaje presentan características comunes: usan la voz para la comunicación, comparten la dotación anatómica y fisiológica las que en el proceso de maduración biológica actúan en interface con la experiencia y el aporte nutricio de la tradición cultural (Welch, 2005).

Según Levitin y Tirovolas (2009) música y lenguaje presentan los siguientes atributos:

- asumen formas de comunicación basadas primariamente en la audición (idéntico input sensorial);

- se desenvuelven en el tiempo bajo la forma de estructuras coherentes;

- muestran un orden jerárquico de sus componentes y

- revelan significado.

Hay acuerdo general en que los lenguajes humanos están compuestos por palabras con un cierto orden lineal que no ocurre al azar; de manera similar en la música, las frases musicales están compuestas por alturas pertenecientes básicamente a acordes que se rigen de acuerdo a normas y principios que han permanecido en el tiempo, todos ellos componentes determinantes ya que un ordenamiento diferente de los elementos produciría una nueva melodía. 
CANTAR CANCIONES ENTRE LOS CUARENTA Y CINCUENTA MESES 45

En términos neuronales Patel (2004) considera que la sintaxis de la música y el lenguaje comparten un set de circuitos comunes en las regiones frontales del cerebro. En numerosos estudios en los que examinó la música y la adquisición de una segunda lengua verificó conexiones entre las habilidades de discriminación musical y las de lectura y pronunciación, por lo cual postula una posible asociación con la aptitud musical.

Registros anecdóticos escolares y familiares sobre el canto infantil así como estudios expertos coinciden en que muchos niños cantan antes de hablar. En tal sentido Schön et al. (2008) consideraron que las canciones:

- contribuyen a la adquisición del lenguaje en diversas direcciones;

- suscitan interés y atención por sus componentes emocionales;

- aportan a la discriminación fonológica ya que los contornos de altura son generalmente coincidentes con un cambio de sílaba que a menudo es acompañada por un cambio de altura y

- optimizan la operación de ciertos mecanismos cognitivos dado el mapeo lógicamente consistente compartido por la estructura musical y lingüística (p.976).

Para los lingüistas la melodía es también patrimonio del habla. Sin embargo, la melodía es diferente al habla, ya que el trazado de alturas del habla raramente llama la atención por sí misma más allá del mensaje semántico que trata de transmitir. En el habla puede hablarse de "inflexiones de alturas no fijas" en cambio en la melodía se trata de relaciones de alturas discretas y fijas en su afinación. Las melodías musicales, 


\section{CANTAR CANCIONES ENTRE LOS CUARENTA Y CINCUENTA MESES 46}

al utilizar alturas fijas y con idénticas relaciones poseen identidad y por ello pueden retenerse en la memoria por décadas (Pattel, 2004).

La habilidad lingüística está distribuida normalmente en la población, pero ¿qué sucede respecto de la habilidad de cantar? Dalla Bella et al. (2007) analizaron las interpretaciones de canciones muy conocidas con 62 cantantes ocasionales. Observaron una distribución normal de la habilidad, ya que la mayoría de las personas podían cantar una melodía bastante ajustadamente. Los autores coinciden con estudios musicológicos transculturales al manifestar que el canto parece ser un rasgo humano universal.

Las relaciones entre música y lenguaje muestran acuerdo entre lingüistas, fonoaudiólogos, psicólogos y neurólogos, sin embargo, dicho acuerdo no ha respondido aún a una cuestión crucial: la frontera entre el habla y el canto en los niños pequeños. Por esta razón, al intentar una descripción del desarrollo del canto, se torna necesario analizar la vinculación con el desarrollo del habla, como así también aislar variables de estudio pertinentes con los rasgos comunes y diferenciales entre ambas performances.

El desarrollo del canto infantil se basa fundamentalmente en el canto de canciones, esto es, una performance de conjunción entre melodía y texto. Los investigadores han prestado particular atención a la relación de dichos componentes: tanto al grado de igualdad entre ellos como a la predominancia de uno sobre otro.

El peso del texto de la canción en la pericia para cantar dio lugar a estudios con melodías sin texto. Así se ha evaluado la interpretación de canciones (música-texto) y de fragmentos melódicos sin texto. Welch (1996) realizó un estudio longitudinal con una muestra de niños de entre 5 y 7 años. La medición se efectuó en tres años sucesivos en el canto de dos canciones. Para ello incluyó el material fragmentado de las canciones omitiendo las palabras e incluyó la reproducción de glissandos. Obtuvo claras 
evidencias de progresos generales sistemáticos y estadísticamente significativos en las habilidades para la reproducción de glissandos y fragmentos melódicos sin palabras; la reproducción de las canciones con su texto fue comparativamente más deficiente. Estos resultados parecen tener relación con la "naturaleza genérica de las canciones" y muestran diferencias en las capacidades del canto infantil en relación con los dos componentes constitutivos de las canciones: el texto y la música. Se observó, año a año, que la exactitud verbal fue significativamente mejor que la de los registros melódicos, más aún, éstos solamente mostraron un leve mejoramiento hacia el final del tercer año de testeo (7 años). Los resultados sugerirían una mayor competencia lingüística que melódica. En tal sentido el autor señala que la habilidad de cantar necesita ir más allá de la interpretación de canciones, dada la dificultad para la combinación música-texto que involucran.

En un estudio previo Welch et al. (1996) propusieron enseñar la música y las palabras separadamente, esto es, al enseñar una canción proponer el aprendizaje del texto por un lado y la melodía sin palabras por el otro, para luego unirlos. Esta sugerencia presenta discrepancia con trabajos de investigadores argentinos por considerar clave la naturaleza de conjunción que implica una canción y el posible riesgo de que el niño a la hora de reunir música y texto, cuando el texto fue memorizado previamente, recite la melodía en lugar de cantarla (Malbrán, 1991; Malbrán y Furnó 1989/1994).

Otros estudios dan cuenta de que en el aprendizaje de una canción nueva los niños obtienen mejores performances en el recuerdo del texto que en el de la melodía. Moore et al. (2008) estudiaron el desempeño de niños de 6 años en Estados Unidos, Taiwan y China. Utilizaron melodías que solamente incluían las alturas Mi4, Sol4 y 
La4. Observaron que frecuentemente los sujetos primero aprenden las palabras rimadas hacia los finales de frases y luego asocian los intervalos y alturas que se corresponden con aquellas palabras. Una vez que los finales de frase rimados son adquiridos se incorporan otras palabras, los contornos melódicos y una mayor precisión en las alturas.

Davidson y Scarlett (1987) llevaron a cabo un estudio con 70 niños cuyas edades oscilaban entre los dieciocho meses y los cinco años. A cada niño se le presentó la canción favorita con la melodía correcta y el texto erróneo y viceversa, con el texto correcto y la melodía errónea. Cuando se les solicitaba decir cuál era la versión correcta los niños de cinco años respondían como los adultos: es la canción con la melodía correcta; mientras que los niños más pequeños hicieron la otra elección, la canción correcta era la que presentaba el texto correcto, pues para ellos la identidad de la canción se vincula con las palabras. Estos avances subrayan que en la temprana infancia hay una supremacía del texto sobre la melodía y sugeriría que el texto opera como anclaje semántico que se sobre-impone al contenido melódico (Dowling, 1994; Mang, 2000; Welch, 1999; White, 2000; Mónaco, 2008).

\subsection{El canto como performance infantil}

\subsubsection{Los esbozos de canto: una iniciativa protomusical.}

Investigaciones del último decenio han recuperado los estudios de Gibson (1969) según los cuales al momento del nacimiento los sentidos se presentan como una percepción unificada que a través del continuum del desarrollo progresan hacia la 
diferenciación y separación de la información proveniente de los diferentes sentidos $\left(\right.$ Gibson, 1969) ${ }^{21}$.

Los bebés desde muy pequeños muestran habilidad para la música; el trabajo de Metchild Papousek (1996) muestra que los bebés presentan un rango de 'comportamientos proto-musicales' en sus interacciones con los cuidadores, usando el ritmo y la altura en una modalidad musical. Dichos comportamientos proto-musicales trascienden la mera audición y acoplan producciones y movimientos mientras escuchan, bajo la forma de "sincronizaciones regulares de los patrones vocales y cinéticos que proveen al bebé información sensorial multimodal, esto es, que incluye contenidos táctiles, visuales y de movimiento" (p.105).

En similares términos Colwyn Trevarthen (1999) ${ }^{22}$ sugirió que las interacciones proto-musicales entre el niño y su cuidador son crucialmente importantes para el bebé ya que le permiten el desarrollo de la intersubjetividad primaria basada en la 'comunión de estados emocionales' entre ambos. La naturaleza temporal, corpórea y ordenada de los comportamientos proto-musicales evidenciados en las interacciones adulto- niño permiten compartir los patrones temporales con el otro y facilitar los encuentros afectivos puestos en juego en la interacción.

Ellen Dissanayake $(2000)^{23}$ acuerda con dichas visiones al proponer que las características musicales de la interacción madre-bebé son de importancia crítica en la adquisición de capacidades de regulación social y unión emocional. A esta estimulación multimodal y parental la autora la ha denominado babytalk, estimulación que el bebé recibe por medio de los diferentes sentidos: la visión, la audición y el tacto.

\footnotetext{
${ }^{21}$ Citado por Ibarretxe (2010)

${ }^{22}$ Citado por Cross (2003)

${ }^{23}$ Citado por Cross (2003)
} 
CANTAR CANCIONES ENTRE LOS CUARENTA Y CINCUENTA MESES 50

Cross (2003) acuerda en el carácter multimodal de la proto-musicalidad infantil porque a su entender involucra sonido y acción además de servir a un rango de funciones que son críticas o fundamentales en el desarrollo del bebé. El autor sostiene que

las actividades proto-musicales tienen una cierta 'intencionalidad flotante', una referencia transpolable y probablemente múltiple. Dicha intencionalidad flotante de los comportamientos proto-musicales puede ser usada en la niñez como estrategia para generar conexiones entre diferentes dominios de la competencia infantil: psicológicos, biológicos y mecánicos. La música, como actividad proto-musical, crea y alimenta la flexibilidad cognitiva que parece ser la singularidad de nuestra especie (p.5).

El mismo autor en 2001 ya había sugerido que las actividades proto-musicales proveen mecanismos de flexibilización cognitiva coadyuvantes a la exploración y adquisición de habilidades de interacción social. En un trabajo posterior Hallam et al. $(2009)^{24}$.postularon que la música se enriquece con funciones que son complementarias aunque diferentes a las del lenguaje y que significa un factor importante para la supervivencia de la humanidad. Proponen que ambos modos de comunicación probablemente han emergido de un patrón común de conducta entre la díada madrehijo, con comportamientos proto-musicales que regulan las emociones y elementos proto-lingüísticos que gradualmente adquieren características prosódicas y fonémicas, las que finalmente empiezan a ser mapeadas con referentes específicos. Consideran las capacidades humanas para la música como una precondición probable de la capacidad lingüística, cuyo origen es la expresión vocal de la emociones. Desde el nacimiento, las interrelaciones del adulto con el bebé se basan en una estimulación multisensorial en la que variaciones de tono, ritmo e intensidad, se producen a través de exageraciones de

\footnotetext{
${ }^{24}$ Revisión de Desmond Sergeant (2009) Psychology or Music, 37, 4
} 


\section{CANTAR CANCIONES ENTRE LOS CUARENTA Y CINCUENTA MESES 51}

los contornos melódicos, la hiperarticulación de las vocales y la repetición de frases cortas, sumadas a estímulos de movimientos del cuerpo y expresiones faciales.

En un trabajo realizado sobre la interacción adulto-bebé en una escena de habla y otra de canto, Martínez (2008) sugirió que ambas interacciones presentan una organización diferente centrada en los modos diversos en que movimiento y sonido se componen en el tiempo y está relacionada con la comunicación de los contenidos de la cultura que en ambos casos es diferente:

en la escena hablada se trata del proceso de desarrollo de la lengua en el contexto de los modos sociales de interacción, en tanto que en la escena cantada el motivo principal es introducir al niño en un juego musical propio de la cultura en el que predominan los componentes de movimiento-sonido al servicio de la enacción motora conjunta adulto-bebé y en donde la pauta de coherencia temporal adquiere otra significación (p.82).

La díada fue la misma para ambas performances, registrada a los 6.5 meses del bebé en la escena hablada y a los 7.5 meses para la cantada. Esta autora señala

la aparente paradoja que emerge del análisis de la composición del sonido y el movimiento de la performance adulta en la escena de habla y en la de canto, se manifiesta en el hecho de que algunos de los rasgos que describen a la ejecución 'musical expresiva' en nuestra cultura se hallan presentes en la escena hablada los que incluso exhiben una sofisticación en la organización del componente sonoro aún mayor que el que encontramos en la escena cantada (p.82).

En un estudio intercultural realizado en el área, Gratier $(1999)^{25}$ ha mostrado que los atributos musicales de las interacciones madre-bebé difieren poco de una cultura a otra y que la coherencia de dichas interacciones es severamente afectada por el grado de dependencia del contexto cultural específico.

Se considera que las actividades proto-musicales son especialmente útiles para la exploración de la interacción social por sus múltiples significados potenciales. Poppel y Wittmann (1999) las describen como medio único para comunicar y compartir estados

\footnotetext{
${ }^{25}$ Citado por Cross (2003)
} 
CANTAR CANCIONES ENTRE LOS CUARENTA Y CINCUENTA MESES 52

corporales y emocionales humanos, ya que proveen al niño medios para la gestación de una capacidad de interacción social y un espacio libre de riesgo para la exploración del comportamiento social.

\subsubsection{El canto de canciones}

Estudios previos han prestado atención a los elementos estructurales de las canciones y los componentes emocionales del canto temprano.

Stadler-Elmer (2009) afirma que la habilidad de cantar trasciende el marco del respeto por las alturas en la tonalidad. Estima que la reproducción de canciones espontáneas o solicitadas y las canciones inventadas contienen rica información acerca de la comprensión infantil implícita de las reglas culturales y que la precisión en la entonación es sólo uno de entre muchos otros criterios a ser observados. Desde una perspectiva holística señala que se trata de analizar la organización completa del canto con respecto a la melodía (altura y ritmo), texto, metro y ciertos aspectos de la conducta tales como movimientos de acompañamiento compartidos con el otro. Por ello considera importante la observación de cómo la organización vocal cambia a lo largo del tiempo. Asimismo vincula los estados emocionales del niño durante el canto, con el disfrute, la alegría, el juego y el bienestar.

Las diferentes modalidades del canto infantil en sus etapas tempranas han sido denominadas de diferente manera:

- manifestación pre-cantora (Routkowski, 1994): los niños “cantan” en el rango de la voz hablada usualmente de La3 a Do4; 
- vocalización intermedia (Mang, 2000): desempeño entre el habla y el canto observada en niños de edad preescolar;

- cantilena (Welch, 1999): los primeros intentos vocales se desenvuelven en un rango restringido de alturas, en el que las palabras de la canción son el centro de interés más que la melodía.

En las melodías un componente perceptualmente saliente es el contorno melódico, expuesto previamente. La sensibilidad al contorno melódico "emerge temprano en la infancia y es probable que esté relacionada con la importancia de la entonación en la percepción del habla" (Patel, 2004, p.328). Los estudios de base neuro-científica sugieren que los niños parecieran estar preparados para la música. Sandra Trehub y sus colaboradores $(1997)^{26}$ han mostrado que bebés de seis meses de edad son 'auditores bastante capaces'; por ejemplo, muestran sensibilidad a la constancia del contorno melódico, al experimentar como iguales las melodías que comparten el mismo contorno o patrón de ascensos y descensos, aunque las alturas hayan cambiado.

Para Dowling (1994) los niños son sensibles al cambio en el contorno melódico desde antes de comenzar a hablar y cantar. Tan pronto como los niños comienzan a hablar comienzan a cantar. Este canto generalmente tiene dos formas: a) juegos vocales explorando los límites de lo que puede hacer su propia voz en altura, intensidad y velocidad y b) creación espontánea de canciones.

Las canciones espontáneas entre el primer y segundo año se caracterizan por un tempo más o menos regular sobre el cual superponen las palabras del discurso de la canción y algunos niveles discretos de alturas. Las alturas no son aquellas de la escala musical del adulto y los niveles de altura fluyen continuamente. No obstante, "la

\footnotetext{
${ }^{26}$ Citado por Cross (2003)
} 
CANTAR CANCIONES ENTRE LOS CUARENTA Y CINCUENTA MESES 54

constancia en los patrones métricos y el uso de niveles de alturas discretas y sostenidas para las vocales, son características que distinguen el canto del habla en esta edad" (Dowling, 1994, p.12). En términos de altura lo que el niño controla generalmente en esta edad, no es exactamente la frecuencia de las alturas sino que atiende a los patrones ascendentes y descendentes del contorno.

En un estudio que examinó la concordancia entre la representación mental de una melodía simple percibida memorizada y su representación gráfica, Segalerba (2005) concluyó en que la curva melódica (contorno) es la característica mejor conservada en la percepción de melodías y que presenta los porcentajes más elevados de exactitud.

En cuanto a la tipología de contorno con mayor presencia en los primeros esbozos de canto, varios autores consideran que los contornos descendentes son más fáciles de cantar (Ramsey, 1983 y Fox, 1990²7; Welch, 2009; Davidson, 1994).

Atterbury y Silcox $(1993)^{28}$ estudiaron la influencia del acompañamiento armónico del piano en la habilidad de cantar de niños de pre-escolar. Estos autores observaron diferencias no significativas entre la habilidad de cantar con acompañamiento y sin acompañamiento después de un año de instrucción.

Sloboda $(1985)^{29}$ comprobó en estas edades, una no preferencia por acompañamientos de la melodía consonantes sobre acompañamientos disonantes.

\subsubsection{Las improvisaciones cantadas}

En los escritos previos hay acuerdo general en que los niños en sus primeros balbuceos cantados "prueban" al jugar su disponibilidad vocal en diversos momentos.

\footnotetext{
${ }^{27}$ Citados por Miyamoto (2007)

${ }^{28}$ Citado por Miyamoto (2007)

${ }^{29}$ Citado por Miyamoto (2007)
} 
CANTAR CANCIONES ENTRE LOS CUARENTA Y CINCUENTA MESES 55

En ellos canturrean esbozos de melodías que conocen o improvisaciones libres en las que usan patrones aprendidos. "Las cantilenas y balbuceos cantados son juegos vocales que el niño ensaya y ensaya por mero placer. Es un canto que parece errante en el que trata de reproduciré estructuras melódicas en las que está interesado" (Malbrán, 1992, p. $153)$.

Acorde con estas observaciones de madres y cuidadores de niños en la primera infancia, $\operatorname{Moog}(1976)^{30}$ señala que a los tres años los niños suelen mezclar vocalizaciones espontáneas con canciones conocidas las que combinan y suceden libremente: a estas producciones las denomina canciones pot-pourri, en las que observó que la tonalidad puede establecerse sólo a nivel de la frase no de la canción completa.

Así también Flohr $(1984)^{31}$ investigó acerca de las improvisaciones exploratorias vocales en niños de 2 a 5 años y comprobó la siguiente secuencia: a los 2 años la producción vocal se genera en la energía motora; a los tres años comienzan a crear patrones con repetición de ideas, particularmente reiteraciones caracterizadas por patrones rítmicos conocidos y a veces por un "aparente" metro tres. Esta apreciación disiente con registros de Edgar Willems (1981), pedagogo suizo que describió acertadas observaciones fundadas en su práctica con niños pequeños. Según dicho autor el metro tres es una cognición aprendida; la producción espontánea es siempre pendular dando cuenta de un metro dos. Asimismo Flohr acuerda con investigaciones ya descriptas al afirmar que a los cinco años se conforman esquemas en los que las repeticiones rítmicas y melódicas ocurren estructuralmente y con un tempo en cierta medida constante.

\footnotetext{
${ }^{30}$ Citado por Hargreaves (1996)

${ }^{31}$ Citado por Miyamoto (2007)
} 


\section{CANTAR CANCIONES ENTRE LOS CUARENTA Y CINCUENTA MESES 56}

Observaciones similares realizó Welch (1991) respecto del canto improvisado de los niños pequeños: generalmente se centran alrededor de Re4 porque habitualmente usan un registro cantado cercano al centro de altura del habla.

En un estudio en 2002 Young $^{32}$ estudió el desarrollo vocal de niños de un jardín maternal entre los dos y tres años. Reportó diversidad de formas de canto espontáneo infantil vinculados al contexto y la actividad: creaciones vocales sin texto asociadas a menudo con el juego solitario con una forma general no definida; canturreo, a menudo de frases repetidas; canto de fragmentos de canciones del entorno cultural; vocalizaciones acompañadas de movimiento propio o de objetos; cantos de animación vinculados con el juego dramático e imitación de sonidos reales asociados a objetos del juego. En la medida del crecimiento entre los tres y cuatro años, los niños del estudio mostraban mayor sociabilidad y resultaba prominente el habla sobre el canto.

Tafuri (2009) al referirse a las canciones creadas por los niños mientras juegan, considera que son bastante imprecisas señalando que en sus comportamientos habituales muestran que se distraen con facilidad, se detienen, cambian de canción y en ocasiones gritan.

Davidson (1994) en un estudio realizado sobre el canto espontáneo a los dos años, señala que las respuestas infantiles muestran que la reproducción de las frases opera como estructura subyacente, esto es, 'como unidad musical inicial' caracterizada por usar un rango de alturas limitado, con una cierta discrepancia entre la tónica, la tonalidad y los contornos descendentes.

\footnotetext{
${ }^{32}$ Citado por Welch (2006)
} 


\subsection{La construcción de la habilidad de cantar}

Cuestiones de sumo interés para los investigadores del canto infantil han sido estudiar comunes denominadores en las performances y su relación con la edad, el desarrollo de constantes en el proceso, como así también el grado de estabilidad o cambio en el itinerario que procede del proto-canto al canto entonado.

En un estudio temprano, Wendrich $(1981)^{33}$ consideró que la habilidad para imitar alturas puede perderse. Analizó una consistente imitación melódica a los 6 meses, que llegaba a ser inconsistente a los tres años y medio. Concluyó que la pérdida de la habilidad puede deberse a la falta de práctica y desarrollo de esquemas-estructuras que son las bases de la percepción.

Diversos estudios han puesto el foco de análisis en la incidencia del rango de alturas que los niños eligen para cantar. Reiko Hata (1987) observó que los niños de 3 a 5 años comenzaban a cantar en una altura más confortable ubicada en el centro de su rango vocal y que esa altura estaba almacenada en su memoria, ya que en sucesivas interpretaciones y en diferentes días, el $29 \%$ comenzaba en la misma nota y el $87 \%$ del total comenzaba en una altura de hasta una 3ra de distancia. Registró que Mib4 fue la nota de comienzo más frecuente con notas comprendidas entre el Do central y el Fa\# hacia el agudo, en el $87 \%$ de los niños de tres años, el $81 \%$ de los de cuatro y el $75 \%$ de los de cinco.

Welch (1991) consideró que Re4 puede ser vista como la altura central del rango vocal confortable para muchos niños pequeños tanto en performances habladas como

\footnotetext{
${ }^{33}$ Citado por Miyamoto (2007)
} 
cantadas. Agrega que sin duda los niños con una práctica sistemática pueden extender su rango cantado.

Mang $(2002)^{34}$ en un estudio con niños de tres y cuatro años realizado en Hong Kong, describió que los niños usaban manipulaciones vocales diferentes para el habla que para el canto. La frecuencia fundamental $(\mathrm{Fo})^{35}$ reportada para el canto fue consistentemente más aguda que la empleada para el habla, aunque con dos tipos de performances: en las "canciones propias" utilizaron una Fo ligeramente más grave que en las canciones enseñadas para el estudio.

En el marco del Programa Nacional de Canto para Escuelas Primarias, llevado a cabo en Inglaterra, Welch et al. (2008) observaron que el centro del habla se ubicaba mayoritariamente en la región de La3 a Do4. Los niños mayores tenían el centro del habla ligeramente más bajo (grave) acción que justifican en que el rango vocal es ligeramente más amplio en la edad de 10 años. Comprobaron que el rango confortable más común para cantar en los niños de 7 años muestreados fue Sol3-Si4, extendiéndose a Fa3-Do5 en los 10 años. Las evidencias indican una tendencia general hacia el incremento con la edad de la competencia para cantar, más allá de diferencias socioeconómicas, culturales o de raza.

Los estudios previos indicarían que el desarrollo eficaz del canto de canciones está sujeto a un proceso de desarrollo en el cual el ajuste al modelo mejora con la edad y es mediado por una práctica específica. Como en otras habilidades, las diferencias individuales existen y su desarrollo depende de la calidad e importancia concedida a la práctica en el contexto educativo y familiar.

\footnotetext{
${ }^{34}$ Citada por Welch (2006)

${ }^{35}$ Un sonido armónico, puede descomponerse en una serie de sinusoides armónicas. La frecuencia de base (menor frecuencia) es la Frecuencia Fundamental (Fo). (Basso, G. (2001) Análisis espectral. La transformada de Fourier en la Música. Ediciones Al Margen. Colección Universitaria. La Plata, Argentina.
} 


\subsubsection{Las habilidades musicales en la primera infancia}

Una cuestión que centra la atención de psicólogos y pedagogos es acerca de la existencia o inexistencia de etapas en el desarrollo artístico y musical. Hargreaves (1996) describe dos posturas opuestas. Una representada por Parsons (1987) y la otra por Gardner (1988). Parsons postula una teoría de base piagetiana conformada por etapas del desarrollo en las Artes Plásticas, según la cual los niños pasan por cinco etapas que van desde el favorecimiento de la acción en la cual simplemente experimentan placer en el trabajo artístico con poca discriminación cognitiva hasta la etapa de "autonomía", en la cual son capaces de adoptar una actitud reflexiva hacia el valor cultural del trabajo. Agrega que las etapas se aplican a través de todas las formas de arte, o sea que ciertos cambios en el pensamiento artístico ocurren como resultado del incremento en la edad y suceden en las artes visuales, la música, el drama y la danza.

Gardner y sus colegas, elaboraron un modelo del desarrollo artístico en el marco del Proyecto Zero de Harvard. Según esta teoría resulta innecesario considerar el desarrollo de las artes en etapas dado que las operaciones cognitivas del tipo de las descriptas por Piaget no son críticamente importantes para muchas de las actividades que los artistas llevan a cabo y no son necesarias para el dominio o comprensión del lenguaje humano, la música o las artes plásticas (Gardner 1973) ${ }^{36}$.

Según Hargreaves (1996) estas posiciones pueden reconciliarse pues si bien los aspectos específicos del desarrollo musical existen -notablemente en los niveles más altos de habilidad y experticia- pueden observarse rasgos generales en el curso del

\footnotetext{
${ }^{36}$ Citado por Hargreaves (1996)
} 
desarrollo artístico a través de los diferentes dominios, rasgos que muestran cambios regulares con la edad. Dichos cambios se producen por operaciones específicas del pensamiento que sirven de base a los desarrollos en cada forma de arte y que son mediadas por la identificación de reglas y la aplicación de estrategias cognitivas que están presentes en el desarrollo artístico y musical.

Hargreaves y Galton (1992) ${ }^{37}$ elaboraron un modelo descriptivo del desarrollo artístico desde un punto de vista psicológico y de raíz piagetiana con implicancias educacionales. Describieron cinco fases en el desarrollo estético: sensoriomotora, figurativa, esquemática, reglada y profesional. Cada una de ellas fue descripta en términos de mecanismos cognitivos subyacentes. Asimismo consideraron cuatro áreas en el desarrollo musical: canto, representación musical, percepción melódica y composición.

Hargreaves, en un trabajo posterior (1996) enriqueció el modelo original ampliando los fundamentos del desarrollo musical basándose en la teoría de Piaget, por un lado y el desarrollo de los niños en las artes-dibujo, escritura y percepción estéticapor el otro. En este nuevo aporte el autor describe las cinco fases anteriores y estipula edades para cada una de ellas en el desarrollo de distintas habilidades: la fase sensoriomotora, que se extiende desde el nacimiento hasta los 2 años; la fase figurativa, de los 2 a los 5 años; la fase esquemática, de los cinco a los 8 años; la fase con sistema de reglas, desde los 9 a los 15 años y la fase profesional desde los 15 años en adelante. Para cada una de ellas especifica las habilidades que un niño puede obtener de acuerdo a cuatro categorías: canto, composición, percepción melódica y representación gráfica.

\footnotetext{
${ }^{37}$ Citado por Hargreaves (1996)
} 


\section{CANTAR CANCIONES ENTRE LOS CUARENTA Y CINCUENTA MESES 61}

En la fase figurativa, que es la de mayor interés para el presente trabajo, el autor considera fundamental que los niños adquieran la habilidad de simbolizar o representar cosas que no están presentes, o sea, adquirir la representación gráfica sin la permanencia del objeto. En cuanto a la notación musical observó que el dibujo sugiere la figura o forma de la secuencia, ya que en esta fase la representación métrica está en ciernes.

Swanwick y Tillman $(1986)^{38}$, se basaron en las composiciones musicales producidas por 48 niños durante cuatro años para establecer una serie de etapas en el proceso de desarrollo, etapas a las que denominan transformaciones. Señalan que son de carácter acumulativo esto es, que cada etapa adquirida se suma y consolida en la siguiente. Presentan estas transformaciones bajo la forma helicoidal por tratarse de un proceso cíclico y recurrente que asocia el desarrollo individual con la respuesta socialmente estimulante y comunitaria.

Los autores tipifican las transformaciones como sigue:

- de dominio, se observa en las composiciones de los niños de 3 y 4 años en las que muestran gran interés por los sonidos, por la altura y la resonancia de los instrumentos. En su modo de hacer música, se observa un impulso mecánico al explorar las sonoridades de los instrumentos con una tendencia a la repetición de fragmentos;

- de imitación: representación de posturas, gestos, carácter y movimiento de la música con rasgos expresivos. Se produce durante los primeros años cuando la imitación que comenzó como expresión personal se integra a las convenciones de producción musical socialmente compartidas. Aproximadamente a los siete

\footnotetext{
${ }^{38}$ Citado por Swanwick (1991)
} 
CANTAR CANCIONES ENTRE LOS CUARENTA Y CINCUENTA MESES 62

años la producción artística de los niños se caracteriza por el respeto a los códigos culturales;

- de juego imaginativo: se manifiesta hacia los once años y consiste en la especulación sobre lo vernáculo, con un interés por la forma y la coherencia musical;

- de metacognición designa el proceso de concientización y articulación de ideas sobre las propias operaciones mentales o sea la autoconciencia de los procesos de pensamiento y sentimiento en una respuesta valorativa a la música. Se observa, según estos autores, desde los quince años y se logra a través de un compromiso estable e intenso con la música.

Todas estas cuestiones resultan de interés para investigaciones futuras.

\subsubsection{El canto desde el nacimiento}

Hay acuerdo entre los investigadores en que el canto como forma de expresión está presente desde los primeros meses de vida y es susceptible de enriquecimiento continuo. Si bien las diferencias inter-individuales están presentes, hay evidencia respecto de la "existencia de una secuencia en su desarrollo en la que ciertas performances tienen preeminencia sobre otras" (Welch, 1999, p.10). En cuanto a la posibilidad de progresión-regresión de la habilidad para cantar, el mismo autor (1999) considera que

hay evidencias de investigación que sugieren que las conductas de canto no son fijas ni inmutables, sino que pueden estar sujetas a cambio. Esta susceptibilidad para el cambio ha sugerido considerar al canto como un continuum de desarrollo en el que los diferentes tipos de canto son ejemplos de categorías, etapas o fases de desarrollo situados a lo largo de dicho continuum (p.6). 
Welch en un estudio previo $(1997)^{39}$, adelantó la visión del progreso para cantar como un continuum que puede durar un año o más, tiempo durante el cual los niños pueden oscilar entre éxito total y éxito relativo. Explica tales variaciones trazando paralelismos con aprender a caminar o a hablar, acciones en las que los seres humanos muestran progresos y retrocesos, bajo la forma de desarrollos fluctuantes entre precisión e imprecisión en la marcha hacia la habilidad.

El autor establece una secuencia en el desarrollo del canto infantil conformado por etapas que se diseñaron a partir de investigaciones sobre muestras infantiles. Dichas etapas se aplican aún en sujetos adultos con una experiencia de canto escasa o restringida. La precedente apreciación abona la idea del progreso del canto como experiencia de desarrollo susceptible de ser aprendida en cualquier edad. Así también considera que en la etapa en que comienza a distinguirse el habla del canto,

hay una creciente evidencia de que la altura del sonido vocal puede ser un proceso consciente bajo la forma de un perfil melódico cantado que comienza a seguir los macro-contornos de la melodía propuesta o de algunas frases constitutivas clave (p.6).

En cuanto al respeto de la tonalidad el autor considera que las respuestas se basan esencialmente en la frase musical. En etapas de mayor pericia los intervalos pueden ser exactos aunque continúan observándose cambios en la tonalidad; en la última etapa no hay errores significativos en cuanto a intervalos y tonalidad al imitar canciones sencillas de la cultura de pertenencia.

Tafuri (2009) realizó un estudio longitudinal del desarrollo vocal de niños exponiéndolos en sesiones regulares al canto de sus madres desde el último trimestre del embarazo hasta los seis años, tanto en el hogar como en un curso especial de canto organizado en el conservatorio de Bologna. Observó que los niños en los comienzos al

\footnotetext{
${ }^{39}$ Citado por Tafuri (2009)
} 


\section{CANTAR CANCIONES ENTRE LOS CUARENTA Y CINCUENTA MESES 64}

cantar repiten la última palabra de una frase de la canción, a veces la mitad de una frase, o las frases con sonidos de onomatopeyas de juguetes o voces de animales (pum, pum; din, din; etc.). Formó parte de sus observaciones que a los dos años a menudo los niños cantan sólo dos frases de la canción y que con la edad se incrementa la habilidad del niño para recordar más palabras y sostener su atención. A pesar de la diferencias individuales, asegura que "algunos niños de dos años y dos meses pueden cantar canciones completando tres frases y con ajuste tonal a pesar de que la pronunciación de las palabras todavía sea imprecisa" (p.64). Esta característica es observada sólo en las canciones aprendidas. La misma autora considera que las tres etapas planteadas por Welch (1999) no bastan para evaluar la producción de los niños de su estudio (cada uno con numerosas y variadas performances) y propuso una escala de siete categorías aunque con fronteras no muy precisas entre las mismas.

Tafuri (2009) estudió 30 niños de entre dos años- nueve meses y tres años, asignándoles a sus producciones vocales las categorías elegidas. Resultó que el $70 \%$ de los niños cantaba aceptablemente entonado, aunque en ocasiones, no siempre. La investigadora señala que los resultados obtenidos resultaron sorprendentes ya que estudios anteriores habían mostrado estándares diferentes. La autora atribuye los resultados obtenidos en su estudio a que las madres de los niños habían seguido un curso especial de música desde antes de nacer. Concluye que "a medida que los niños crecen y se les da la oportunidad, cantan más y mejor" (p.67).

Un tema de interés es la comparación entre el canto de canciones completas o de frases de estas canciones. Según Tafuri (2009) la habilidad de cantar canciones completas progresa con la edad y la habilidad de cantar frases de las canciones parece sufrir una regresión respecto del canto en la tonalidad y que a medida que los niños 
crecen realizan menos detenciones al cantar unas pocas frases de la canción. Los niños que se detienen después de cantar algunas frases son aquellos que se sienten menos seguros en el canto entonado o que cambian de canción. Esto sucede en las diferentes edades infantiles del estudio de la autora y para dar razones de algunos comportamientos observados los compara con otros del habla infantil, que muestran que a la edad de dos años han desarrollado el sentido de comienzo y final de un cuento, aunque no hayan desarrollado la conexión y coherencia lógica entre las aperturas y los cierres (Cowie, 1989) ${ }^{40}$. Tafuri considera que esta habilidad del habla puede influenciar el sentido dado a una canción como algo que tiene un comienzo, un desarrollo y una conclusión. Según la autora las evidencias encontradas en su trabajo longitudinal (p.68) son básicamente tres: “1) los mecanismos perceptivos-cognitivos y fonatorios están listos, antes de la edad de tres años, para imitar una melodía correctamente"... "2) la habilidad no se desarrolla para todos al mismo tiempo y 3 ) en dicha edad el canto es una habilidad inestable, el mismo niño que cantó una canción perfectamente una vez, puede cantarla con errores unos minutos o una semana después". Concluye en que los datos obtenidos en su estudio sugieren, que un factor decisivo para el desarrollo de la habilidad para cantar es contar con "un contexto social con un entorno familiar musicalmente rico que provea estímulos tanto como elogios y atención e interés por el niño" (p.70).

Jorquera et al. $(2000)^{41}$ testearon dos grupos de niños en su primer año de escuela elemental y señalaron que el $15 \%$ desarrolló la habilidad de cantar aceptablemente entonado.

\footnotetext{
${ }^{40}$ Citado por Tafuri 2009

${ }^{41}$ Citado por Tafuri 2009
} 


\section{CANTAR CANCIONES ENTRE LOS CUARENTA Y CINCUENTA MESES 66}

En una muestra muy amplia Reiko Hata (1987) estudió las interpretaciones $a$ capella de una canción favorita de niños de 3 a 5 años (N:410). Las calificó según tres categorías: precisa, bastante precisa y no precisa. Encontró que a los tres años el $92 \%$ de los niños cantaban en forma no precisa y el $8 \%$ con bastante precisión. A los cuatro años el $70 \%$ era de respuesta no precisa, el $25 \%$ bastante precisa y el $5 \%$ precisa. A los cinco años el $56 \%$ era no precisa, el $30 \%$ bastante precisa y el $14 \%$ precisa.

Los estudios de Davidson (1994) trazan un paralelismo entre las etapas del desarrollo tonal y las tres etapas planteadas por Piaget para el conocimiento operacional (sensoriomotora, concreta operacional y formal operacional). Según esta autora un análisis de los elementos de la música, difícilmente revelará el conocimiento (saber) psicológico sobre el que el aprendizaje está basado: la naturaleza psicológica del aprendizaje trasciende un análisis lógico de rasgos, aprendizaje que puede llegar a ser evidente por la comparación minuciosa de diferentes niveles de habilidad.

El desarrollo musical lo ubican en mesetas en las que cada una de las etapas prepara el camino para la siguiente, aunque dicho tránsito hacia el aprendizaje puede resultar mediato. Describe etapas en el desarrollo del canto infantil vinculándolas con edades específicas. Observó que la respuesta típica a los tres años depende de la letra de la canción si bien los niños pueden producir distintas alturas, no presentan estabilidad interválica ni coherencia tonal. A los cuatro años todavía se centran en las palabras de la canción y, si bien la reproducción del contorno melódico presenta mayor precisión, todavía la performance no posee coherencia global. Alrededor de los cinco años o más, los contornos individuales y los intervalos son reproducidos con precisión. Davidson sugiere que el desarrollo del canto en los niños está vinculado con un proceso esquemático del contorno melódico. Sus estudios con niños de uno a seis años de edad le 
permitieron establecer cinco niveles específicos del desarrollo de las alturas en el canto. Estos niveles se expanden desde un esquema de contorno melódico inicial con un intervalo de tercera, a otro que abarca la octava completa.

Rutkowski (1997) ${ }^{42}$ diseñó nueve categorías para estudiar el desarrollo de la voz cantada infantil en niños de preescolar. Delimitó la tesitura que emplean los niños en cada etapa. Si bien son nueve, las etapas en las que se producen cambios son cinco, con fases intermedias entre las mismas. La primera es la etapa "pre-cantora", los niños en lugar de cantar, canturrean el texto de la canción. La segunda "cantores del rango hablado", sostienen algunos tonos, exhiben alguna sensibilidad a la altura y permanecen en el rango de la voz hablada (usualmente de La3-Do4). La tercera etapa "cantantes de rango limitado e inconsistente", oscilan entre la voz hablada y la voz cantada usando un limitado rango en la voz cantada (usualmente hasta Fa4). En la etapa cuatro "cantantes del rango inicial", muestran un uso consistente del rango inicial cantado (usualmente Re4-La4). Por último la quinta etapa "cantantes", se caracteriza por el uso de un rango cantado extendido, porque cantan ampliando el registro hacia el agudo, desde la nota Sib y más agudo.

Los estudios precedentes acuerdan en que el canto se inicia bajo la forma de un proto-canto en el que algunos niños sugerirían el uso de categorías, otros etapas y otros evoluciones en meseta. Sin embargo todos acuerdan en que es un proceso continuo en el que pueden observarse marchas y contramarchas, avances y retrocesos momentáneos en un itinerario de "asentamiento" de la compleja habilidad de cantar entonado.

${ }^{42}$ Citado por Welch 2009 


\subsection{El canto infantil en los escritos de pedagogos argentinos}

La Educación Musical en la Argentina mostró un proceso de amplio desarrollo a partir de la década del 60. Notables pedagogos iniciaron experiencias emergentes de la "pedagogía activa", generando importantes aportes bibliográficos que impactaron en el área hispano-parlante.

Violeta Hemsy de Gainza (1964) en su temprana obra señaló que "la canción infantil es el alimento musical más importante que recibe el niño" (p.113).Consideró asimismo que las canciones necesitan atender a ciertas características tales como i) la tesitura que dependerá de la edad de los niños, sin sobrepasar el ámbito de doce o trece notas en niños de entre nueve y trece años. Adelantándose a estudios empíricos realizados posteriormente por Mónaco (2001) señala "el niño que asiste en nuestro país al Jardín de Infantes canta generalmente en el registro grave" (p.116). En tal sentido asigna capital importancia al rol del maestro especializado responsable de atender a

i) el registro medio utilizado por los niños e ir ampliándolo hacia el agudo, dado que entre los 5 y 7 años el registro normal se sitúa alrededor de la sexta Do4-La4;

ii) la tonalidad, "las más frecuentemente usadas son Si, Do y Re mayor o menor en las canciones que se desarrollan entre la tónica y la quinta o sexta superior y Re, Mi y Fa y hasta Sol mayor y menor para las canciones que se extienden además hasta la quinta por abajo" (p.118)

iii) la estructura, debe contener frases cortas de dos o cuatro compases con frases claramente divididas en motivos cortos que concuerden con la capacidad respiratoria del niño; 
iv) el ritmo atendiendo al ritmo y sentido de las palabras;

v) el texto con calidad acorde a la de la melodía para alcanzar nivel artístico.

Gainza (1964) consideró que en los países latinoamericanos se disponía de escaso repertorio para los más pequeños, o sea canciones que se entonen sobre dos, tres y hasta cinco sonidos e instaba a los docentes a indagar en las raíces del cancionero tradicional y a crear sus propias canciones. A lo largo de su experiencia docente encontró que "los tipos de desafinaciones más frecuentes observadas en los niños son el hablar en lugar de cantar, los que cantan con voces graves o roncas y los que presentan una afinación imprecisa" (p.119). Según ella la mayoría de estos problemas se deben a una confluencia entre factores vocales y auditivos los que pueden ser superados con una educación musical adecuada.

Gorini (1983) con fértil experiencia en la dirección de coros infantiles, considera que el canto es el mejor camino para llegar a la música; agrega que cantar en un coro tiene "un enorme valor social, enseña a esperar, a adquirir conciencia de la propia personalidad respetando también la del compañero" además de contribuir a "la higiene de la voz, la educación del oído armónico y el despertar de la sensibilidad" (p.7). La autora concede suma importancia al repertorio a seleccionar, con melodía clara y sencilla, texto comprensible y diáfano. Por otra parte aconseja indagar en el acervo folklórico local o de otros países. Señala que la mala respiración y la falta de articulación ocasionan la emisión vocal inadecuada con niños que hablan o gritan en lugar de cantar:

lo esencial es llevarlos hacia el agudo, para que el niño descubra que allí también pueden sonar sus cuerdas, y sonar mejor. Aún los niños con problemas foniátricos llegan a solucionarlos más fácilmente cantando en los registros medio y agudo (p.10). 
Propone iniciar la tarea con canciones en el ámbito de una 5ta (Fa4-Do5 y Sol4Re5). Recomienda ampliar la tesitura infantil considerando que "la extensión normal de la voz infantil comprende de La3 al Sol5"(p.30).

Malbrán (1991) en su libro El aprendizaje musical de los niños, señala como fundamental el modelo vocal que se ofrece al niño "es tan poderosa la influencia del modelo que en su recreación el niño hasta respira donde lo hacía su circunstancial maestro" (p.139). Añade que cuanto antes se inicie el niño en el canto más oportunidades tendrá de cantar mejor y de que el canto se convierta en una actividad placentera. Advierte que "el repertorio de canciones es una ayuda importante como recurso de enseñanza, pero debiera formar parte del repertorio habitual el uso de melodías sin texto..." (p.138). En el caso de la enseñanza de canciones, descarta "el procedimiento frecuente de recitar el texto y luego agregarle la melodía" (p.141), ya que considera a la canción como un todo: una simbiosis entre melodía y texto. En un artículo escrito para una revista dirigida a maestros de educación inicial esta autora señala que cantar es una manera de darnos a conocer y expresarnos a través de la música. Más adelante hace alusión a la representación mental de los modelos melódicos que los niños poseen desde muy pequeños, a cómo la habilidad va desarrollándose por aproximaciones sucesivas y al rol de los adultos y de otros niños en el desarrollo de la habilidad;

pareciera que de la misma manera que 'ensaya' las palabras reiteradamente, al cantar va "modelando" su instrumento vocal hasta que consigue ajustar lo que canta con los modelos melódicos que intenta reconstruir. Es por ello que el canto de otros niños más grandes o de los adultos, son alimentos de una importante vía de expresión que se articula y refina ininterrumpidamente (Malbrán, 1992, p.153).

Según Furnó (2001) “el medio escolar parecería ser un ámbito propicio para lograr la adquisición de la habilidad de afinación en el canto"(p.1). Por ello aconseja 
CANTAR CANCIONES ENTRE LOS CUARENTA Y CINCUENTA MESES 71

comenzar en el nivel inicial a consolidar la habilidad "ofreciendo alternativas remediales destinadas a niños que han carecido de una experiencia musical valiosa en el seno del hogar y que por ello muestran un desarrollo incipiente o nulo en la habilidad del canto" (p.2).

Furnó (2004) realiza un análisis de las particularidades de la factura musical de las canciones infantiles y establece un paralelismo con las habilidades del canto. Reconoce que para establecer la dificultad de una melodía, tradicionalmente se consideraron aspectos como la complejidad rítmica, el ámbito, algunas relaciones interválicas, el número de sonidos componentes de la melodía y el centro tonal. Pero se ven complementados con estudios más recientes que establecen la dificultad de las canciones considerando el contorno melódico, el ámbito y su relación con el número de alturas componentes pertenecientes o ajenas a la tonomodalidad. Sostiene además que el análisis de las unidades formales menores a la frase en términos de dimensión, con sus relaciones de proporción y balance entre las unidades internas, son propiedades que inciden en el manejo del aire del cantante.

El primer proyecto de investigación universitaria en el campo de la Educación Musical: Un instrumento objetivo para determinar la dificultad de melodías y canciones llevado a cabo por un equipo de investigadores dirigido por Silvia Malbrán y Silvia Furnó (1989-1994) concluyó en que el grado de dificultad de un determinado ejemplar para ser cantado, necesita atender a las interacciones de sus rasgos componentes. En el marco de dicha investigación las autoras presentaron un trabajo en el Eleventh International Seminar on Research in Music Education en el que dieron a conocer un proyecto en marcha denominado Test for songs ${ }^{43}$ que incluía las categorías:

${ }^{43}$ Malbrán, S, y Furnó, S. (1987) 
1) Melodía con las subcategorías i) Rango y número de alturas ii) Organización de las alturas iii) Cualidad de los intervalos; iv) Encadenamiento de los intervalos.

2) Ritmo incluía las subcategorías i) Tempo; ii) Rítmica; iii) Metro iv) Encadenamiento de los grupos rítmicos, v) Densidad cronométrica.

3) Estructura, las subcategorías fueron i)Variedad de las unidades formales menores i-i Unidades formales melódicas y i-ii Unidades formales rítmicas ii) Equivalencia de las unidades formales menores (ufm) ii-i Tipos de comienzo y ii.ii Tipos de cierre iii) Cesura. iv) Regulación del tiempo.

4) Expresión contiene i) Variedad del carácter ii) Dinámica; iii) Emisión y iv) Estilo. Concluían en que la determinación del nivel de dificultad de las melodías para ser cantadas permite

- determinar la secuencia de enseñanza

- establecer jerarquías de aprendizaje;

- verificar el grado de progreso y

- organizar el repertorio seleccionando el ejemplar adecuado para cada nivel.

Furnó (2004) en su labor como jurado en la valoración de canciones infantiles autorales, realizó un estudio en el que analizó 219 canciones en variables distribuidas en tres categorías: valor estético, construcción musical y correlación música-texto. Observó que la mayoría de los ejemplares analizados correspondían a: i) estilos populares (jazz, rock, pop y folklore), ii) la estructura de la forma canción (estrofaestribillo) y iii) una tendencia en la estructuración del discurso musical en segmentos de igual dimensión o proporcionales (al doble o mitad). El estudio permitió comprobar que los compositores no tomaron suficientemente en cuenta al producir sus canciones la 
dificultad para sostener la respiración del fraseo (fiato), aspecto dependiente de la maduración y desarrollo del aparato respiratorio y de fonación. En efecto, el 80\% de los ejemplares analizados presentaban unidades formales internas excesivamente extensas para las posibilidades vocales infantiles y muchas de ellas poseían temáticas argumentales relacionadas con intereses de personas adultas. Furnó (2004) aconseja distinguir entre

canciones susceptibles de ser interpretadas por niños [de otras que] aunque están claramente destinadas a un auditorio infantil, dependen de un intérprete adulto para alcanzar una correcta resolución técnica y expresiva [ya que] cuando la expresión se ve limitada por exceder las posibilidades del intérprete el mensaje se limita en su nivel de implicación para el auditor (p.8).

La autora señala que otras perspectivas, como la de Pescetti $(1992)^{44}$ postulan una visión de adhesión afectiva sin conceder importancia al grado de dificultad que propone la canción, sosteniendo que, en el caso de que el niño no pueda resolver dificultades técnicas, de afinación o de interpretación, la aproximación a una canción difícil primero será de modo global, para ir dominándola a través del tiempo por ensayo y error. En tal sentido Furnó (2004, p.9) advierte sobre "la alta dificultad que implica ajustar, mejorar o corregir melodías que han sido alojadas en la memoria con errores y/o distorsiones". La solución a este tipo de dificultades es la administración de un repertorio con criterio progresivo en términos de dificultad.

Malbrán y García Malbrán (2010) reconocen que en el aprendizaje de una canción nueva, en la primera audición "solo podemos recordar una aproximación grosera de su contenido de alturas, esto es, retenemos el contorno (esquema)" (p.161). Este modo de retener en la memoria una melodía desconocida funciona tanto para los adultos como para los niños pequeños, los que "comienzan el desarrollo del canto a

\footnotetext{
${ }^{44}$ Citado por Furnó (2004)
} 


\section{CANTAR CANCIONES ENTRE LOS CUARENTA Y CINCUENTA MESES 74}

través de esbozos de canto basados en el perfil melódico". La denominan como "una forma de proto-canto, que, por aproximaciones sucesivas y reiteradas prácticas se va tornando más precisa hasta alcanzar la reproducción de los intervalos melódicos propios de una canción" (p.161).

En cuanto a la enseñanza de las canciones, las autoras señalan la importancia del modelo vocal a imitar por los niños, ya que "también se aprende el canto disfónico, la desafinación y el canto gritado" (p.170). Especifican que el registro vocal normal de los niños es agudo ya que el pequeño tamaño de su laringe coincide con la longitud de cuerda. Dan indicaciones metodológicas para el trabajo con las canciones en el aula: i) es imprescindible un análisis previo de la canción para establecer el modo más apropiado para abordar su enseñanza; ii) necesita realizarse sobre las tonalidades que les resultan cómodas a los niños de acuerdo al registro de la canción; iii) en el caso de

maestros varones deberán usar el falsete en la enseñanza de la canción; iv) el aprendizaje tiene dos momentos, la presentación en la que los niños no cantan, solo se dejan impregnar por la canción y una vez logrado, se comienza con su enseñanza. Consideran importante que el docente observe la respuesta de cada niño durante el canto colectivo, pues si un niño no canta "igual está aprendiendo, está incorporando la experiencia perceptivo-motriz, está participando" (p.183), aconsejan no exigir el canto ya que los niños pequeños tienen un proceso natural de recepción/ reproducción con cierto "delay", modo particular de actuar en la primera infancia.

Akoschky es autora de numerosas canciones y del Diseño Curricular para la Educación Inicial de la Ciudad de Buenos Aires (2000). Akoschky (2007) señala que la búsqueda y selección de las canciones es un tema primordial a tomar en cuenta en la enseñanza del canto en los niños de Jardín de Infantes. El cancionero popular con sus 
arrullos, cantos de cuna, coplas de nana con rimas y juegos del adulto con el niño, los romances, romancillos, el cancionero folklórico con materiales estilísticos específicos y las producciones de autor creadas especialmente para niños, aportan materiales valiosos para el repertorio infantil. Esta autora recomienda para los muy pequeños los juegos tradicionales en los que se acompaña el ritmo de la acción con la palabra y la melodía: juegos de manos, de cosquillas, de balanceo, de galope. A estos se suman otros cuando los niños comienzan a tener mayor autonomía en el lenguaje, en los desplazamientos y en la motricidad en general: juegos de sorteo, juegos ritmados acompañados con palmeos, con objetos diversos, con coreografías, sumado al vasto repertorio de rondas. Akoschky (2007, p.6) concluye "un cancionero bien seleccionado ayuda al desarrollo de la percepción y educa la sensibilidad musical de los alumnos" y advierte sobre las canciones de autor

la creación de canciones no es sencilla, se requieren tanto condiciones musicales como poéticas. Al sumar música y poesía, se están asociando dos lenguajes, con sus propias exigencias, con sus propias características. A los creadores les cabe gran responsabilidad: asumir ambas con igual capacidad o compartir autoría (p.6).

El aporte de pedagogos conocedores de la realidad vocal de los niños que asisten a las escuelas argentinas y sus posibilidades de desarrollo y mejoramiento en performances cantadas, unido a investigaciones llevadas a cabo sobre el tema, sin embargo, no han generado la suficiente atención por parte de los educadores musicales, encargados de desarrollar la habilidad del canto en todos los niños. En la Argentina se observa un déficit en relación al canto como bien compartido entre las personas. Investigaciones (Mónaco, 1998a, 2000, 2001) y registros anecdóticos de las aulas muestran que el común de los niños no alcanza la habilidad de entonar una melodía sencilla y llegan a la edad adulta manifestando esta carencia. La influencia familiar y del contexto social así como la educación musical en la escuela son factores 
CANTAR CANCIONES ENTRE LOS CUARENTA Y CINCUENTA MESES 76

determinantes para la adquisición de estas habilidades tan apreciadas por nuestra cultura. 


\section{Capítulo 4}

\section{Metodología}

Este trabajo estudia el canto de canciones por niños que asisten a Jardines de Infantes de la provincia de Buenos aires, cuyas edades oscilan entre los cuarenta y cincuenta meses.

Se intenta avanzar en los estudios sobre la emisión vocal, la puesta en uso de la tonalidad y el tempo como adquisiciones altamente vinculadas con la enculturación, el rol del texto literario en la simbiosis música texto y el grado de dominio en la reproducción del contorno de alturas.

Dichas variables serán examinadas en las respuestas obtenidas para dos canciones de una estrofa, enseñadas previamente.

\subsection{Planteo del problema}

Hipótesis de trabajo

El canto infantil se desarrolla bajo la forma de un continuum que progresa desde la voz hablada al canto entonado. En el continuum pueden identificarse jalones susceptibles de ser aislados y descriptos.

\subsection{Variables y Sub-variables}

Las variables aisladas son: I.- Emisión Vocal; II.- Adecuación Tonal y III.Continuidad Temporal.

Cada variable es abierta en sub- variables las que a su vez son descriptas en categorías. 
CANTAR CANCIONES ENTRE LOS CUARENTA Y CINCUENTA MESES 78

\subsubsection{Emisión vocal}

El constructo emisión vocal hace referencia a la producción del niño en términos de la colocación de la voz en el registro del canto.

Sub-variables

Estudio previos (Mónaco, 2008) permitieron aislar para cada variable diferentes sub-variables (Localización de la altura y Contorno melódico) que a continuación se describen

\subsubsection{Localización de la altura}

Describe desde la fonación "hablada" hasta la ubicación en el registro del canto.

Categorías

- Hablada monotónica (HM): recitado del texto de la canción en una altura compleja (altura del habla) sin insinuar el contorno de la melodía.

- Hablada con tendencias de movimiento sonoro (HC) (dirección ascendente o descendente). Uso de inflexiones vocales recitando el texto de la canción con alturas complejas propias del habla y con inserciones remedando el contorno.

- Entonada oscilante. (EO) Presencia de algunas alturas tónicas Fluctuación entre el habla y el canto entonado de algunas alturas.

- Entonada estable (E).Canto con supremacía de alturas con tonicidad en la emisión de la altura. Para ubicar la respuesta en este estadio se requiere la emisión de alturas con tonicidad sostenida en un porcentaje superior al $70 \%$ del total de las alturas de la melodía.

\subsubsection{Contorno melódico}

Describe la versatilidad vocal para operar con los movimientos de ascenso y descenso de las alturas. 
Categorías

- Concordancia (paridad) entre la respuesta cantada y los diseños de contorno (ascensos y descensos de la melodía) en niños que emiten en el registro de la voz cantada.

- Interdependencia con la Localización de la altura: el contorno solamente es susceptible de ser aplicado a las sub-variables Hablada con tendencias de movimiento sonoro (HC), Entonada oscilante. (EO) y Entonada estable (E)

\subsubsection{Adecuación tonal}

El constructo Adecuación tonal hace referencia a la puesta en acto de la percepción de la tonalidad en la entonación al cantar.

Estudio previos (Mónaco, 2008) permitieron aislar para esta variable diferentes sub-variables (i) Estabilidad tonal ii) Apareamiento de la altura

Sub-variables

\subsubsection{Estabilidad tonal}

Analiza el establecimiento de un centro tonal definido, la tónica ${ }^{45}$ subyacente, y su grado de permanencia en el centro tonal (en la totalidad de la composición o por secciones)

Categorías

- Centro tonal ausente. (CTA) En la respuesta no se advierte una altura dominante (tónica) sobre el resto.

\footnotetext{
${ }^{45}$ Es necesario plantear la diferencia entre el concepto de la Teoría Musical Centro tonal a partir de una Nota tónica y que alude a la presencia en una melodía/canción, de una altura que ejerce dominancia sobre el resto con relaciones de subordinación de las restantes y el concepto de la Acústica Tonicidad de la altura, que alude al grado de precisión en la frecuencia al imitar una altura cantando. En el extremo opuesto se habla de atonicidad de la altura que es el caso de los sonidos del habla.
} 
- Centro tonal parcialmente presente (CT2) El centro tonal se hace presente en por lo menos dos de los segmentos formales.

- Centro tonal por frase (CTF) El centro tonal se hace presente en los cuatro segmentos formales pero cambia en varios de ellos.

- Centro tonal estable insuficiente (CTEI) La respuesta muestra el $20 \%$ o más de alturas fuera de tono.

- Centro tonal estable suficiente (CTES) La respuesta muestra menos del 20\%de alturas fuera de tono.

\subsubsection{Apareamiento de la altura}

Utilización de las alturas de comienzo y cierre de acuerdo con la tonalidad propuesta por la banda grabada (Re mayor). Estudio previos (Mónaco, 2008) permitieron aislar para esta variable diferentes sub-variables.

Sub.variables

4.2.2.2.1 Altura de comienzo Primera altura de la canción

\subsection{Altura de cierre Última altura de la canción}

\subsection{Vinculaciones entre las alturas de comienzo y cierre}

Relaciones entre las alturas de comienzo y cierre en el marco de la tonalidad de la canción impuesta por la banda grabada.

Categorías

- Alturas absolutas Respuesta que acuerda con las alturas absolutas de la banda grabada La4 - Re4

- Alturas transpuestas Respuesta que desacuerda con la altura impuesta por la banda y que respeta las relaciones interválicas (una 5ta justa: por ejemplo Sol4 - Do4 o Fa4 - Sib3) 


\section{CANTAR CANCIONES ENTRE LOS CUARENTA Y CINCUENTA MESES 81}

- Alturas erróneas Respuesta que no atiende al rango de alturas impuestas ni a las relaciones interválicas.

\subsubsection{Continuidad Temporal.}

El constructo Continuidad temporal hace referencia a la reproducción de la canción atendiendo a la "unión natural que tienen las partes del todo" "46. En el presente estudio se alude a la continuidad de la ejecución en el tempo impuesto y a la reproducción ordenada del texto literario de acuerdo con el original.

Sub-variables

4.2.3.1 Ajuste al tempo se refiere al grado de concordancia entre el tempo propuesto por la banda grabada y el empleado al cantar

4.2.3.2 Réplica del texto literario hace referencia a la reproducción de la letra de las canciones en términos de su continuidad en el tiempo atendiendo a la reproducción literal del original.

Categorías

- Reproducción literal de las palabras del texto

- Reemplazo de palabras del texto

- Omisión de palabras /frases del texto

\footnotetext{
${ }^{46}$ Diccionario de la Real Academia Española
} 


\subsection{Prueba piloto}

La autora realizó en 2008 la aplicación piloto de las variables y sub-variables con una canción de tres alturas en el ámbito de Tercera Mayor (N-60). La canción estudiada en las performances infantiles fue Dos por diez (Ver Partitura 1)

Este estudio previo permitió ajustar la prueba final. En tal sentido se decidió cambiar de ejemplar para el test experimental y ajustar el entorno de prueba para que resulte de mayor validez ecológica.

- Partitura 1. Canción Dos por diez.

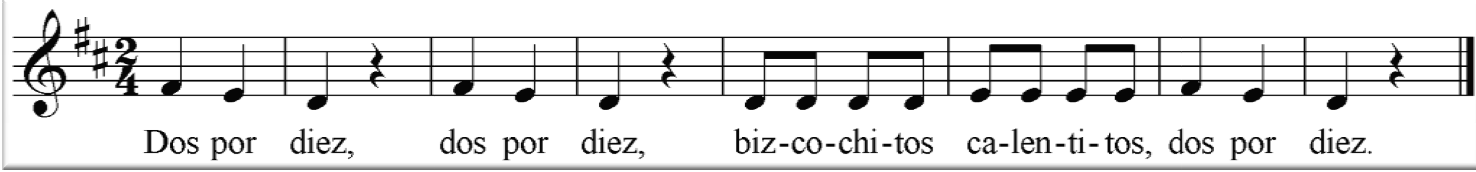

\subsubsection{Decisiones adoptadas para la prueba final (post prueba piloto).}

- Usar canciones en las que se presente el pentacordio inicial de la escala mayor, recurso que ayuda a establecer la tonalidad de manera contundente desde el inicio del canto.

- Grabar a los niños con micrófono exterior en pequeños grupos, aunque la interpretación sea individual ${ }^{47}$.

- Registrar el mayor número de niños de cada grupo para lo cual deben programarse otras estrategias de aplicación.

\footnotetext{
${ }^{47}$ Esta metodología de registro en pequeños grupos, en la cual los compañeros observan la tarea ejecutada por un par y que luego realizarán, es aconsejada por Welch (2009) quien considera que permite obtener mejor calidad en las respuestas.
} 
- Crear bandas grabadas de acompañamiento armónico para que el canto de ambas canciones (ensayo y test) se realicen con la banda grabada. De este modo se fijan la tónica, el tempo y la introducción.

- Mantener para la banda sonora la tonalidad de Re Mayor tanto en la práctica como en el registro final del test.

\subsection{Estudio final}

\subsubsection{Selección de las canciones}

Se realizó en primera instancia un análisis del cancionero de nivel inicial, para seleccionar dos canciones que presentaran un diseño melódico con unidades formales claramente establecidas desde su inicio y con fuerte anclaje tonal.

Se seleccionaron las canciones Pata pata plum (canción 1) y La ranita Cri (canción 2). Ver partituras 2 y 3.

- Partitura 2: Canción 1. Pata pata plum

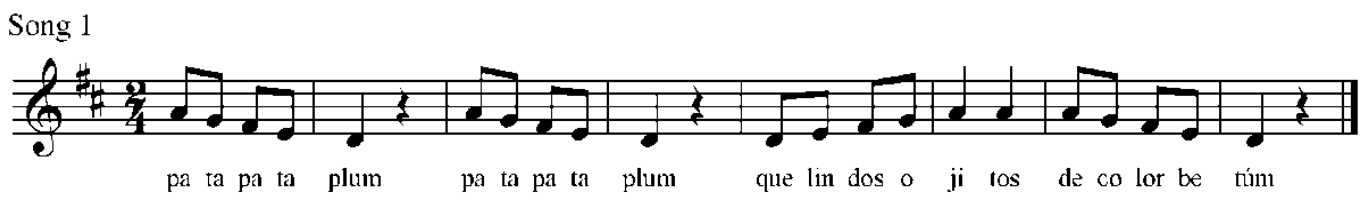

- Partitura 3: Canción 2. La ranita Cri

Song 2

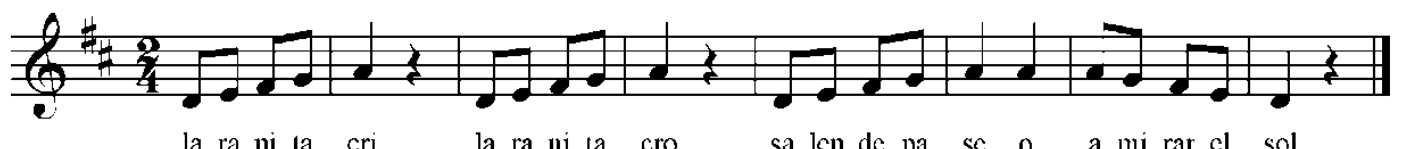

la ra ni la cri

la rá nì tá cro

sa len de pa se o a ni rar el sol 
Las canciones seleccionadas utilizan recursos similares. Ambas presentan

- cuatro segmentos, los dos primeros segmentos separados por un tiempo del compás en silencio;

- marchas dominante tónica o tónica dominante, en sucesiones por grado conjunto;

- un segundo segmento que es repetición musical del primero;

- idéntico ritmo en el que se alternan los valores de tiempo y división del tiempo en el compás $2 / 4$;

- $\quad$ segmentos formales de cuatro tiempos (dos compases);

- el grupo consecuente común, con igual diseño melódico, diseño rítmico y ubicación formal.

Difieren en

- direccionalidad del contorno Los dos primeros segmentos formales de Pata pata plum presentan contorno con sentido descendente; los de La ranita Cri con sentido ascendente.

- tratamiento del texto. Pata pata plum usa onomatopeyas en los dos primeros segmentos; La ranita Cri usa un texto con sentido con un segundo segmento que es una variación mínima del texto del primero.

\subsubsection{Dispositivos y aparatos}

- Karaoke Se creó una banda de acompañamiento armónico en Re Mayor en dos tempi, con introducción y ayudas para la fácil adecuación al karaoke $e^{48}$

- Grabador digital Sony, modelo MZ-R55

\footnotetext{
${ }^{48}$ Se agradece a la Dra. Silvia Furnó por la elaboración y grabación del karaoke.
} 
- Micrófono Lavalier corbatero

\subsubsection{Selección de la muestra.}

$\mathrm{N}=43$

Selección de dos grupos del mismo establecimiento, por ende de similar condición socio-económico-cultural. Testeo de la totalidad de niños asistentes en la franja etaria estudiada.

Estas decisiones permitieron homologar la muestra y proporcionar

- igual estimulación musical formal (en la institución)

- idéntico maestro para enseñar ambas canciones ${ }^{49}$

La muestra final fue conformada por niños que cumplieron con las dos interpretaciones de cada canción, cada una de ellas con dos ensayos sucesivos. El número total de sujetos asistentes a los dos cursos de tres años de la institución seleccionada fue de 54. Siete sujetos se negaron a cantar y cuatro no lograron completar los dos registros requeridos (se ampliará en el capítulo $\mathrm{V}$ en el apartado "Registros Anecdóticos").

\subsubsection{Obtención de las respuestas.}

Se programó y solicitó a la Institución seleccionada la colaboración del maestro de música, a quien se proporcionó la banda sonora grabada para la interpretación de las dos canciones. ${ }^{50}$

\footnotetext{
${ }^{49}$ Se agradece a la Profesora Mariana Ganem, docente habitual de los niños de la muestra, por la enseñanza de las canciones

${ }^{50}$ Se agradece la colaboración de las autoridades del Instituto José Manuel Estrada de City Bell- Sección Inicial, especialmente la Vicedirectora, Prof. Rosa Torres sin cuyo apoyo constante no hubiera sido posible el registro de las muestras.
} 
CANTAR CANCIONES ENTRE LOS CUARENTA Y CINCUENTA MESES 86

\subsubsection{Restricciones previas}

Las sugerencias del investigador consistieron en que el maestro de los niños

- enseñara y ensayara las canciones siempre sobre la banda grabada ${ }^{51}$;

- administrara el test cuando considerara que los niños recordaban y podían cantar ambas canciones;

- grabara la respuesta de los niños para las dos canciones, cada canción cantada dos veces sucesivas acorde a la presentación de la pista del karaoke y

- administrara la primera toma del test (a la que se denomina primera interpretación) y en fecha diferente la segunda toma (segunda interpretación en este estudio)

\subsection{Grabación de las respuestas}

Aparatos: Realizado en señal digital con un grabador mini-disk con micrófono exterior.

Modalidad: Se invitó a los niños a cantar en forma individual, con la presencia del testista, el maestro y un grupo pequeño de compañeros. Dada la dispersión en la atención característica de estas edades, se proporcionaba a cada niño un micrófono de gran tamaño con el que replicaban el "jugar a cantar". Simultáneamente se le colocaba un micrófono corbatero que era el que efectivamente registraba su voz para el estudio.

\subsection{Análisis de los registros vocales}

Las muestras fueron analizadas por tres evaluadores ${ }^{52}$, a quienes se les brindaron las variables de análisis y se explicitaron los detalles y alcances de las mismas.

\footnotetext{
${ }^{51}$ Cantando en karaoke sobre la banda grabada.
} 
Como lo indica el píe de página, para estimar la justeza de entonación se vio la necesidad de recurrir a evaluadores expertos en lugar de utilizar software de uso en mediciones de sonidos discretos. En este caso, al utilizar melodías tonales las relaciones sonoras se ven teñidas por apreciaciones más holísticas y musicales. Por otra parte, lo que interesa es apreciar el grado de entonación al cantar tal cual lo hacen los auditores ordinarios, ya sean músicos o no músicos (en este caso educadores musicales) ${ }^{53}$. El acuerdo entre evaluadores fue del $75 \%$.

Los evaluadores determinaron para cada interpretación infantil:

- cuál fue la mejor versión de cada canción en cada interpretación, si el primer intento o el segundo en que cantó cada canción en el test;

- la categoría asignada según el tipo de localización de la altura;

- el ajuste al tempo, propuesto por el acompañamiento;

- la reproducción de los textos y su grado de literalidad

- el ajuste al contorno, excepción hecha de la categoría Hablada monotónica.

En el caso de las categorías Entonada oscilante (EO) y Entonada Estable (E) el evaluador determinaba además:

- la altura en la que comienza a cantar;

- la presencia/ausencia de un centro tonal predominante;

- el centro tonal de cada segmento formal y en el que finaliza la canción;

\footnotetext{
${ }^{52}$ Coincidiendo con Tafuri (2009) se prefirió una evaluación "humana" a la realizada por un software de análisis vocal acústico, ya que los evaluadores estiman la respuesta desde un punto de vista holísticomusical.

${ }^{53} \mathrm{Se}$ agradece i) la colaboración de las evaluadoras expertas, educadoras musicales, Prof. Emilia Natali, Prof. Rosa Torres y Prof. Marina Peña.
} 
- la cantidad de alturas desajustadas (más de cuatro, menos de cuatro) y

- el ajuste a la banda grabada en cuanto a la relación entre altura de comienzo y de cierre.

\subsection{Escala de puntajes de las respuestas}

\subsubsection{Emisión vocal.}

\subsubsection{Localización de la altura.}

Los puntajes se ordenaron con criterio creciente

1= Hablada Monotónica,

$2=$ Hablada con tendencia de movimiento sonoro

3= Entonada oscilante

4= Entonada estable

\subsubsection{Contorno melódico}

Los puntajes se organizaron según la concordancia entre las respuestas cantadas y los diseños de contorno. Se puntuó a los sujetos que "hablan" para efectuar comparaciones sobre el total de la muestra.

$0=$ emisión hablada sin contorno

$1=$ no sigue el contorno

$2=$ respeta el contorno

\subsubsection{Adecuación Tonal}

\subsubsection{Estabilidad tonal}

Los puntajes se organizaron según el centro tonal que predomina en las frases y en el que finaliza la canción. 
Se determinó un puntaje creciente

1= Centro Tonal Ausente,

$2=$ Centro tonal parcialmente presente

3= Centro Tonal por Frase,

4= Centro Tonal Estable Insuficiente

5= Centro Tonal Estable Suficiente

\subsubsection{Apareamiento de la altura}

4.7.2.2.1 Altura de comienzo: primera altura de la canción

4.7.2.2.2 Altura de cierre: última altura de la canción

4.7.2.2.3 Vinculaciones entre las alturas de comienzo y cierre: relaciones entre ambas alturas en el marco de la tonalidad de la banda grabada.

En todos los casos se compararon las alturas emitidas por los sujetos con las de la banda grabada. Se consignó:

- altura exacta

- altura a distancia de \pm un semitono de la altura exacta

- altura a distancia de \pm un tono de la altura exacta

\subsubsection{Continuidad Temporal}

4.7.3.1 Ajuste al tempo propuesto por la grabación: el puntaje consignó el ajuste al tempo en todos los sujetos muestreados.

$1=$ se ajustaron al tempo de la banda

$0=$ no se ajusta al tempo de la banda

\subsubsection{Réplica del texto literario}


CANTAR CANCIONES ENTRE LOS CUARENTA Y CINCUENTA MESES 90

Se estudió tanto la reproducción literal de las palabras del texto, como así también el reemplazo de palabras y/o la omisión de algunas frases del texto. También se analizaron performances con dificultades en el habla.

La Metodología empleada ha permitido obtener informaciones de carácter cualitativo que se incluirán bajo la forma de Registros Anecdóticos en el capítulo de Resultados. 


\section{Capítulo 5}

\section{Resultados}

Los resultados que se presentan a continuación incluyen los correspondientes a la Prueba Piloto y la Prueba final

\subsection{Prueba Piloto}

La autora realizó en 2008 la aplicación piloto de las variables y sub-variables con una canción de tres alturas en el ámbito de Tercera Mayor. Esta tonalidad fue seleccionada por resultar adecuada a la edad según Greenberg (1979) ${ }^{54}$, Rutkowski (1984) y Mónaco (2001) y además por la tesitura en que se desarrolla la canción, según estudios previos (Mónaco, 2001).

Canción Dos por diez (ver Metodología)

Muestra $\mathrm{N}=60$

Se seleccionaron cuatro grupos de niños provenientes de diferentes Jardines de Infantes de la ciudad de La Plata.

Los niños de la muestra no fueron la totalidad de los que asisten a los grupos seleccionados. Se consideró oportuno, (dado el carácter piloto de la prueba) aceptar que participaran del test aquellos niños que "desearon cantar" el día en que se realizó el registro.

Requerimiento: Canto a capella de la canción

Registro Grabación de la respuesta en un ambiente silencioso con presencia del docente de música habitual y la investigadora.

\footnotetext{
${ }^{54}$ Citado por Kim (2000)
} 
CANTAR CANCIONES ENTRE LOS CUARENTA Y CINCUENTA MESES 92

Resultados

Del total de niños muestreados un tercio cantó con localización de la altura Entonada Estable (E), mientras que otro tercio de ellos lo hizo con una localización de la altura Entonada Oscilante (EO).

El más alto porcentaje (31\%) corresponde a los que eligieron Do4 como tónica para cantar la canción, un 20\% Do\#4 y 23\% la altura Re4. Por lo tanto aproximadamente un $75 \%$ eligió espontáneamente una tónica de hasta un tono descendente de la tónica empleada para su enseñanza (Re Mayor).

La mayoría de los niños no pudieron reproducir la canción completa omitiendo alguna de sus partes $\mathrm{y}$ en algunos casos inventaron palabras $\mathrm{o}$ interpolaron construcciones verbales de otras canciones para "rellenar con texto" las alturas que tenían registradas en su memoria. Estas canciones "mosaico" son características en los niños de estas edades y han sido denominadas "canciones potpourrî" por Moore ${ }^{55}$

Este estudio piloto resultó esclarecedor para ajustar la prueba final, por diversas razones:

1) la canción seleccionada para realizar la medición (Dos por diez) resultaba de cierta dificultad para iniciar el canto, dado su comienzo en la tercera de la escala (mediante) y porque la nota tónica se afirma en el segundo compás. Estas consideraciones sugirieron elegir un nuevo ejemplar para la Prueba Final.

2) la metodología deberá revisarse para crear un ambiente de prueba con mayor validez ecológica.

3) la tonalidad de Re Mayor, resulta adecuada cuando la canción (como en este caso) se inscribe en el ámbito de la tónica baja.

\footnotetext{
${ }^{55}$ Ver capítulo 4 pág.11 de esta tesis
} 
CANTAR CANCIONES ENTRE LOS CUARENTA Y CINCUENTA MESES 93

\subsection{Prueba Final}

Se tomaron dos registros de cada canción en cada día de administración del test: cada niño cantó en la primera interpretación dos veces cada canción y dos veces en la segunda interpretación recuperada en una fecha distinta a la primera y con una diferencia de veinte días entre la primera y segunda interpretación.

Cada muestra fue analizada de acuerdo a las variables aisladas y descriptas en Metodología.

El primer análisis fue determinar para cada interpretación en cuál intento el sujeto lograba mejor performance, esto es, en la primera o en la segunda, una cantada a continuación de la otra de acuerdo con la banda grabada.

Los cuadros siguientes muestran en cuál intento los sujetos obtuvieron una mejor performance vocal (Gráfico 1: canción Pata pata plum y Gráfico 2: canción La ranita Cri)

- Gráfico 1. Canción 1: Pata pata plum. Mejor perfomance de los dos intentos.

- primera interpretación $\quad$ segunda interpretación

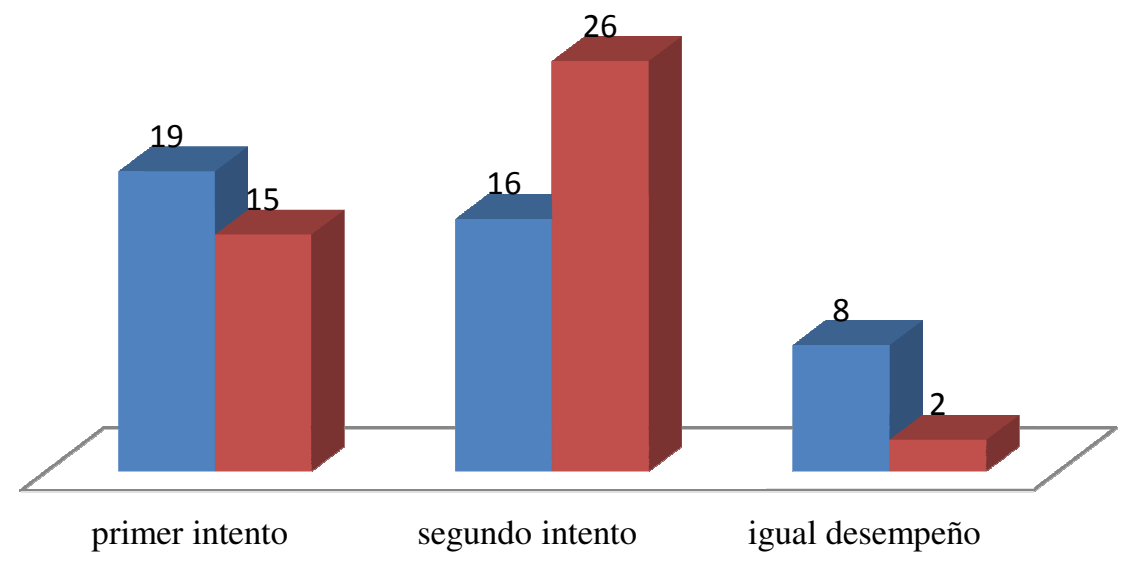


- Gráfico 2. Canción 2: La ranita Cri. Mejor performance de los dos intentos.

a primera interpretación $\quad$ segunda interpretación

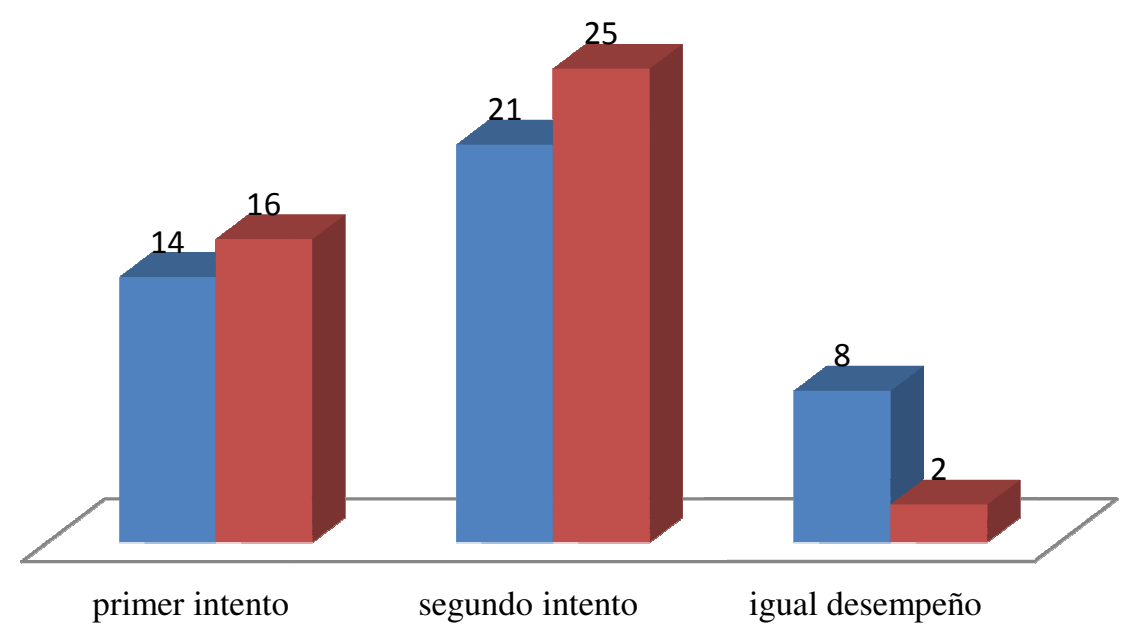

Una vez establecido la mejor performance lograda en los dos intentos, todas las mediciones se realizaron sobre esa performance, o sea, se tomó solo un intento por cada canción en cada interpretación, obteniéndose cuatro performances por sujeto: dos por canción tomadas en distintas fechas.

\subsubsection{Emisión vocal.}

Variable analizada en base a las sub-variables Localización de la altura ${ }^{56}$ y Contorno Melódico

\subsubsection{Localización de la altura.}

Categorías i) Hablada monotónica (HM) ii) Hablada con tendencias de movimiento sonoro (HC) iii) Entonada oscilante (EO) iv) Entonada estable (E).

\footnotetext{
${ }^{56}$ Pueden escucharse performances de los niños de la muestra respecto de la sub-variable Localización de altura, en los archivos de sonido adjuntos a esta tesis. Se denominan según las categorías a las que aluden.
} 
- Gráfico 3. Canción 1: Pata pata plum. Localización de la altura

- primera interpretación segunda interpretación

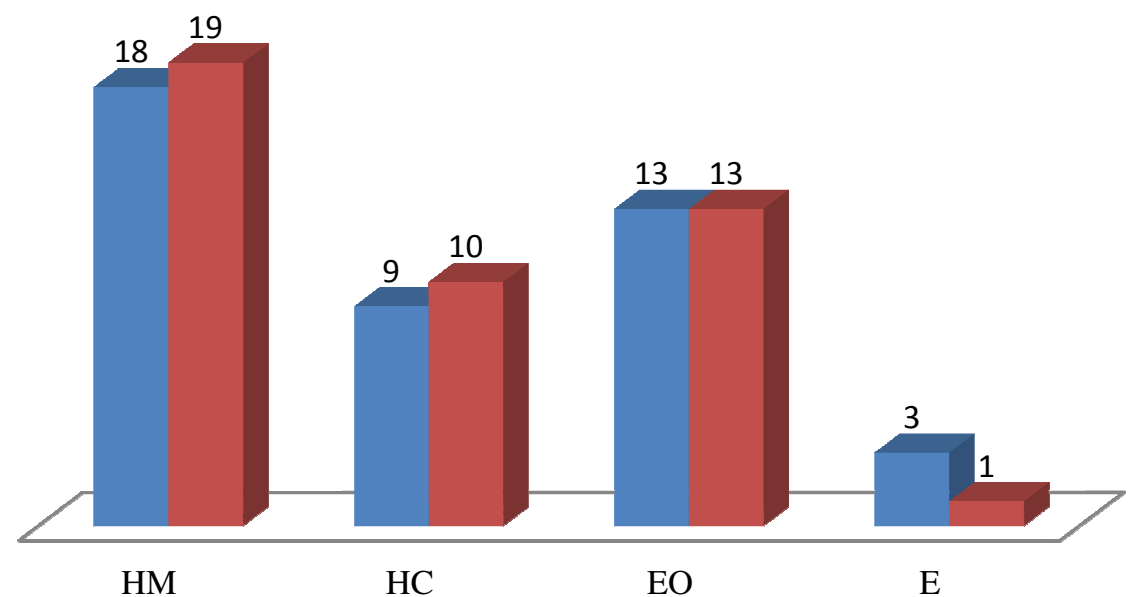

Los resultados muestran un incremento mínimo de respuestas en la segunda interpretación en las categorías Hablada monotónica y Hablada con tendencia de movimiento sonoro y un decremento en la categoría Entonada estable.

Estos indicadores sugerirían que la segunda interpretación no aporta mejoras en el rendimiento. 


\section{- Gráfico 4. Canción 2: La ranita Cri. Localización de la altura}

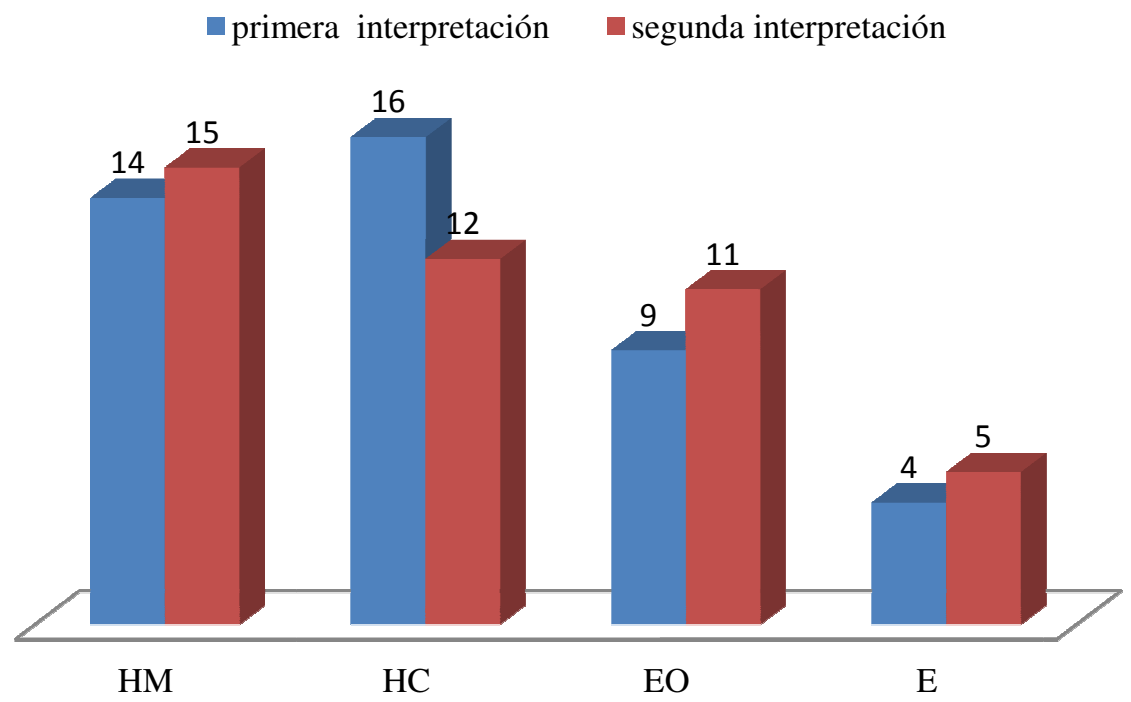

Los resultados muestran un incremento mínimo de respuestas en la categoría Hablada monotónica en la segunda interpretación y un decremento en la Hablada con tendencia de movimiento sonoro. En cambio muestra incremento mínimo en las categorías Entonada oscilante y Entonada estable.

Estos indicadores entre las sub-variables, aunque parecieran contradictorios, resultan consistentes: los niños obtienen mejor performance en la segunda interpretación en las categorías que describen respuestas en las que comienzan a emitir en el rango de la voz cantada. 


\section{CANTAR CANCIONES ENTRE LOS CUARENTA Y CINCUENTA MESES 97}

\subsubsection{Contorno melódico}

Variable que tiene como pre-requisito la pertenencia de las respuestas a las categorías Hablada con tendencias de movimiento sonoro (HC) Entonada oscilante (EO) y Entonada estable (E).Para estimar la significación de las respuestas de contorno en el total de la muestra, en los gráficos se incluyeron con puntaje cero los niños con respuesta hablada.

Los puntajes asignados a cada categoría fueron: Respuesta hablada $=0$; No sigue el contorno $=1 \mathrm{y}$ respeta el contorno $=2$

Tabla 1. Contorno

\begin{tabular}{lccccc}
\multicolumn{1}{c}{ Ajuste al contorno } & $\mathrm{N}$ & Minimum & Maximum & Mean & Std. Deviation \\
\hline Pata pata plum A & 43 & 0 & 2 & 1,09 &, 97 \\
Pata pata plum B & 43 & 0 & 2 &, 9 &, 94 \\
La ranita Cri A & 43 & 0 & 2 & 1,28 &, 93 \\
La ranita Cri B & 43 & 0 & 2 & 1,26 &, 95 \\
\hline
\end{tabular}

Los resultados muestran que las medias más altas se obtuvieron en la Canción 2 La Ranita Cri en la primera interpretación (A) 1,28 en cambio en la segunda interpretación (B) bajan a 1,26. Las medias más bajas se obtuvieron tanto en la segunda interpretación de la canción 1 Pata pata plum $(, 98)$ como en la primera 1,09.

La mayor variabilidad de las respuestas (desviación estándar) se obtuvo en la primera interpretación de la canción Pata pata plum seguida por la segunda interpretación de la canción La ranita Cri.

En ambas canciones la segunda interpretación es de menor calidad en las respuestas que la primera respecto de la concordancia entre la respuesta cantada y los 


\section{CANTAR CANCIONES ENTRE LOS CUARENTA Y CINCUENTA MESES 98}

diseños de contorno. También se observan mejores resultados en la canción 2 que en la canción 1 en ambas interpretaciones.

Los gráficos siguientes muestran la comparación comentada. Se presentan los resultados de los sujetos que manifiestan una localización de la altura Hablada monotónica (en los cuales no se analiza la reproducción del contorno) y por otro lado el resto de los sujetos (con localización de la altura $\mathrm{HC}$, EO y E) en términos de cuántos siguen /no siguen el contorno de las canciones ${ }^{57}$.

- Gráfico 5. Canción 1: Pata pata plum. Fidelidad al contorno

$$
\text { - primera interpretación } \quad \text { segunda interpretación }
$$

22

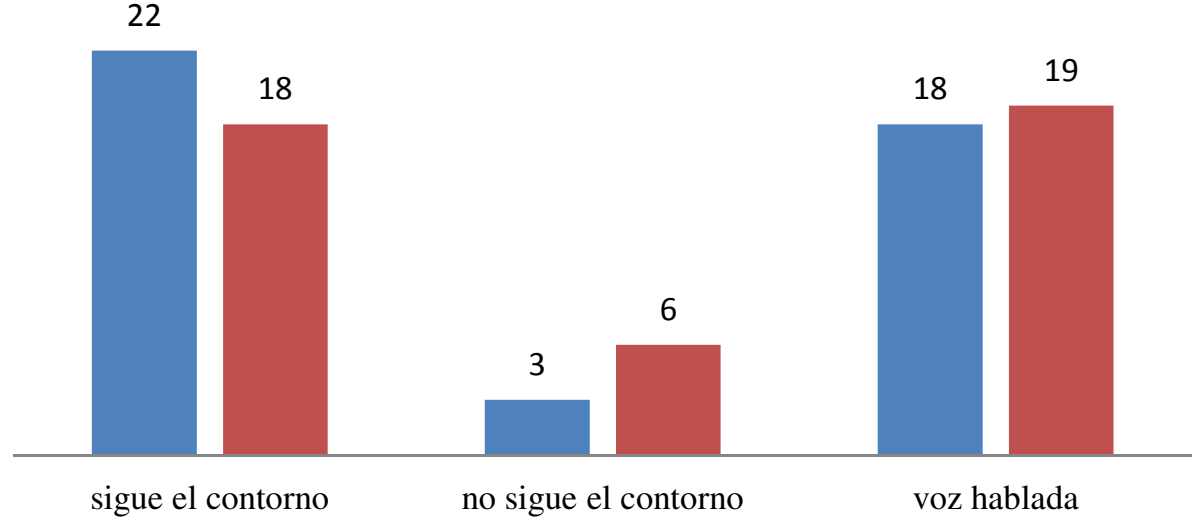

\footnotetext{
${ }^{57}$ Puede escucharse un ejemplo de un niño de la muestra que no sigue el contorno de la melodía, en un archivo de sonido adjunto a esta tesis.
} 
- Gráfico 6. Canción 2 La ranita Cri. Fidelidad al contorno

$$
\text { - primera interpretación } \quad \text { segunda interpretación }
$$

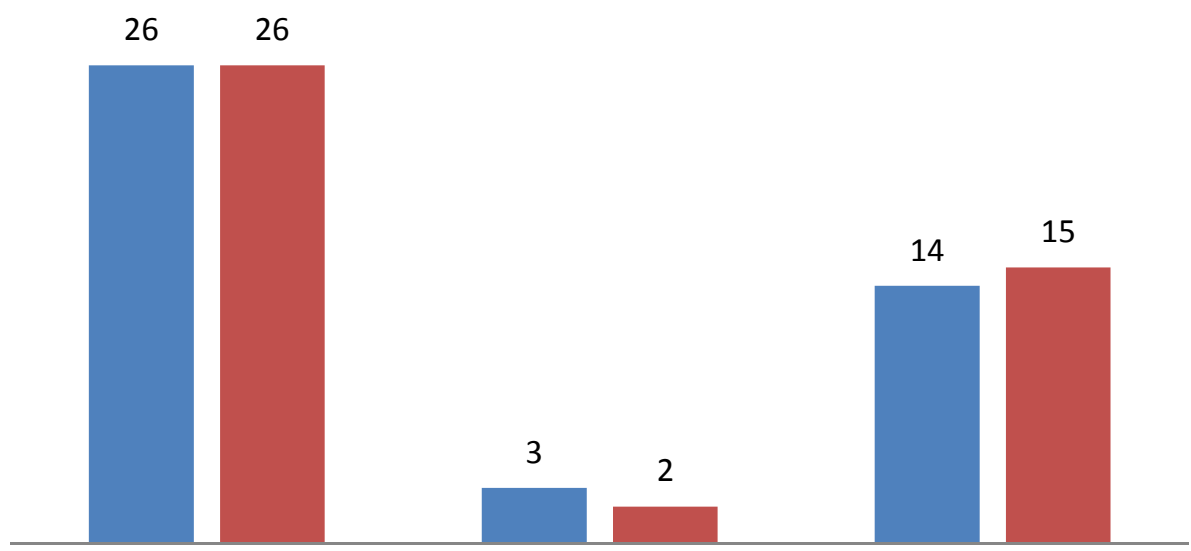

sigue el contorno

no sigue el contorno

voz hablada

Los resultados muestran en ambas interpretaciones:

- predominio de las respuestas con respeto por el contorno en ambas canciones;

- el puntaje siguiente se corresponde con aquellos sujetos que hablan sin ningún tipo de consideración al contorno (monotónicos). El gráfico trata de mostrar en la totalidad de los sujetos de la muestra, cuántos hablan (puntaje 0) y cuantos sugieren un esbozo de canto, y de estos últimos (los correspondientes a las otras tres categorías de Localización de la altura), cuántos siguen el contorno y cuántos no lo consideran.

- el mínimo puntaje en la categoría No sigue el contorno en ambas canciones (de sujetos con esbozo de canto), presenta relativa relevancia (14 sujetos) 


\subsubsection{Adecuación tonal.}

Variable analizada en base a las sub-variables Estabilidad tonal y Apareamiento de la altura.

\subsubsection{Estabilidad tonal}

Categorías i) Centro tonal ausente. (CTA); ii) Centro tonal parcialmente presente (CT2);

iii) Centro tonal por frase (CTF); iv) Centro tonal estable insuficiente (CTEI) y v)

Centro tonal estable suficiente (CTES).

Los puntajes asignados a cada categoría fueron; $\mathrm{CTA}=1 ; \mathrm{CT} 2=2 ; \mathrm{CTF}=3 ; \mathrm{CTEI}=4$;

$\mathrm{CTES}=5$.

En la Tabla 2 se consigna la primera interpretación como A y la segunda como B.

Tabla 2 - Estabilidad tonal

\begin{tabular}{|c|c|c|c|c|c|}
\hline & $\mathrm{N}$ & Minimum & Maximum & Mean & $\begin{array}{c}\text { Std. } \\
\text { Deviation }\end{array}$ \\
\hline $\begin{array}{l}\text { Tonal Categories } \\
\text { Pata plum A }\end{array}$ & 43 & 1 & 5 & 1,56 & ,96 \\
\hline $\begin{array}{l}\text { Tonal Categories } \\
\text { Pata plum B }\end{array}$ & 43 & 1 & 5 & 1,51 & ,96 \\
\hline $\begin{array}{l}\text { Tonal Categories } \\
\text { Ranita A }\end{array}$ & 43 & 1 & 5 & 1,49 & ,94 \\
\hline $\begin{array}{l}\text { Tonal Categories } \\
\text { Ranita B }\end{array}$ & 43 & 1 & 5 & 1,63 & 1,07 \\
\hline Valid N (listwise) & 43 & & & & \\
\hline
\end{tabular}

Los resultados muestran que la media más alta $(1,63)$ de las dos canciones y las dos interpretaciones se obtuvo en la Canción La Ranita Cri interpretación B.. Así también muestra la mayor variabilidad de las respuestas (desviación estándar). Sin embargo el puntaje que le sigue por escasa diferencia en la media $(1,56)$, es en la otra canción Pata pata plum interpretación A. 


\section{CANTAR CANCIONES ENTRE LOS CUARENTA Y CINCUENTA MESES 101}

Los valores obtenidos sugerirían que los mejores puntajes no se vinculan con el orden de la performance (primera o segunda interpretación) y que si bien la segunda canción en la segunda interpretación obtiene la media más alta de toda la muestra, en la primera interpretación obtiene la media más baja.

Tabla 3 - Categorías de Estabilidad Tonal Pata pata plum A

\begin{tabular}{|ll|r|r|r|r|}
\hline & & Frequency & Percent & $\begin{array}{c}\text { Valid } \\
\text { Percent }\end{array}$ & $\begin{array}{r}\text { Cumulativ } \\
\text { e Percent }\end{array}$ \\
\hline Valid & 1 & 29 & 9,6 & 67,4 & 67,4 \\
& 2 & 7 & 2,3 & 16,3 & 83,7 \\
& 3 & 5 & 1,7 & 11,6 & 95,3 \\
& 4 & 1 &, 3 & 2,3 & 97,7 \\
& 5 & 1 &, 3 & 2,3 & 100,0 \\
& Total & 43 & 14,2 & 100,0 & \\
Missing & System & 260 & 85,8 & & \\
Total & & 303 & 100,0 & & \\
\hline
\end{tabular}

Tabla 4 -Categorías de Estabilidad Tonal Pata pata plum B

\begin{tabular}{|ll|r|r|r|r|}
\hline & & Frequency & Percent & $\begin{array}{c}\text { Valid } \\
\text { Percent }\end{array}$ & $\begin{array}{r}\text { Cumulativ } \\
\text { e Percent }\end{array}$ \\
\hline Valid & 1 & 31 & 10,2 & 72,1 & 72,1 \\
& 2 & 5 & 1,7 & 11,6 & 83,7 \\
& 3 & 5 & 1,7 & 11,6 & 95,3 \\
& 4 & 1 &, 3 & 2,3 & 97,7 \\
& 5 & 1 &, 3 & 2,3 & 100,0 \\
& Total & 43 & 14,2 & 100,0 & \\
Missing & System & 260 & 85,8 & & \\
Total & & 303 & 100,0 & & \\
\hline
\end{tabular}

Los resultados muestran que:

- un niño alcanzó la categoría más alta (CTES) en las dos interpretaciones y que otro niño alcanzó la inmediata inferior (CTEI);

- la mayoría de los niños se ubican en la categoría centro tonal ausente (CTA); 
- el número de respuestas se incrementa levemente en la segunda interpretación: sobre cuarenta y tres niños de la muestra, se registran veintinueve respuestas $(67,4 \%)$ en la primera y treinta uno en la segunda $(72,1 \%)$;

- la calidad de las respuestas procede de la categoría más baja centro tonal ausente a la categoría más alta Centro tonal estable suficiente con una distribución heterogénea: una meseta amplia en el nivel más bajo, centro tonal ausente (entre 67 y $72 \%$ ) una segunda meseta en torno a las categorías intermedias Centro tonal parcialmente presente y Centro tonal por frase en un porcentaje que oscila entre el 27 y el $23 \%$ y una tercera ubicación con sólo dos respuestas $(0,3 \%)$ en las categorías más altas.

Tabla 5 - Categorías de Estabilidad Tonal - La ranita Cri A

\begin{tabular}{|ll|r|r|r|r|}
\hline & & Frequency & Percent & $\begin{array}{c}\text { Valid } \\
\text { Percent }\end{array}$ & $\begin{array}{r}\text { Cumulativ } \\
\text { e Percent }\end{array}$ \\
\hline Valid & 1 & 30 & 9,9 & 69,8 & 69,8 \\
& 2 & 9 & 3,0 & 20,9 & 90,7 \\
& 3 & 1 &, 3 & 2,3 & 93,0 \\
& 4 & 2 &, 7 & 4,7 & 97,7 \\
& 5 & 1 &, 3 & 2,3 & 100,0 \\
& Total & 43 & 14,2 & 100,0 & \\
Missing & System & 260 & 85,8 & & \\
Total & & 303 & 100,0 & & \\
\hline
\end{tabular}

Tablas 6 - Categorías de Estabilidad Tonal - La ranita Cri B

\begin{tabular}{|ll|r|r|r|r|}
\hline & & Frequency & Percent & $\begin{array}{c}\text { Valid } \\
\text { Percent }\end{array}$ & $\begin{array}{r}\text { Cumulativ } \\
\text { e Percent }\end{array}$ \\
\hline Valid & 1 & 29 & 9,6 & 67,4 & 67,4 \\
& 2 & 6 & 2,0 & 14,0 & 81,4 \\
& 3 & 4 & 1,3 & 9,3 & 90,7 \\
& 4 & 3 & 1,0 & 7,0 & 97,7 \\
& 5 & 1 &, 3 & 2,3 & 100,0 \\
& Total & 43 & 14,2 & 100,0 & \\
Missing & System & 260 & 85,8 & & \\
Total & & 303 & 100,0 & & \\
\hline
\end{tabular}


Los resultados muestran que:

- solo un niño alcanzó la categoría más alta (CTES) en ambas interpretaciones de la canción La ranita Cri;

- la mayoría de los niños se ubican en la categoría centro tonal ausente (CTA);

- el número en la categoría más baja decrementa mínimamente en la segunda interpretación con veintinueve respuestas (sobre la muestra de cuarenta y tres= $67,4 \%)$ y treinta en la primera $(69,8 \%)$

- la calidad de las respuestas procede de la categoría más baja centro tonal ausente a la última categoría, aunque con solamente dos respuestas en la más alta Centro tonal estable suficiente;

- la distribución es heterogénea una meseta amplia en el nivel más bajo, centro tonal ausente (entre 69,8 y $67,4 \%$ ) una segunda meseta en torno a las categorías intermedias Centro tonal parcialmente presente y Centro tonal por frase en un porcentaje del $23 \%$, una tercera ubicación con tres respuestas en la categoría Centro tonal estable insuficiente y Centro tonal estable suficiente en la primera interpretación y cuatro en la segunda.

\subsection{Vinculaciones entre tipo de Localización de la altura y Estabilidad tonal}

Se aplicaron pruebas de correlación para responder a la pregunta ¿pueden relacionarse el tipo y calidad de la Localización de altura con la centralidad tonal de las respuestas?

Para este análisis se consideraron las dos interpretaciones de cada canción como una sola muestra (tipo de Localización de la altura) y se compararon con las dos interpretaciones tonales como otra muestra. 
Tabla 7 - Correlación Localización de la altura-

Estabilidad tonal. Pata pata plum (Pearson)

\begin{tabular}{|ll|r|r|}
\hline & & $\begin{array}{l}\text { Dos interp. } \\
\text { Localización de } \\
\text { la altura } \\
\text { Pata pata plum }\end{array}$ & $\begin{array}{l}\text { Dos interp. } \\
\text { Estabilidad tonal } \\
\text { Pata pata plum }\end{array}$ \\
\hline Dos interpretaciones- & Pearson Correlation & 1,000 & 776 \\
Localización de la altura & Sig. (2-tailed) &, & .000 \\
Pata pata plum & $\mathrm{N}$ & 86 & 86 \\
\hline Dos interpretaciones - & Pearson Correlation &, $776 * *$ & 1,000 \\
Estabilidad tonal & Sig. (2-tailed) &, 000 &, \\
Pata pata plum & $\mathrm{N}$ & 86 & 86 \\
\hline
\end{tabular}

${ }^{* *}$. Correlation is significant at the 0.01 level (2-tailed).

Tabla 8 - Correlación Localización de la altura-Estabilidad tonal. Pata pata plum (Spearman)

\begin{tabular}{|c|c|c|c|c|}
\hline & & & $\begin{array}{l}\text { Dos interp. } \\
\text { Localización de } \\
\text { la altura } \\
\text { Pata pata plum } \\
\end{array}$ & $\begin{array}{l}\text { Dos interp. } \\
\text { Estabilidad tona } \\
\text { Pata pata plum }\end{array}$ \\
\hline \multirow[t]{4}{*}{ Spearman's rho } & $\begin{array}{l}\text { Dos interpretaciones - } \\
\text { Localización de la } \\
\text { altura } \\
\text { Pata pata plum }\end{array}$ & $\begin{array}{l}\text { Correlation Coefficient } \\
\text { Sig. (2-tailed) }\end{array}$ & 1,000 & $\begin{array}{r}, 799\left(^{* *}\right) \\
, 000\end{array}$ \\
\hline & & $\mathrm{N}$ & 86 & 86 \\
\hline & $\begin{array}{l}\text { Dos interpretaciones - } \\
\text { Estabilidad tonal } \\
\text { Pata pata plum }\end{array}$ & $\begin{array}{l}\text { Correlation Coefficient } \\
\text { Sig. (2-tailed) }\end{array}$ & $\begin{array}{r}, 799\left(^{* *}\right) \\
, 000\end{array}$ & 1,000 \\
\hline & & $\mathrm{N}$ & 86 & 86 \\
\hline
\end{tabular}

Correlation is significant at the .01 level (2-tailed).

Tabla 9 Correlación Localización de la altura-

Estabilidad tonal. La ranita Cri (Pearson)

\begin{tabular}{|ll|r|r|}
\hline & & $\begin{array}{l}\text { Dos interp. } \\
\text { Localización de } \\
\text { la altura } \\
\text { La ranita Cri }\end{array}$ & $\begin{array}{l}\text { Dos interp. } \\
\text { Estabilidad tonal } \\
\text { La ranita Cri }\end{array}$ \\
\hline Dos interpretaciones - & Pearson Correlation & 1,000 &, $792^{* *}$ \\
Localización de la altura & Sig. (2-tailed) &, &, 000 \\
La ranita Cri & $\mathrm{N}$ & 86 & 86 \\
\hline Dos interpretaciones - & Pearson Correlation &, $792^{* *}$ & 1,000 \\
Estabilidad tonal & Sig. (2-tailed) &, 000 &, \\
La ranita Cri & $\mathrm{N}$ & 86 & 86 \\
\hline
\end{tabular}

${ }^{* *}$. Correlation is significant at the 0.01 level (2-tailed). 
Tabla 10 Correlación Localización de la altura - Estabilidad tonal. La ranita Cri (Spearman)

\begin{tabular}{|c|c|c|c|c|}
\hline & & & $\begin{array}{l}\text { Dos interp. } \\
\text { Localización } \\
\text { de la altura } \\
\text { La ranita Cri }\end{array}$ & $\begin{array}{l}\text { Dos interp. } \\
\text { Estabilidad } \\
\text { tonal } \\
\text { La ranita Cri }\end{array}$ \\
\hline Spearman's rho & $\begin{array}{l}\text { Dos interpretaciones - } \\
\text { Localización de la } \\
\text { altura } \\
\text { La ranita Cri } \\
\\
\text { Dos interpretaciones - } \\
\text { Estabilidad Tonal } \\
\text { La ranita Cri }\end{array}$ & $\begin{array}{l}\text { CorrelationCoefficient } \\
\text { Sig. (2-tailed) } \\
\mathrm{N} \\
\text { Correlation Coefficient } \\
\text { Sig. (2-tailed) } \\
\mathrm{N}\end{array}$ & $\begin{array}{r}1,000 \\
, \\
86 \\
, 805\left(^{* \star}\right) \\
, 000 \\
86\end{array}$ & $\begin{array}{r}, 805{ }^{\left.{ }^{* *}\right)} \\
, 000 \\
86 \\
1,000 \\
86\end{array}$ \\
\hline
\end{tabular}

* Correlation is significant at the .01 level (2-tailed).

La significación de los resultados (.01) de los estadísticos aplicados (Pearson y Spearman) muestra que una mejor Localización de la altura contribuye a una mayor centralidad tonal.

\subsection{Vinculaciones entre Fidelidad al Contorno y tipo de Localización de} la altura

Se aplicaron pruebas de correlación para responder a la pregunta ¿pueden observarse relaciones entre la Fidelidad al contorno y el Tipo de localización de la altura?

Se tomaron las dos interpretaciones de cada canción como una sola muestra tanto en lo que respecta al respeto del contorno como al tipo de localización de alturas. 
Tabla 11 Correlación Contorno melódico-Localización de la altura. Pata pata plum

\begin{tabular}{|ll|r|r|}
\hline & Pearson Correlation & $\begin{array}{l}\text { Dos interp. } \\
\text { Contorno } \\
\text { Pata pata } \\
\text { plum }\end{array}$ & $\begin{array}{l}\text { Dos interp. } \\
\text { Localización } \\
\text { de la altura } \\
\text { Pata pata plum }\end{array}$ \\
\hline $\begin{array}{l}\text { Dos interpretaciones }- \\
\text { Contorno }\end{array}$ & Sig. (2-tailed) &, 000 &, $849 *$ \\
Pata pata plum & $\mathrm{N}$ & 86 &, 000 \\
\hline Dos interpretaciones - & Pearson Correlation &, $849 * *$ & 1,000 \\
Localización de la altura & Sig. (2-tailed) &, 000 &, \\
Pata pata plum & $\mathrm{N}$ & 86 & 86 \\
\hline
\end{tabular}

${ }^{* *}$. Correlation is significant at the 0.01 level (2-tailed).

Tabla 12 Correlación Contorno melodico-Localización de la altura. La ranita Cri

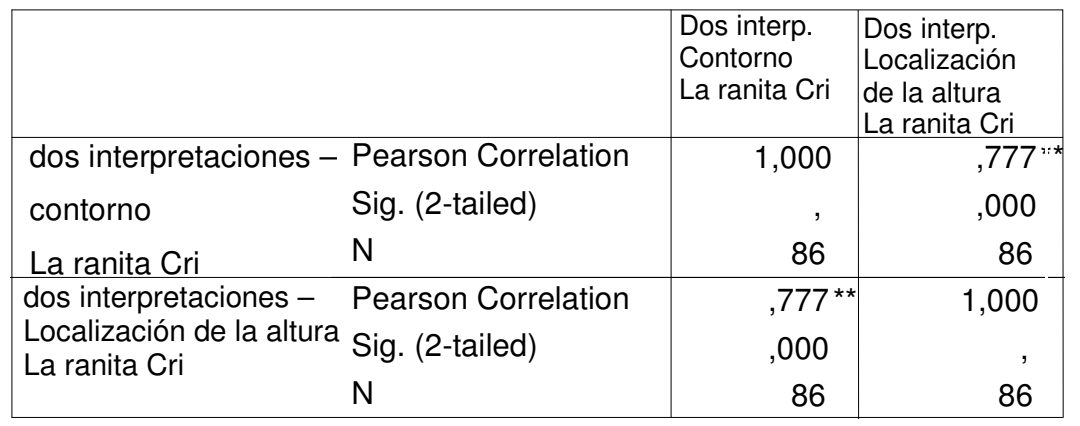

${ }^{\star *}$. Correlation is significant at the 0.01 level (2-tailed).

Los resultados muestran que en las dos canciones la correlación entre ambas variables es significativa al nivel de .01 lo que supone que a mayor tonicidad en la Localización de la altura mayor Fidelidad en la reproducción del contorno melódico.

\subsection{Vinculaciones entre Fidelidad al Contorno y Estabilidad Tonal}

Se aplicaron pruebas de correlación para responder a la pregunta ¿pueden observarse relaciones entre la Fidelidad al contorno y la Estabilidad tonal a lo largo de la performance?

Se tomó para el análisis las dos interpretaciones de cada canción como una sola muestra (tanto para el contorno como para la estabilidad tonal). 
Tabla 13 Correlación Contorno melódico-Estabilidad tonal Pata pata plum

\begin{tabular}{|c|c|c|}
\hline & \begin{tabular}{|l|} 
Dos interp. \\
Contorno \\
Pata pata plum
\end{tabular} & $\begin{array}{l}\text { Dos interp. } \\
\text { Estabilidad } \\
\text { Tonal } \\
\text { Pata pata plum } \\
\end{array}$ \\
\hline Dos interpretaciones Pearson Correlation & 1,000 &, $485^{\star * *}$ \\
\hline $\begin{array}{l}\text { Contorno } \\
\text { Pata pata plum }\end{array}$ & , & ,000 \\
\hline dia pala piumin & 86 & 86 \\
\hline Dos interpretaciones Pearson Correlation &, $485^{* *}$ & 1,000 \\
\hline Estabilidad Tonal ～Sig. (2-tailed) &, 000 & , \\
\hline rata pala piumi & 86 & 86 \\
\hline
\end{tabular}

${ }^{\star *}$. Correlation is significant at the 0.01 level (2-tailed).

Tabla 14 Correlación Contorno melódico-Estabilidad tonal La ranita Cri

\begin{tabular}{|ll|r|r|}
\hline & & $\begin{array}{l}\text { Dos interp. } \\
\text { Contorno } \\
\text { La ranita Cri }\end{array}$ & $\begin{array}{l}\text { Dos interp. } \\
\text { Estabilidad } \\
\text { Tonal } \\
\text { La ranita Cri }\end{array}$ \\
\hline $\begin{array}{l}\text { Dos interpretaciones } \\
\text { Contorno } \\
\text { La ranita Cri }\end{array}$ & Pearson Correlation & 1,000 &, $414^{* *}$ \\
\hline $\begin{array}{l}\text { Dos interpretaciones } \\
\text { Estabilidad Tonal }\end{array}$ & $\mathrm{N}$ &, &, 000 \\
La ranita Cri & Pearson Correlation &, $414^{* *}$ & 1,000 \\
\hline
\end{tabular}

${ }^{* *}$. Correlation is significant at the 0.01 level (2-tailed).

Los resultados muestran que en las dos canciones la correlación entre ambas variables es significativa al nivel de .01 lo que supone que a mayor Estabilidad tonal, mayor Fidelidad en la reproducción del contorno melódico.

\subsubsection{Apareamiento de la altura}

Para determinar el grado de ajuste a la tonalidad de la banda grabada (Re mayor) se estudió la altura de comienzo y la altura de cierre que utilizaba cada niño al cantar. Las respuestas que podían formar parte de este análisis debían cumplir la condición de pertenecer a las categorías de Localización de la altura Entonada oscilante (EO) o Entonada estable (E). 
Del total de interpretaciones de ambas canciones $(\mathrm{N}=43 \times 4$ interpretaciones $=$ 172) se obtuvieron 46 performances en la categoría Entonada Oscilante y 13 Entonada Estable. Por lo tanto son éstos sujetos los analizados tanto en altura de comienzo y altura de cierre (que en ambas canciones es la tónica) y la consiguiente vinculación entre estas alturas (Total 59 performances).

Corresponden a la canción 1 primera interpretación 16 sujetos y en la segunda interpretación 14 sujetos.

En la canción 2, primera interpretación 13 sujetos y en la segunda 16 sujetos.

En los gráficos que siguen se puede visualizar por canción e interpretación, el porcentaje de respuestas analizadas, que corresponden al tipo de Localización de la altura EO y E.

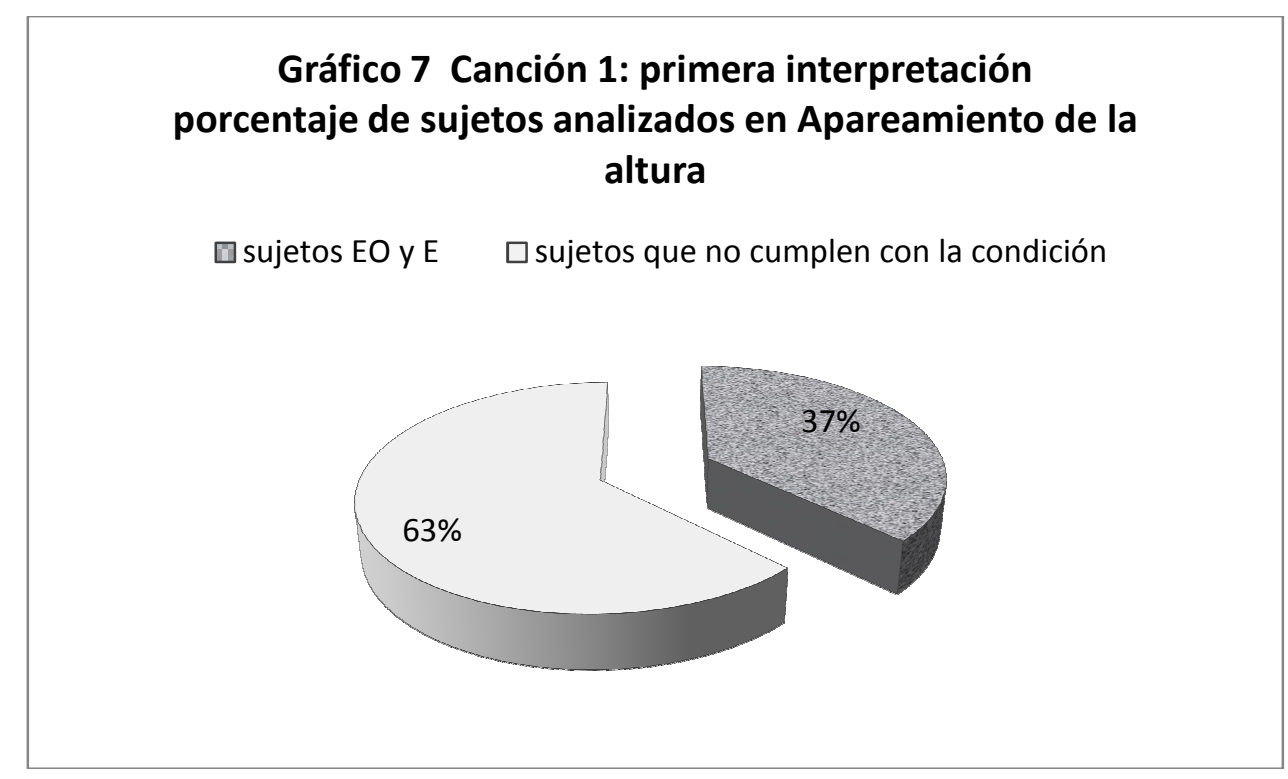




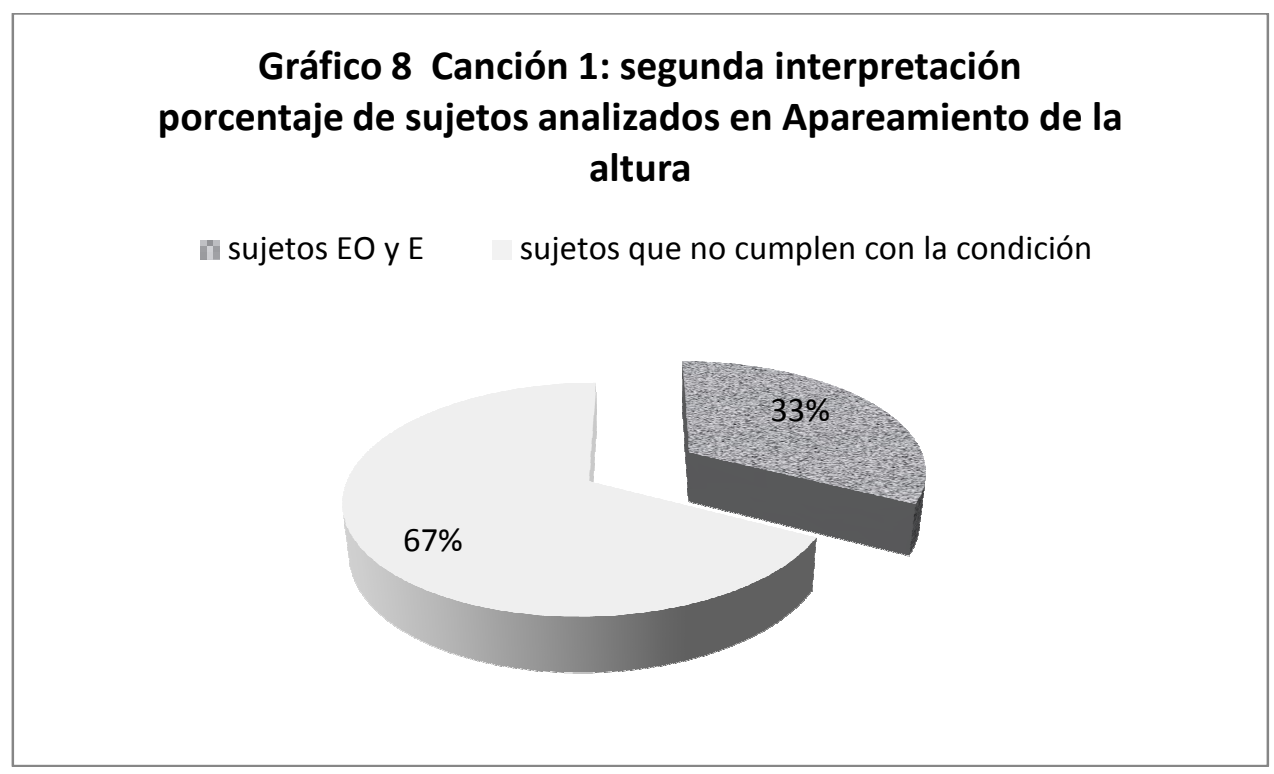

Gráfico 9 Canción 2: primera interpretación porcentaje de sujetos analizados en Apareamiento de la altura

In sujetos EO y E sujetos que no cumplen con la condición 


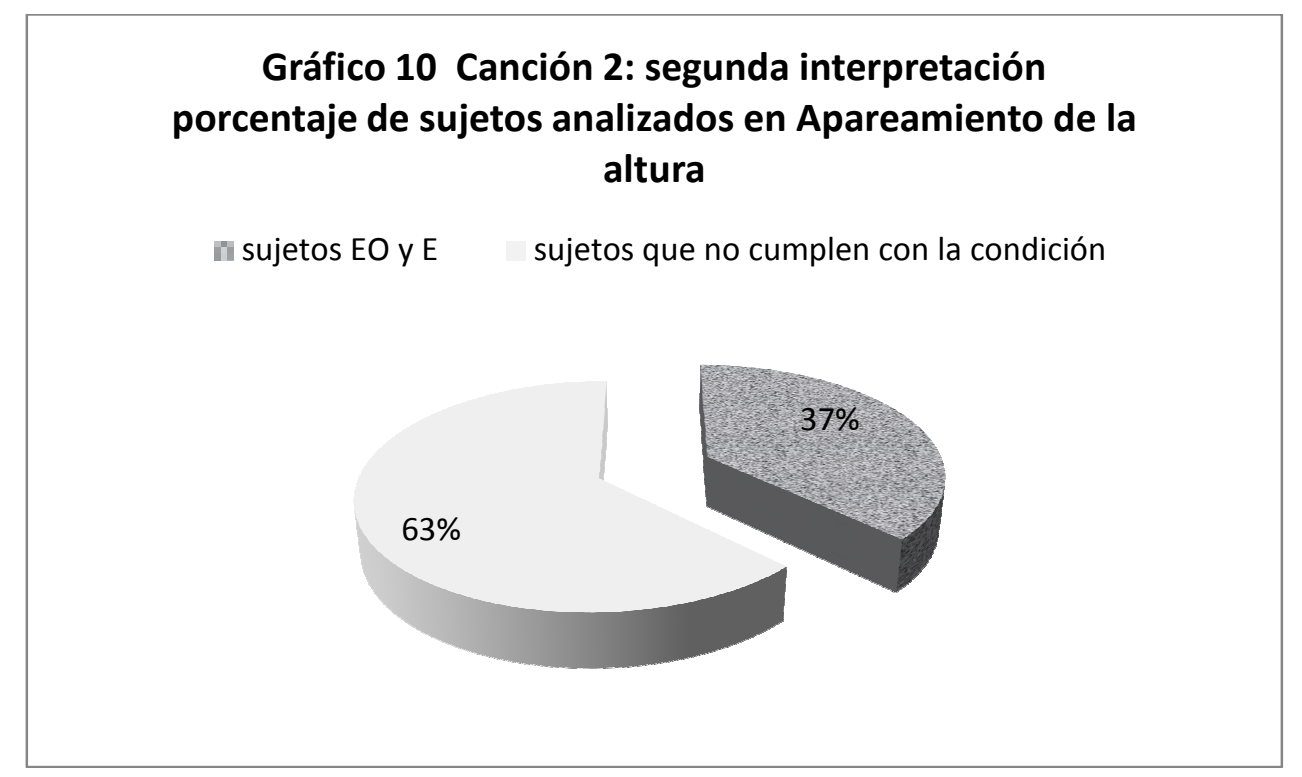

\subsection{Altura de comienzo}

En la Canción 1 Pata pata plum, que comienza en la quinta nota de la escala, los niños debían ubicarse en La4, mientras que en la Canción 2 La ranita Cri, que comienza en la tónica, debían hacerlo en Re4.

Los evaluadores identificaron la nota de comienzo consignando la altura exacta en la que cada niño inició cada interpretación para ambas canciones.

Para consignar la altura de comienzo se consideraron tres categorías: la altura exacta (La4 para la canción 1 y Re4 para la canción 2), altura a distancia de \pm un semitono y altura a distancia de \pm un tono de la altura exacta. Se observaron los siguientes resultados: 


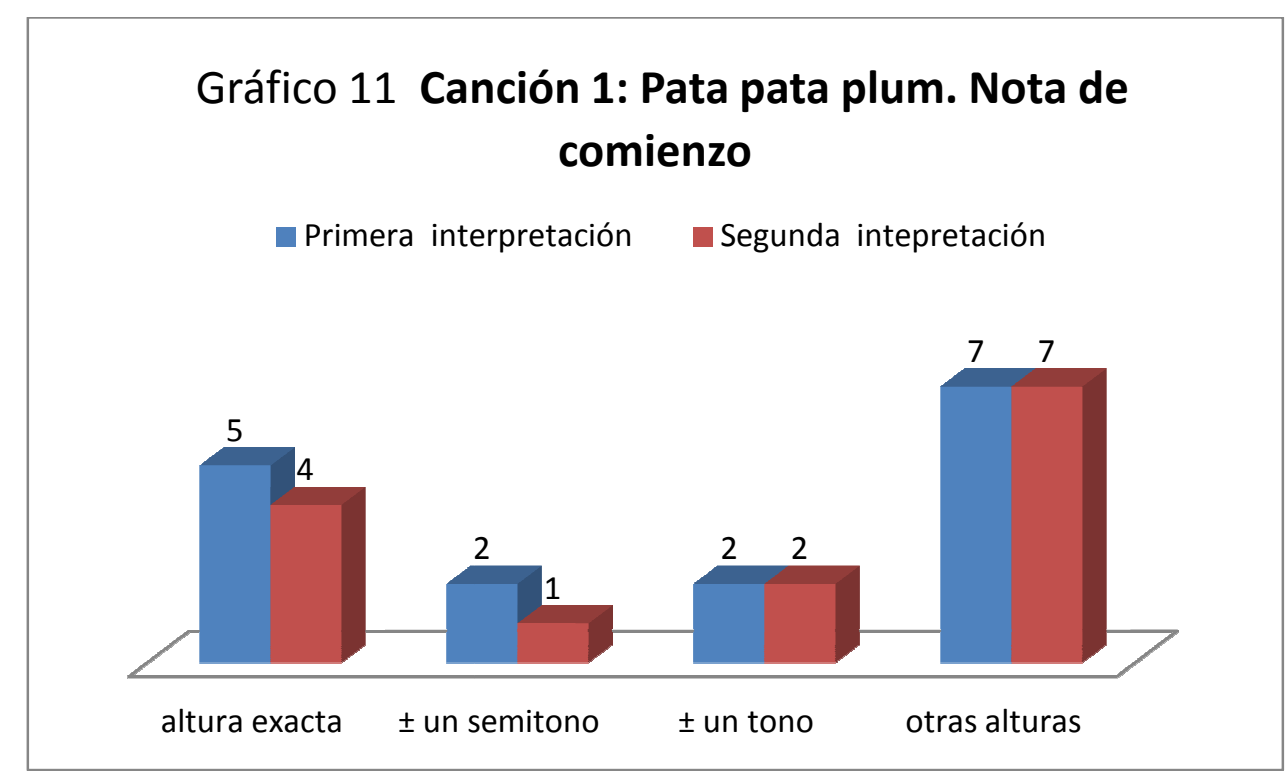

\section{Gráfico 12 Canción 2: La ranita Cri. Nota de comienzo}

Primera interpretación $\quad$ Segunda intepretación

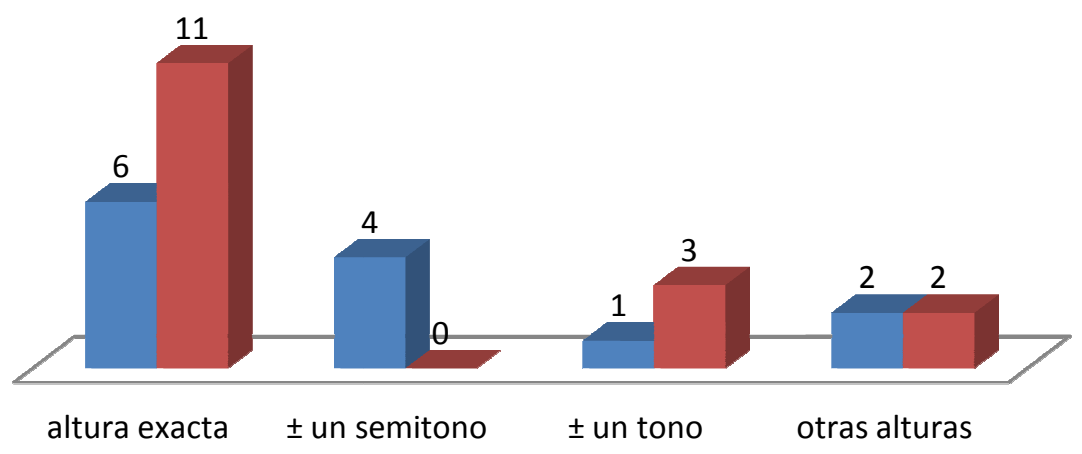

Los resultados muestran diferencias entre ambas canciones:

- La altura exacta obtiene mayor número de respuestas en la segunda interpretación de la Canción 2, y menor número de respuestas en la Canción 1;

- La elección de otras alturas registra el mayor número de respuestas en la canción 1 y la menor en la canción 2. 
Comparando las dos interpretaciones de la misma canción en cada sujeto, se observó una gran variabilidad en la nota de comienzo empleada.

\subsection{Altura de cierre}

Se analizó la altura a la que arribaron los sujetos al final de cada canción. Como se establece más arriba, solamente fueron evaluados los sujetos con Localización de la altura EO y $\mathrm{O}$. Se consideraron tres categorías: la altura exacta (Re 4 para ambas canciones), altura a distancia de \pm un semitono y altura a distancia de \pm un tono de la altura exacta.

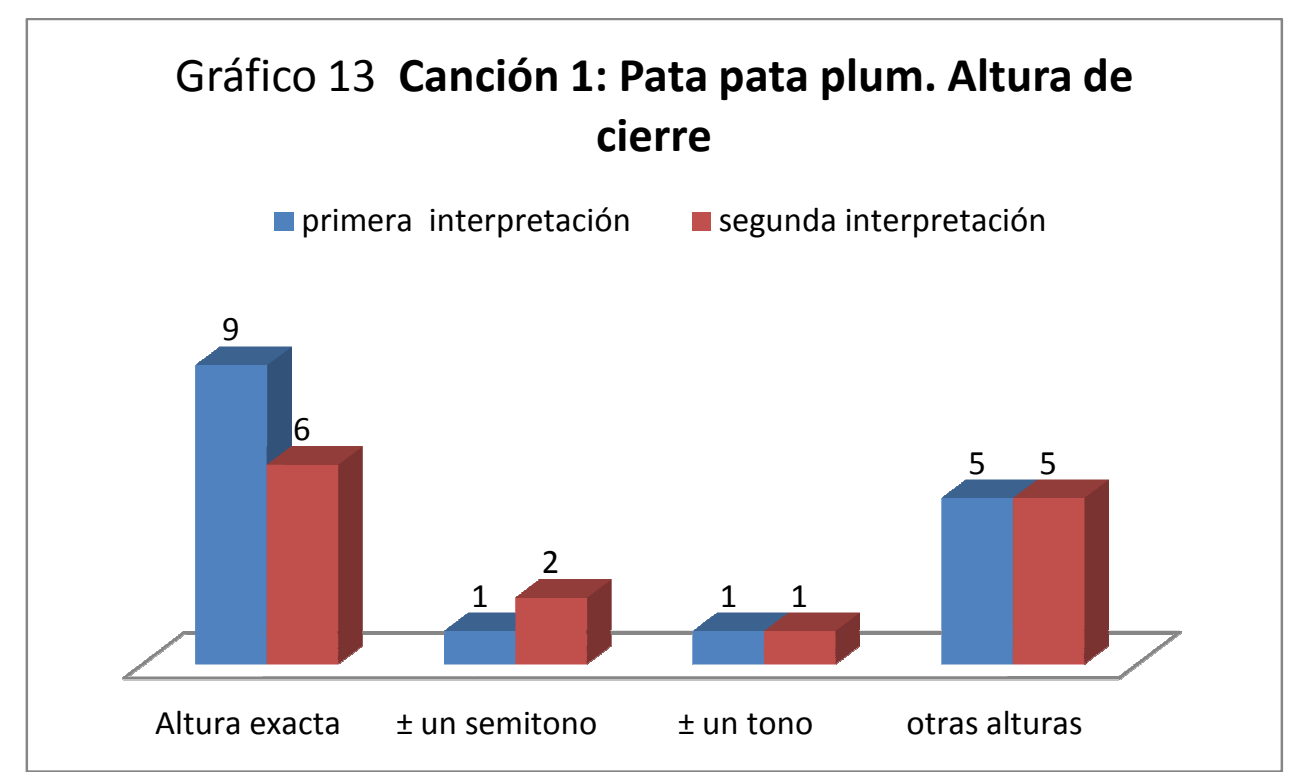




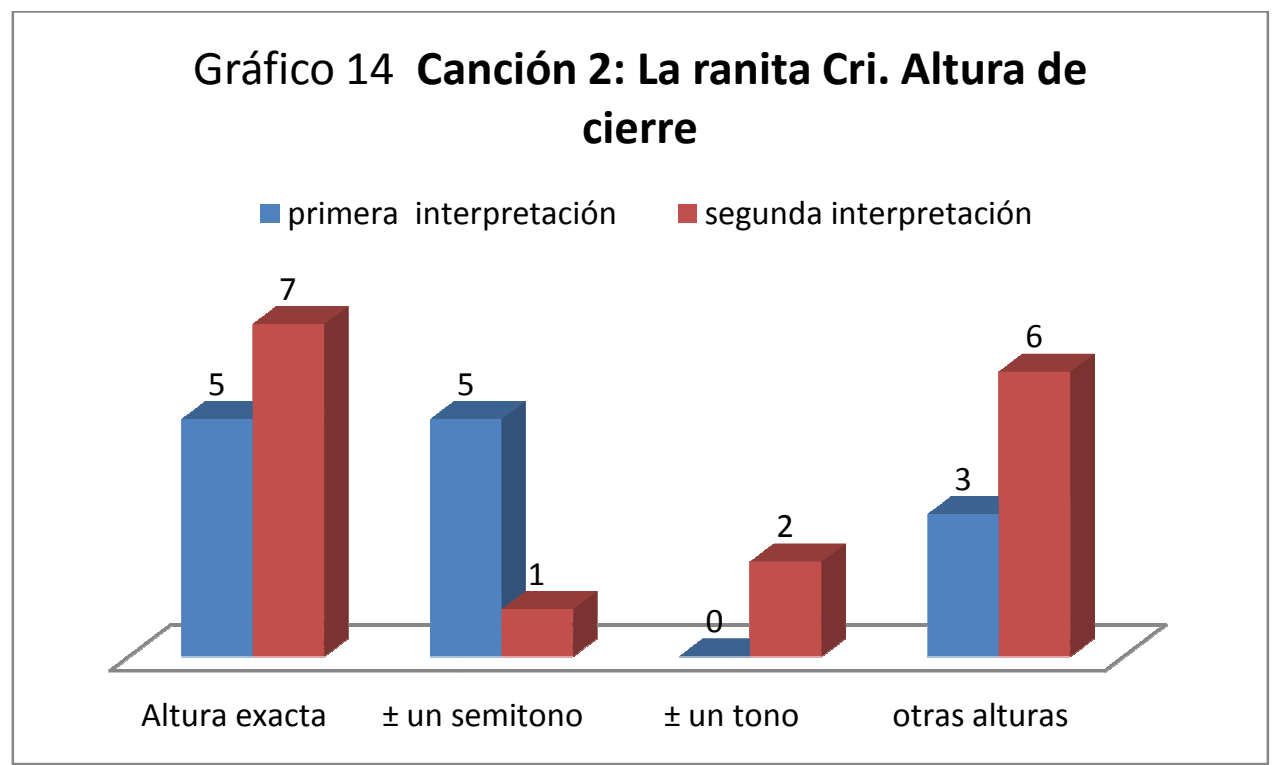

Hubo cuatro sujetos que finalizaron en la tónica propuesta por la banda grabada $(\operatorname{Re} 4)$ en las cuatro interpretaciones evaluadas.

Las respuestas de los niños que se encuentran en las etapas próximas al canto entonado y los que entonan muestran que:

- la altura inicial (dominante) en la Canción 1 Pata pata plum sobre 30 respuestas obtiene un porcentaje del $30 \%$ de niños que utilizan la altura exacta; si sumamos a las respuestas exactas las que se distancian un semitono, el porcentaje aumenta a un $40 \%$;

- la altura inicial (tónica) en la Canción 2 sobre 29 respuestas muestra un porcentaje del $60 \%$ que usan la altura exacta; si sumamos a las respuestas exactas las que se distancian un semitono aumenta a un $72 \%$;

- el uso de alturas de comienzo a más de un tono de distancia de la tonalidad impuesta por la banda obtiene un porcentaje del $50 \%$ en la Canción 1 Pata pata plum y un $13 \%$ en la canción 2 La ranita Cri;

- la altura de cierre (tónica) en la Canción 1 Pata pata plum sobre 29 respuestas un porcentaje del $50 \%$ de los niños utiliza la altura exacta; si sumamos a las 
respuestas exactas las que se distancian un semitono el porcentaje aumenta a un $63 \%$

- la altura de cierre (tónica) en la Canción 2 La ranita Cri sobre 29 respuestas un porcentaje del $41 \%$ de los niños utiliza la altura exacta; si sumamos a las respuestas exactas las que se distancian un semitono aumenta a un $62 \%$;

- el uso de alturas de cierre a más de un tono de distancia de la tonalidad impuesta por la banda obtiene un porcentaje del $33 \%$ en la Canción 1 Pata pata plum y un $31 \%$ en la canción 2 La ranita Cri.

Estos resultados indicarían una cierta variabilidad en las respuestas con respecto a la acertada elección de las alturas de comienzo y cierre en ambas canciones.

\subsection{Vinculaciones entre las alturas de comienzo y cierre}

Se consideró de interés analizar el rango de alturas utilizadas al cantar la canción en los niños de la muestra evaluados con tipo de Localización de la altura Entonada oscilante y Entonada estable.

La sub-variable se examinó en base a la utilización de las alturas absolutas de comienzo y cierre de la performance.

Categorías

Canción 1 Pata pata plum

Alturas absolutas: Respuesta que acuerda con las alturas absolutas de la banda grabada La4 - Re4.

Alturas transpuestas: Respuesta que desacuerda con las alturas impuestas por la banda y que respeta las relaciones interválicas (una 5ta justa: por ejemplo Sol4 - Do4, o Fa4 - Sib3). 
Alturas erróneas: Respuesta que no atiende a las alturas impuestas ni a las relaciones interválicas.

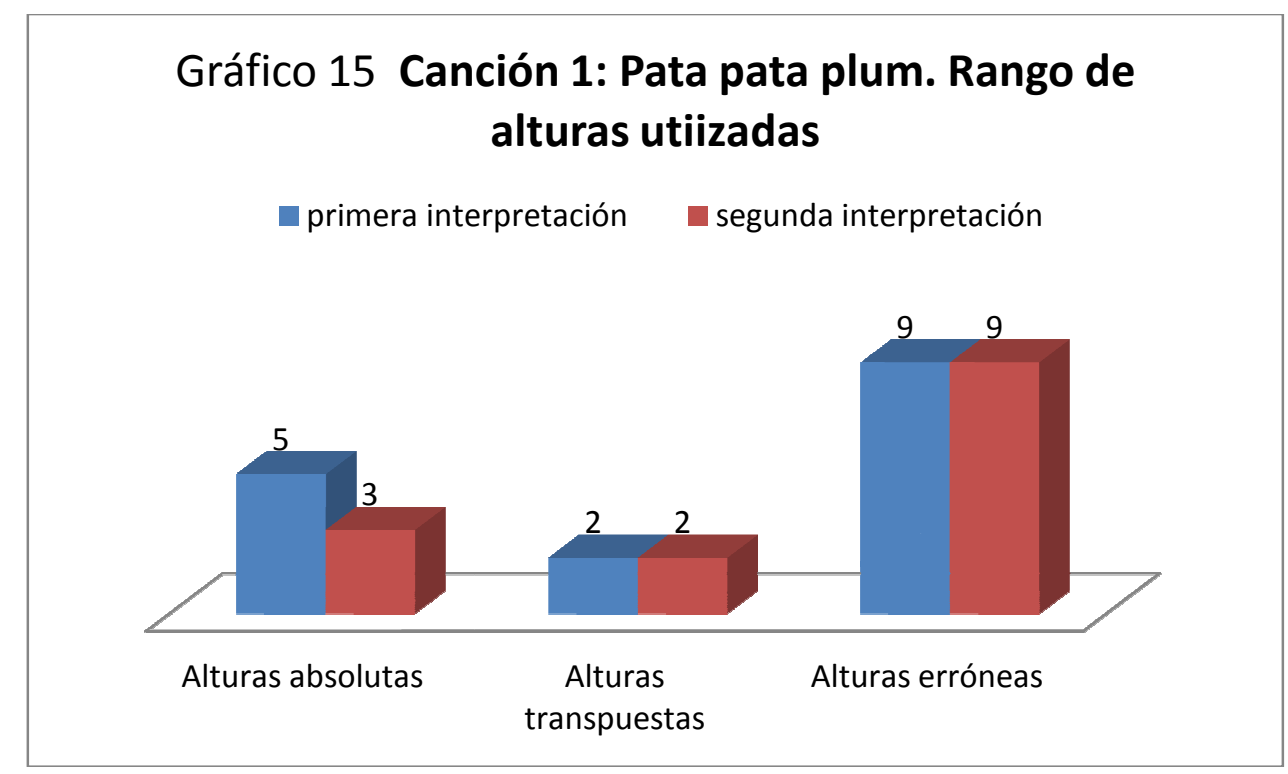

Canción 2 La ranita Cri

En este caso como la canción comienza en Re4 y termina en Re4 la vinculación entre las alturas de comienzo y cierre es el sostenimiento de la altura Re4 para la categoría alturas absolutas; para la categoría alturas transpuestas correspondería al mantenimiento de otra altura para el comienzo y cierre de la canción (que no sea Re4) y se consideran alturas erróneas en el caso de comenzar y finalizar con diferentes alturas. 


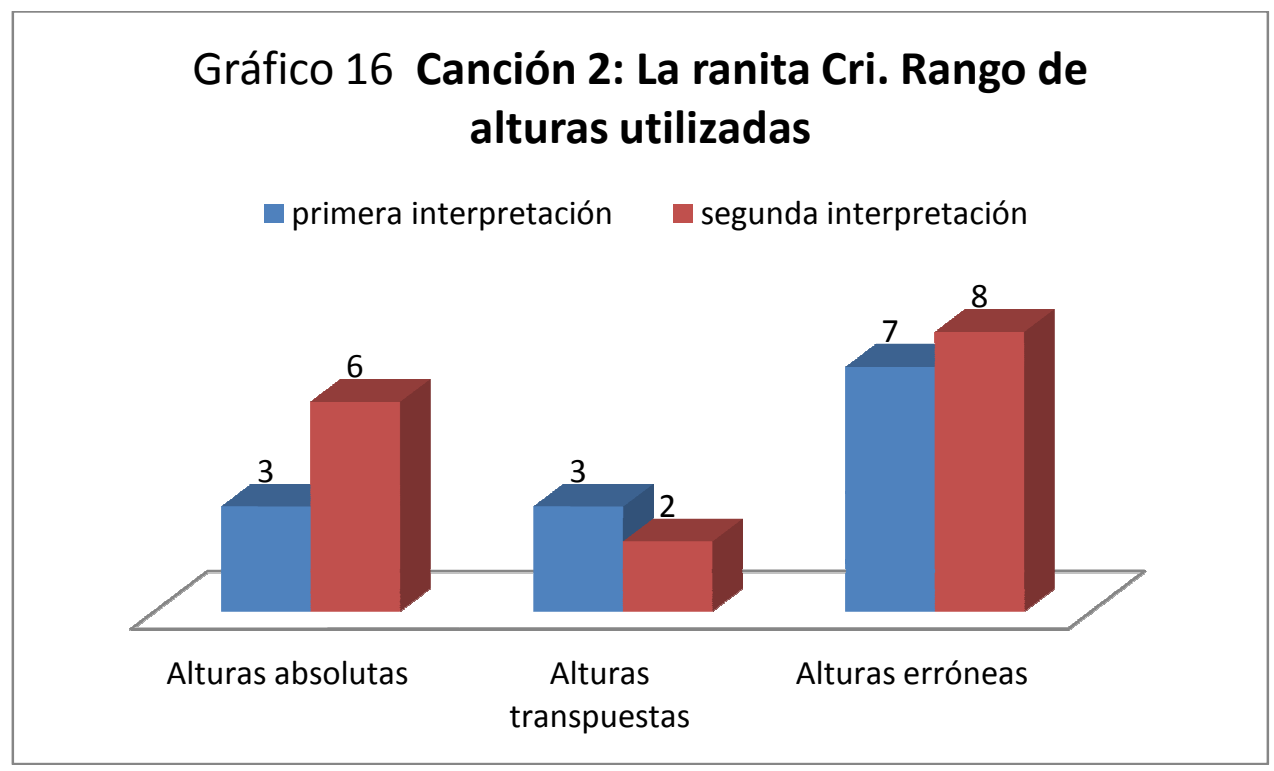

No se observó correspondencia entre los niños que utilizaron el rango de alturas absolutas para cantar las canciones (en los términos descriptos) y una mejor puntuación en las categorías de Estabilidad tonal.

Los resultados señalan que en esta muestra reducida de 30 niños en la canción Pata pata plum y 29 en La ranita Cri los porcentajes se distribuyen del siguiente modo:

- Las respuestas dominantes pertenecen a la categoría alturas erróneas: $60 \%$ en Pata pata plum y $52 \%$ en La ranita Cri;

- Las respuestas que siguen en puntaje pertenecen a la categoría alturas absolutas: $27 \%$ en Pata pata plum y $32 \%$ en La ranita Cri;

- Las respuestas de menor presencia son las que pertenecen a la categoría alturas transpuestas: $13 \%$ Pata pata plum y $17 \%$ en La ranita Cri;

Estos resultados indicarían la dificultad de los niños para adecuarse a la tonalidad impuesta por la banda grabada.

Algunas cuestiones resultan sugestivas: la canción que se inicia con la marcha tónica/dominante obtiene un $60 \%$ de certeza en la emisión de la altura inicial, mientras 
que la canción que se inicia con la marcha dominante tónica el porcentaje es de $30 \%$. Nos preguntamos, los resultados podrían sugerir que:

- ¿Resulta perceptivamente más saliente la marcha distensión/tensión melódico tonal que la progresión opuesta tensión /distensión?

- ¿La mayor precisión es dependiente de la mayor comodidad vocal para entonar?

- ¿La fuerza tonal de la tónica afianza la entonación de la altura?

- ¿La fuerza tonal del comienzo consolida el desempeño a lo largo de la canción y facilita el cierre en la tónica?

- ¿Las repuestas a distancia de un semitono muestran un estadio de desarrollo próximo al afianzamiento del emplazamiento tonal preciso de la canción?

- ¿Las respuestas en otras tónicas indicarían que los niños poseen la habilidad de adoptar un centro tonal pero aún no dominan la habilidad de adecuarse a una tonalidad impuesta por el karaoke?

Todos estos interrogantes sugieren la necesidad de continuar con estudios que respondan a la compleja cuestión de cómo lo niños logran la habilidad de entonar adecuándose a una tonalidad a elección versus una tonalidad impuesta.

\subsubsection{Continuidad Temporal}

Variable analizada en base a las sub-variables Ajuste al tempo y Réplica del texto literario.

\subsubsection{Ajuste al tempo}


El ajuste al tempo se compara entre la 1era y 2da interpretación en ambas canciones para todos los tipos de respuestas

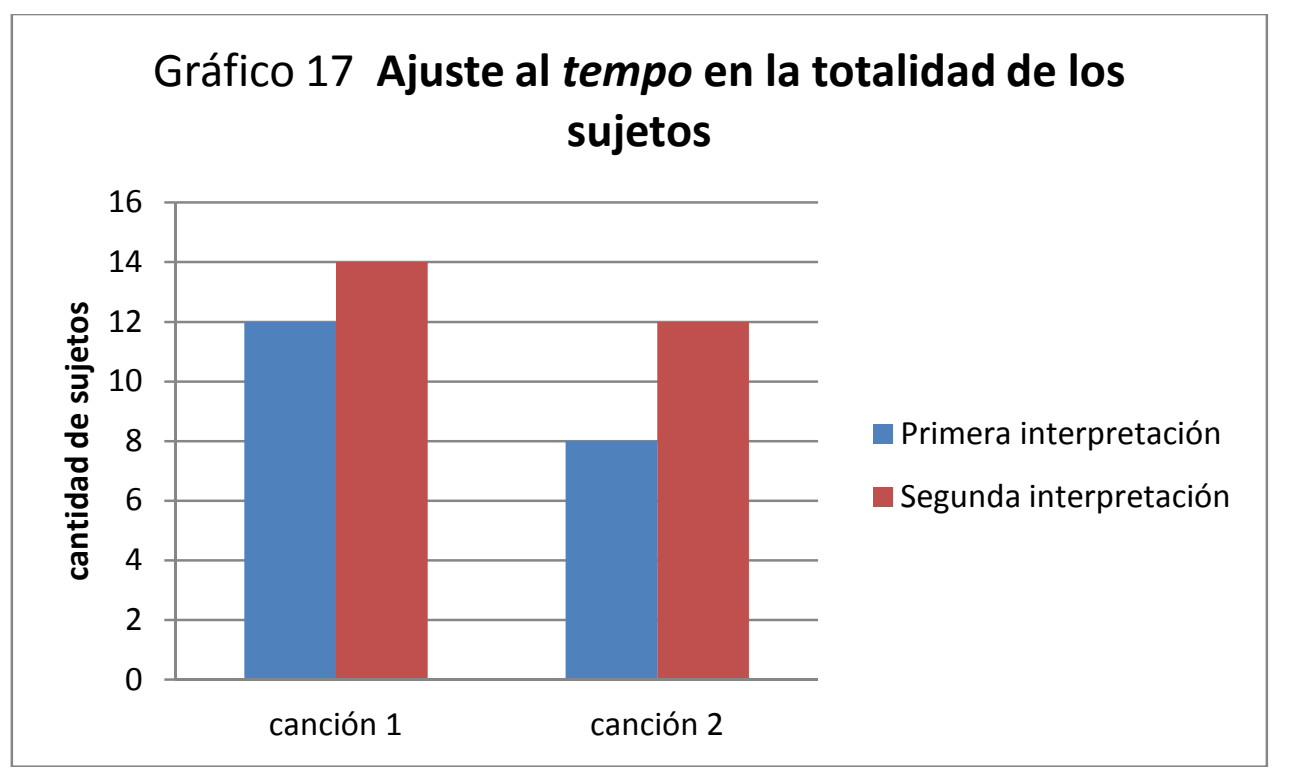

Se comparan los resultados en tres grupos i) los sujetos con Localización de la altura Hablada Monotónica (consignado con el vocablo "habla" en los gráficos 18 y 19) ii) los sujetos con Localización de la altura Hablada con tendencias de movimiento sonoro (HC), Entonada oscilante (EO) y Entonada estable (E) que no respetan el tempo y iii) los sujetos con Localización de la altura Hablada con tendencias de movimiento sonoro (HC), Entonada oscilante (EO) y Entonada estable (E) que respetan el tempo. 

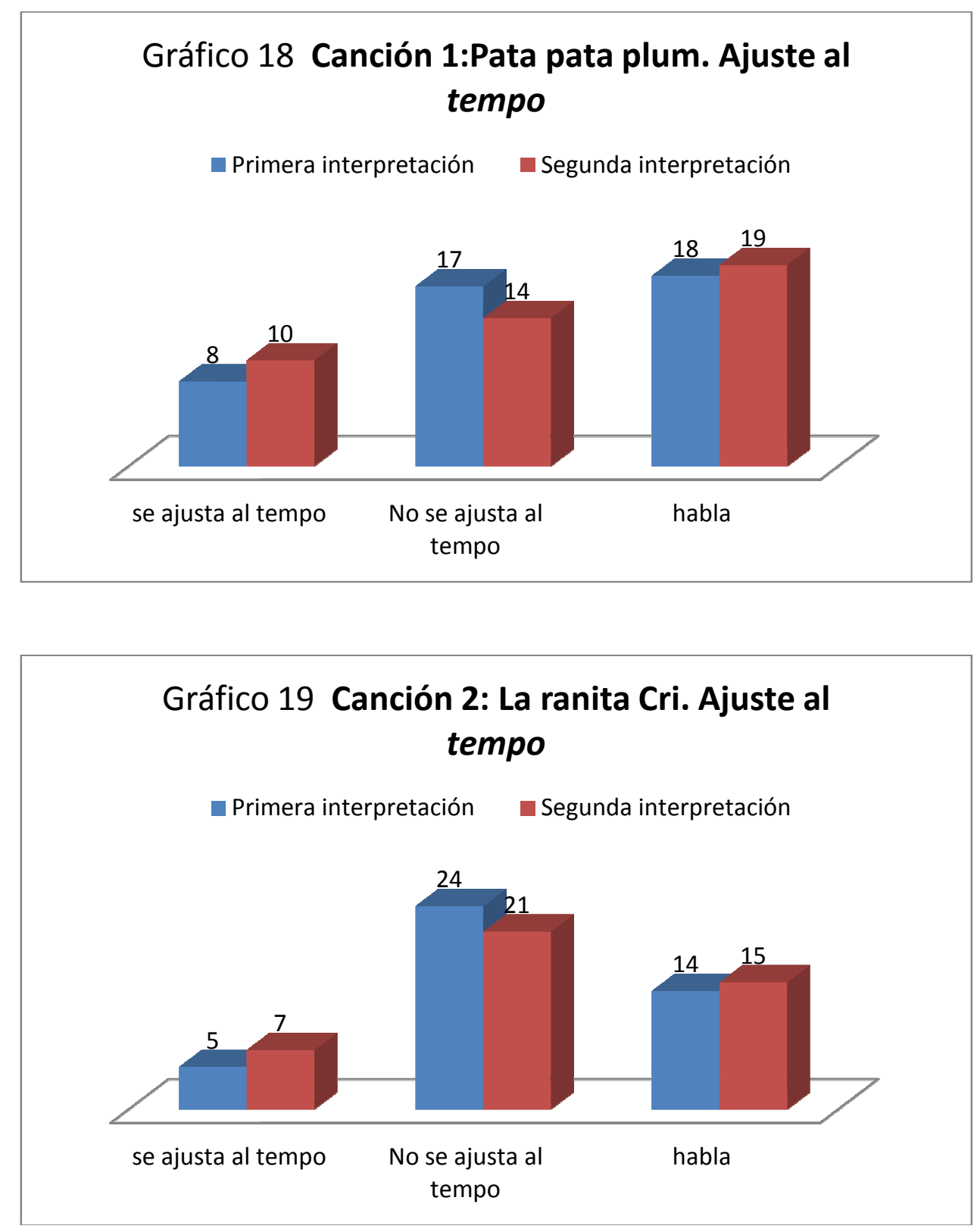

Los resultados muestran que:

- La respuesta dominante en los sujetos con Localización de la altura Hablada con tendencias al movimiento sonoro, Entonada oscilante y Entonada estable es la falta de ajuste al tempo del acompañamiento en karaoke, para ambas canciones y en ambas interpretaciones.

- En la segunda interpretación, un mayor número de sujetos ajustan al tempo del karaoke para ambas canciones. 
Al analizar separadamente las respuestas de los sujetos con Localización de la altura Hablada monotónica HM (graficados bajo el rótulo habla en los gráficos 18 y 19) se observa que algunos de ellos hablaban rítmicamente el texto de la canción con ajuste al tempo propuesto por la grabación. Del total de interpretaciones de ambas canciones hay dos sujetos que en todas sus interpretaciones presentan ajuste al tempo de la grabación y tipo de Localización de la altura Hablada monotónica.

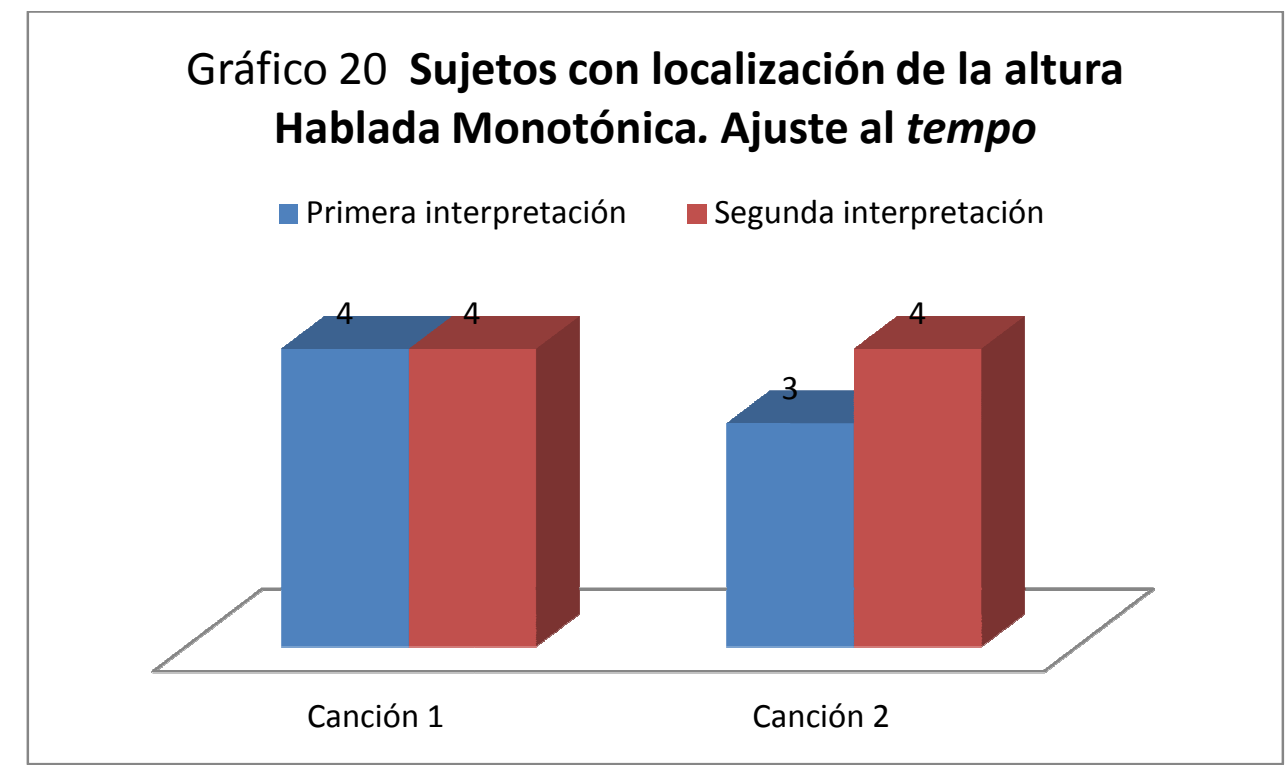

Los resultados muestran que:

- Algunos sujetos (no más de cuatro por interpretación), a pesar de pertenecer al nivel inferior en el tipo de localización de la altura, ajustan el tempo correctamente con la banda grabada ${ }^{58}$;

- Se observan similares resultados en ambas canciones.

\subsubsection{Réplica del texto literario}

Se estudió tanto la reproducción literal de las palabras del texto, como el reemplazo de palabras y la omisión de algunas frases del texto ${ }^{59}$. También se señaló las

\footnotetext{
${ }^{58}$ Puede escucharse un niño de la muestra que se ajusta al tempo de la banda grabada y tiene un tipo de localización de altura Hablada Monotónica, en un archivo de sonido adjunto a esta tesis.
} 


\section{CANTAR CANCIONES ENTRE LOS CUARENTA Y CINCUENTA MESES 121}

performances con dificultades en el habla por lo cual los sujetos reproducen con claras dificultades de pronunciación (señalado en el gráfico 21 como dificultad en el habla). Estas características se analizaron por canción y por interpretación.

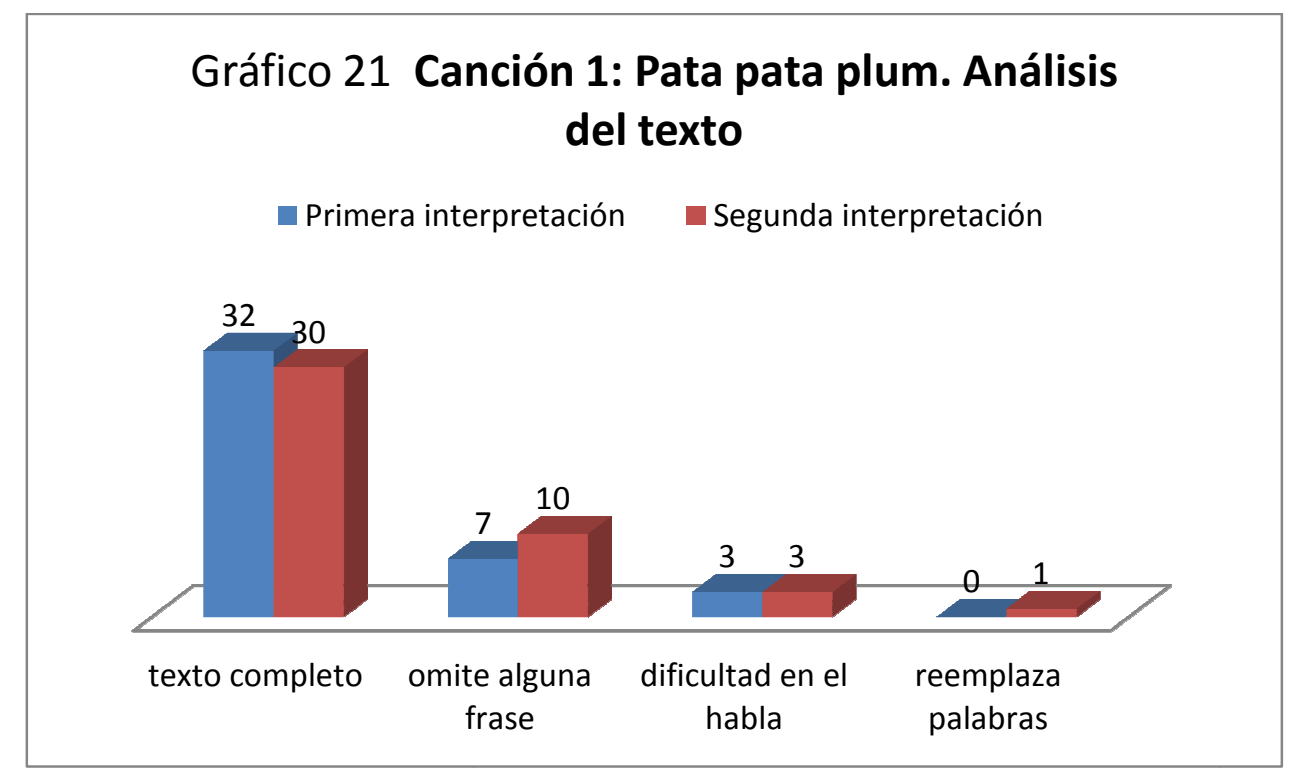

Los resultados muestran que:

- la mayoría de los sujetos reproducen correctamente el texto completo;

- algunos sujetos omiten alguna frase del texto, la segunda frase fue la más omitida 5 sujetos para la primera interpretación y 8 en la segunda interpretación. En el caso de otras frases omitidas son 2 para la primera interpretación y 2 para la segunda.

- El reemplazo de palabras se da en un caso en la segunda interpretación en la que el sujeto inventa palabras para completar las alturas guardadas en su memoria en la cuarta frase de la canción.

\footnotetext{
${ }^{59}$ Puede escucharse a un niño de la muestra que omite una frase y además reemplaza palabras del texto en un archivo de sonido adjunto a esta tesis.
} 
- Los sujetos con dificultades en el habla se corresponden con el tipo de Localización de altura Hablada monotónica.

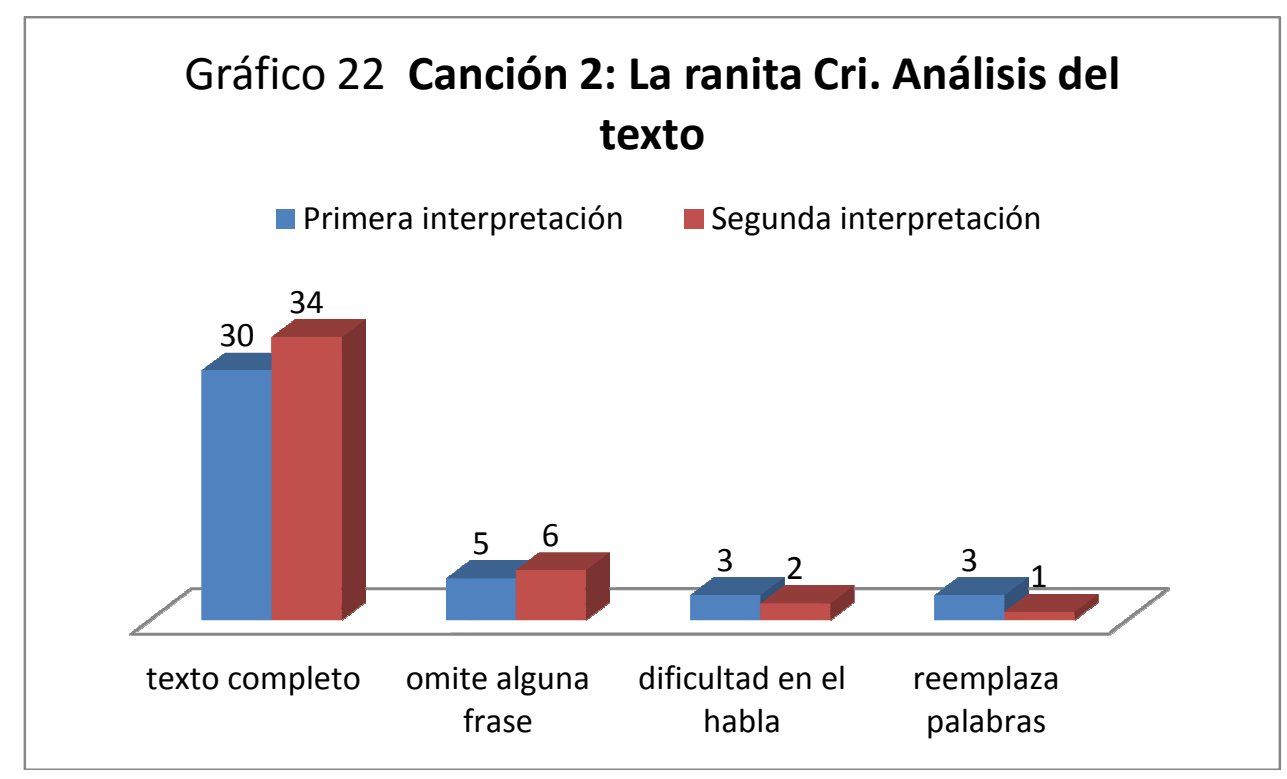

Los resultados muestran que:

- la mayoría de los sujetos reproducen correctamente el texto completo;

- algunos sujetos omiten alguna frase del texto, la segunda frase fue la más omitida 4 sujetos para la primera interpretación y 4 en la segunda interpretación. En el caso de otras frases omitidas, se observó una para la primera interpretación y dos para la segunda;

- El reemplazo de palabras se observa en 3 sujetos con remplazos por otras con equivalente sentido: "a tomar el sol" en cambio de "a mirar el sol" o similares. Un sujeto en la primera interpretación inventó palabras para completar las alturas retenidas en la memoria en la última frase de la canción;

- Los sujetos con mala dicción corresponden al tipo de Localización de altura Hablada monotónica. 
Los resultados muestran que en ambas interpretaciones un alto porcentaje de niños pueden reproducir el texto literalmente. Esta comprobación es coincidente con estudios previos descritos en el marco teórico de este trabajo acerca de la supremacía del texto por sobre la melodía en la interpretación de canciones en edades tempranas. (Davidson y Scarlett, 1987; Dowling, 1994; Welch, 1999; Mang, 2000; White, 2000; Moore et al., 2008; Mónaco, 2008).

\subsubsection{Registros Anecdóticos}

Durante el registro de las voces infantiles se observaron una gran variabilidad de desempeños vocales y actitudes hacia la tarea que necesitan ser analizados para comprender mejor la actividad. Si bien los estudios estadísticos son útiles a la hora de diseñar un entrenamiento vocal grupal, los desempeños vocales individuales merecen atención.

Se trata de observar algunas cuestiones tales como:

- los desempeños en las performances sucesivas (el canto de cada canción dos veces seguidas);

- la uniformidad o diferenciación de desempeños de los registros individuales en diferentes días;

- el "estudio de casos" para los niños que se encuentran en los extremos de las categorías; 
Si bien para los estudios estadísticos se seleccionó el mejor intento de los dos cantados en forma sucesiva, se observó en ocasiones marcadas diferencias en ambas performances, lo que podría deberse a la dispersión de la atención en estas edades. Cantan el primero o el segundo intento en una mejor versión, variabilidad que se observa en el ajuste al tempo propuesto por la banda, en el tipo de localización de la altura como asimismo en la estabilidad tonal.

Caso J. P. evaluado con localización de altura Entonada estable en todas sus interpretaciones. En tres de ellas obtiene mejor performance en el segundo intento; pero en Pata pata plum, primera interpretación se evaluó como más logrado su primer intento. Esto se puede deber a que, a pesar de que comienza tarde a cantar (según la banda grabada) canta en la tonalidad propuesta, mientras que en su segundo intento pierde el centro tonal.

\section{Tipo de localización de la altura}

Algunos sujetos presentan una mejor Localización de la altura en una canción que en otra y en una interpretación que en otra.

Caso D. en tres de sus performance puntuó con un tipo de Localización de la altura hablada con tendencia de movimiento sonoro (HC) y en La ranita Cri segunda interpretación cantó con Localización Entonada Estable.

Caso J. cantó las dos interpretaciones de Pata pata plum con Localización Entonada Oscilante y las dos interpretaciones de La ranita Cri con Localización Entonada Estable. Obtuvo en distintas fechas los mismos resultados por canción.

\section{Estabilidad tonal}


En los sujetos con centro tonal ausente CTA, hay uniformidad de las respuestas en cuanto a esta variable en las diferentes interpretaciones de las dos canciones. Una excepción a esta constante es el caso E. que posee CTA en tres de sus interpretaciones (HC) y en La ranita Cri segunda interpretación cantó con centro tonal por frase CTF, con Localización Entonada Oscilante.

En las categorías Centro tonal parcialmente presente (CT2), Centro tonal por frase (CTF), Centro tonal estable insuficiente (CTEI) y Centro tonal estable suficiente (CTES) se observó gran variabilidad en las diferentes interpretaciones y canciones en un mismo sujeto.

Caso Mch. obtuvo en tres de sus interpretaciones el tipo de localización Entonada Estable, aunque se correspondan con ellas las categorías de estabilidad tonal: Centro tonal por frase CTF, centro tonal estable insuficiente CTEI y centro tonal estable suficiente CTES. La interpretación restante obtiene una Localización Entonada Oscilante EO y una estabilidad tonal con centro tonal parcialmente presente CT2.

\section{Contorno melódico - Canciones pot-pourri}

Se observó que algunos niños no seguían el contorno de la canción, pero tomaban la melodía de otra canción de su entorno cultural e interpretaban, con el texto de la canción solicitada, otro contorno (lo que Moore llama "canciones potpurrî"). Dicha mezcla de canciones está descrita como espontánea, y se observaron diferentes sujetos con este tipo de producciones en diferentes interpretaciones.

En total se observaron 14 interpretaciones en las cuales los sujetos de la muestra cambiaban el contorno de una frase, tomando el de otra canción. Hubo un contorno muy utilizado, que correspondería en estas canciones a Fa-Fa-Mi-Mi-Re (o sea la tercera de 
la escala repetida, la segunda de la escala repetida, para arribar a la tónica como sonido más largo), un giro melódico muy presente en el cancionero infantil. Este giro aparece en cuatro interpretaciones ubicado en diferentes lugares de la canción.

En algunos casos podría suponerse que más que espontáneo este trocar giros melódicos en realidad parece ser una mala fijación del contorno, ya que repiten el contorno erróneo en la misma canción en diferentes fechas. Caso J. cambió el contorno de la última frase de Pata pata plum en su primera interpretación y pasados veinte días volvió a "errar" el contorno en esa canción de la misma manera.

Un caso diferente es el de JT que replica los contornos correctos de Pata pata plum y La ranita Cri en las primeras interpretaciones (tomadas en la misma fecha), pero en la siguiente fecha cambia el contorno de la última frase de la canción Pata pata plum (registrada en primer lugar) y luego aplica ese mismo contorno a la última frase de la canción La ranita Cri.

Texto

Se observan diferentes comportamientos en referencia al recuerdo del texto.

Caso E. en los primeros intentos sucesivos de Pata pata plum mezcla los textos de ambas canciones y termina cantando el texto de las dos últimas frases de La ranita Cri (ambas frases presentan igual melodía). En el segundo día de grabación canta la canción 1 con texto correcto en el primer intento y en el segundo mezcla los textos de la misma manera que en el primer día de grabación.

\section{Algunos casos ilustrativos}


Caso An. en La ranita Cri primera interpretación repite dos veces la ranita Cri, allí reacciona y canta la ranita Cro y luego termina la canción totalmente ajena al acompañamiento pues le queda una canción de cinco segmentos formales en lugar de cuatro. Este tipo de desempeño lo realiza tanto en el primer intento como en el segundo. En la segunda interpretación canta el texto completo correctamente.

Caso Mo en las dos interpretaciones de Pata pata plum omite la segunda frase y en las dos interpretaciones de La ranita Cri reemplaza el texto "salen de paseo a mirar el sol" por "se fueron de paseo a buscar el sol" con lo que confirmaría que tiene el texto guardado en forma errónea en su memoria.

No se observaron niños que presentaran una mala pronunciación y que tuvieran un desempeño en el tipo de Localización que no fuera Hablada monotónica, ¿será que la dificultad en la adquisición del lenguaje precondiciona para la adquisición del canto?

La muestra total del Estudio Final se redujo, como se explicó en Metodología, de 54 a 43 sujetos. Siete niños manifestaron su falta de interés en ser registrados, tal vez por timidez o por desconocimiento del testista, a pesar de las numerosas visitas a la institución. Incluso algunos se presentaron para ser grabados y en el momento en cuestión, se negaban.

Diferente fue el caso de los cuatro niños que no lograron completar las dos interpretaciones, a causa de su ausencia durante los registros por enfermedad o viajes.

Las observaciones emergentes de los Registros Anecdóticos confirman en muchos sentidos los resultados obtenidos en los estudios cuantitativos realizados en el presente estudio: los niños de estas edades se encuentran recorriendo un camino que procede del no canto al canto incipiente. Los procesos se caracterizan por idas y vueltas, avances y retrocesos con las siguientes particularidades: 
- son independientes del número de ensayos y de la canción puesta en ejecución;

- se presentan en todas las sub variables aisladas;

- están teñidos por cuestiones del momento probablemente atribuibles a cansancio, altibajos en la memoria y/o distracciones;

- los desempeños más eficientes también muestran que a lo largo de las distintas tomas se desenvuelven en procesos con dificultades para su consolidación;

- la adecuación o inadecuación al modelo de la canción pareciera ser insuficientemente registrado por los niños durante la performance, ya que no realizan correcciones "sobre la marcha";

- el rasgo común de las performances individuales estudiadas es la falta de linealidad en los procesos de desarrollo melódico, tonal y vocal.

\subsubsection{Resultados Sumarios}

Los resultados obtenidos en el estudio pueden sintetizarse considerando que en estas edades:

- La repetición de la práctica al momento no incide en la performance vocal: los niños obtienen mejor localización en la primera interpretación en una canción y en la segunda en otra.

- La repetición de la práctica al momento permite afincar más fielmente el tempo. Las segundas interpretaciones de ambas canciones mostraron un mayor ajuste al tempo impuesto por la grabación.

- La habilidad de ajustar a un tempo impuesto es interdependiente de otras habilidades analizadas: emisión vocal y estabilidad tonal. 
- La tonalidad es una adquisición no disponible: se registra un solo caso en la categoría más alta Centro tonal estable suficiente. La mayoría de los niños se ubican en la categoría Centro tonal ausente.

- La calidad de las respuestas refleja una curva de distribución por mesetas, desde la categoría más baja centro tonal ausente a la categoría más alta Centro tonal estable suficiente con una distribución heterogénea. La meseta más amplia se ubica en el nivel más bajo, centro tonal ausente (entre 67 y $72 \%$ ); la segunda meseta en torno a las categorías intermedias Centro tonal parcialmente presente y Centro tonal por frase en un porcentaje que oscila entre el 27 y el $23 \%$ y una tercera ubicación con sólo dos respuestas $(0,3 \%)$ en las categorías más altas.

- La mejor Localización de la altura contribuye a la centralidad tonal.

- La reproducción del contorno melódico es una habilidad disponible: en ambas canciones se registró un alto predominio de respuestas con respeto por el perfil de alturas.

- La mayor tonicidad del sonido emitido en la Localización de la altura facilita la mejor reproducción del contorno de alturas.

- La mejor fidelidad en la reproducción del contorno melódico ayuda a una cierta estabilidad tonal a lo largo de la performance.

- El ajuste en la nota de comienzo (de los sujetos en las categorías Entonada Oscilante y Entonada Estable) presenta mayores aciertos en la canción 2 que comienza en la tónica, que en la canción 1 que comienza en la dominante. Los resultados son más estables para ambas canciones en la altura de cierre.

- En la vinculación entre las notas de comienzo y cierre se observa la dificultad de los niños para adecuarse a la tonalidad impuesta por la banda grabada. 
- La reproducción literal del texto de la canción es una habilidad disponible: un alto porcentaje de niños pudo reproducirlo en ambas canciones y en las diferentes versiones.

- El uso de onomatopeyas respecto al texto que no las usa pareciera no presentar diferencias. 


\section{Capítulo 6}

\section{Conclusiones y Aportes potenciales}

\subsection{Conclusiones}

Los resultados obtenidos permiten arribar a ciertas conclusiones relativas al objeto de estudio. Se considera que algunos comportamientos de los niños de la muestra confirman trabajos previos $\mathrm{y}$ otros señalan nuevas aproximaciones $\mathrm{e}$ interrogantes.

El análisis de los marcos teóricos, de la masa crítica disponible y su comparación con los resultados obtenidos, permiten considerar ciertos avances en torno a los comportamientos propios de la edad a la hora de entonar una canción.

Así también se consideran avances de este trabajo la construcción de variables, sub-variables y categorías con la jerarquización concomitante entre las mismas. Tales variables resultaron adecuadas para la descripción de las respuestas melódicas en esta muestra ya que permitieron la inclusión de todas las respuestas analizadas.

Se considera que los resultados obtenidos ilustran el constructo denominado protocanto, ya que muestran que es predominante en la muestra la Hablada monotónica (HM) y la Hablada con tendencia de movimiento sonoro (HC), ambos tipos de interpretación con ausencia de centro tonal (CTA). Estos datos señalan que los niños de la muestra están en etapas iniciales del desarrollo del canto.

En cuanto a los Desempeños Vocales se ha visto que

- Los mejores desempeños vocales se vinculan con el respeto por el contorno, independientemente del ejemplar melódico. 
Estos resultados confirman investigaciones anteriores de Dowling, (1994), Welch (1997, citado por Tafuri, 2009), Welch, (1999), Davidson (1994), Mónaco (2000).

- Resulta de interés notar la diferencia de los resultados en esta variable entre las dos canciones: la canción 2 La ranita Cri, obtuvo mejores resultados tanto con la mayor cantidad de sujetos que emitían su voz para cantar superando la emisión hablada, como aquellos que siguen el contorno.

- El rasgo común de la muestra es la inestabilidad en las respuestas; la reiteración del ejemplar en el momento y en días posteriores ha permitido comprobar que niños que en una performance alcanzan un buen desempeño, ante el mismo ejemplar en otro intento pueden bajar ostensiblemente en la calidad de la reproducción. Esto indicaría que los procesos de desarrollo de la habilidad son incipientes, caracterizados por avances y retornos y que al finalizar la performance carecen de una apreciación de lo realizado, lo que explicaría la variabilidad e inconsistencia entre una ejecución y su repetición.

Estos comportamientos han sido descriptos por Welch (1997) y Tafuri (2009).

- Si bien la muestra del test es pequeña, el contorno melódico por grado conjunto ascendente (en este caso el pentacordio) es de más fácil y mejor resolución que la descendente. Un factor de incidencia en este caso es que la Canción 1 Pata pata plum, se inicia en la nota dominante en cambio la Canción 2 La ranita Cri, se inicia con la nota tónica. Una interpretación posible es que luego de la introducción de la banda grabada al niño le demanda mayor destreza vocal ubicarse en la nota dominante lo que podría comprometer un mejor dominio tonal que comenzar con la nota tónica en la que acaba de cerrar la introducción. 
CANTAR CANCIONES ENTRE LOS CUARENTA Y CINCUENTA MESES 133

Este desempeño señalaría diferencias con investigaciones anteriores que consideran que le tendencia descendente al cantar es de más fácil resolución que la ascendente Ramsey, 1983 y Fox, 1990 (citados por Miyamoto, 2007), Welch (2009), y Davidson (1994).

- La adecuación a la tonalidad es una habilidad no disponible: la mayoría de los niños se ubican en la categoría centro tonal ausente. En toda la muestra un solo niño alcanzó la categoría Centro tonal estable suficiente en ambas ejecuciones. Asimismo las categorías seleccionadas para esta sub-variable han permitido observar que las respuestas se ubican por estratos, con mesetas de amplia incidencia en los niveles más bajos. Esto permitiría preguntarse si en un estudio longitudinal resultaría factible observar el tiempo promedio de permanencia en cada meseta y el grado de variabilidad o cambio entre las mismas.

Las respuestas por estratos y la tonalidad como habilidad en ciernes ha sido postulada por Moog (1976), Welch(1997), Davidson (1984) y Mónaco (2008).

- La calidad de la Localización de la altura es factor del desempeño para el resto de las sub-variables, dado que i) las performances de niños con Localización monotónica resultan inconsistentes para analizar las variables y sub-variables vinculadas con la emisión de alturas; ii) la reproducción del contorno de alturas correlaciona positivamente con la mejor Localización de alturas iii) el anclaje tonal es mayor cuanto mejor es la Localización y podría estar latente como parte del acopio perceptivo disponible por enculturación, pero pareciera que a los niños no les resulta posible hacer uso de tal disponibilidad por no contar con el “instrumento templado" para cantar. 
La emisión vocal ha sido descripta por varios autores Reiko Hata (1987), Welch(1991, 1996, 1998, 1999), Davidson (1984), Dowling (1984) Flohr (1984) Malbrán (1992), Rutkowski (1994), Mang (2000, 2002), Mónaco (2000, 2008), y Tafuri (2009). Aunque no consta que se la haya considerado funcional a las otras competencias comprometidas en el canto infantil.

- La altura de comienzo en términos absolutos mostró un buen promedio de respuestas el que se incrementa cuando se consideran las respuestas a distancia de un semitono de la altura real. Estas comprobaciones ampliarían la base de sustentación de la conclusión anterior que describe el anclaje tonal como constructo "latente", ya que poder ubicarse con certeza en la primera altura sería un indicador de tal anclaje pero a la vez mostraría que es condición necesaria pero no suficiente: hace falta además mantenerse en el "sistema de reglas" de la tonalidad a lo largo de la ejecución.

La altura de comienzo fue estudiada por Reiko Hata quien obtuvo porcentajes de acierto similares a los realizados en esta tesis (30\%). Dicho autor vincula tal competencia con la memoria de alturas absolutas sin vincularla con el anclaje tonal.

- La comparación de las respuestas en torno a la altura de comienzo en términos absolutos, pareciera indicar que a los niños de este estudio les resulta más fuertemente tonal comenzar por la tónica que por la dominante.

No nos constan estudios similares.

- La altura de cierre en términos absolutos mostró un buen promedio de respuestas, el que aumenta cuando se consideran las respuestas a distancia de un semitono de la altura real. Ambas canciones terminan en la tónica por lo cual se incrementa la suposición del anclaje tonal como constructo "latente" pero 
además como "esquema subyacente". En tal sentido se considera que cerrar la performance ubicando correctamente la tónica sería un indicador indirecto de que el universo de alturas de la tonalidad con sus relaciones mutuas se encuentra operando en la mente aunque sin alcanzar la condición suficiente ya descripta: adecuarse al "sistema de reglas" de la tonalidad a lo largo de la ejecución.

Al igual que en los estudios de la altura de comienzo, las investigaciones de otros autores no vinculan tal competencia con el anclaje tonal.

- La adecuación a la tonomodalidad impuesta por la banda grabada (karaoke) no fue resuelta por los niños de la muestra, a pesar de que los ensayos siempre se realizaron con el acompañamiento de la banda.

Atterbury y Silcox (1993) encontraron diferencias no significativas entre la habilidad de cantar con acompañamiento y sin acompañamiento después de un año de instrucción en niños de preescolar.

- El ajuste al tempo del karaoke mostró mayor precisión de las repuestas en la segunda interpretación. Esto sugeriría que la internalización de la cadencia temporal requiere un mayor tiempo de exposición del y convivencia con el estímulo.

No tenemos constancia de estudios similares.

- Se observaron algunos sujetos que se ajustan al tempo de la grabación recitando el texto en forma monotónica, sin indicios de entonación.

Coincide con Malbrán y Mónaco (2002) acerca de que las ejecuciones melódicas y rítmicas son habilidades con procesos de configuración y progreso independiente.

- En cuanto a la reproducción del texto literario la mayoría de los sujetos pueden repetir correctamente el texto completo; las omisiones de una frase completa se 
han producido en la segunda frase de la canción lo que ilustraría los principios psicológicos del orden serial (primacía y recencia).

Esta comprobación es coincidente con estudios de Dowling, (1994), Davidson, (1994), Welch (1996), Mang (2000); Moore et al. (2008), y Mónaco (2008). En cambio disiente, al menos en parte con Tafuri (2009), quien asegura que a pesar de las diferencias individuales "algunos niños de dos años y dos meses pueden cantar canciones completando tres frases y con ajuste tonal a pesar de que la pronunciación de las palabras todavía sea imprecisa" (p. 64). Esta característica es observada por Tafuri sólo en las canciones aprendidas. Indudablemente las diferencias interindividuales atestiguan estas diferencias.

- Los sujetos que presentan dificultades de dicción del texto también pertenecen a las categorías más pobres de emisión vocal.

Estas performances pueden relacionarse con los escritos sobre las características comunes en el desarrollo del habla y el canto descriptos por Welch (2005), Levitin y Tiravolas (2009), Schön et al. (2008), y Hallam et al. (2009).

En cuanto a las variables se considera que en esta tesis

- Delimitan tres áreas de estudio: comportamiento vocal (emisión vocal), anclaje tonal (adecuación tonal) y anclaje temporal (continuidad temporal)

Los estudios previos aluden a las respuestas en términos vocales (Reiko Hata, 1987; Welch, 1991, 1996, 1998, 1999; Davidson, 1984; Dowling, 1984; Flohr, 1984; Malbrán, 1992; Rutkowski, 1994; Mang, 2000; Mónaco, 2008; Tafuri, 2009), tonales (Moog, 1976; Welch, 1997; Davidson, 1984; Mónaco, 2008) y temporales (Dowling, 1994; Davidson, 1994; Welch, 1996; Mang, 2000; Moore et al., 2008; Mónaco, 2008). 
En este estudio se configuran como tres áreas que necesitan ser estudiadas en su conjunto, por la fuerte imbricación entre las mismas.

En cuanto a las sub-variables se estima que

- Especifican el "foco de análisis", lo tipifican, describen y puntúan en términos de mayor o menor grado de ajuste al comportamiento esperado.

No nos consta que en estudios previos se haya diseñado una estructura jerárquica relativa a la habilidad de cantar entonado en la primera infancia, asunto que, probablemente, sea el principal avance de esta tesis.

- Asumen cada variable como unidad supra-ordinal que conjuga estructuras subordinadas, lo que permite concebir la competencia de cantar entonado como la suma de sub-habilidades.

El análisis de los resultados y la comparación entre los diferentes niveles de la jerarquía llevada a cabo en esta tesis, muestran una iniciativa prometedora para iluminar la habilidad compleja del canto entonado.

- Tipifican en términos de acción las categorías subsumidas por cada sub-variable y proponen su denominación de acuerdo a la naturaleza del comportamiento motivo de análisis.

Los estudios previos de la autora permitieron tipificar comportamientos compartidos por niños de la misma edad; estas observaciones demandaron aislar el comportamiento observado, definirlo como constructo y hallar la denominación más apropiada de acuerdo a sus características intrínsecas. Puede considerarse otro de los aportes originales de la presente tesis.

- Permiten la comprobación de la pertinencia de los constructos creados, mediante pruebas empíricas que aportan a la estimación de su validez. Se considera que 
los indicadores seleccionados contribuyen al esclarecimiento de esta habilidad compleja conformada por habilidades y sub-habilidades de amplio espectro.

Operacionalizar los constructos, diseñar el modo de estimarlos objetivamente y seleccionar los recursos estadísticos apropiados para ello, permiten asumir un cierto grado de confianza en tales avances.

- Facilitan el análisis de categorías intra-sub-variable de acuerdo a una jerarquía interna entre las diferentes sub-variables de carácter vertical y no transversal.

La transversalización podría concebirse como una meta de estudios futuros. Al momento, haber alcanzado una jerarquía vertical confiable resulta un paso adelante en el avance del objeto de estudio.

- Proponen nuevos focos de atención a la problemática, presentando la habilidad de entonar como una estructura "mosaico" conformada por micro-estructuras. Si bien algunos de estos focos han formado parte de escritos previos, los mismos han sido presentados como entidades aisladas lo que dificulta la concepción de la habilidad como un todo unificado con sus jerarquías internas.

La concepción de estructura mosaico (patchwork) probablemente sea un común denominador de las habilidades complejas. En tal sentido alcanzar la meta de tipificar cada micro-unidad del mosaico es un avance.

- Acuñan nuevas denominaciones para el objeto de estudio al definir nuevos constructos. 
Para la variable Emisión vocal las sub-variables y categorías siguientes

- Localización de la altura y sus respectivas categorías Hablada monotónica, Hablada con tendencias de movimiento sonoro, Entonada oscilante y Entonada estable. Los estudios previos aluden a algunos de los comportamientos descriptos en estas categorías aunque no son denominados ni presentados conformando una estructura exhaustiva que contenga los diferentes tipos y niveles de respuesta.

Se trata de concebir la ubicación de la altura precisa dentro del amplio espectro que cubre desde la voz hablada hasta la voz cantada. No constan en trabajos anteriores tales puntualizaciones y denominaciones.

- Contorno melódico: es el constructo más desarrollado en escritos anteriores aunque no se ha podido rescatar una estructura orgánica y exhaustiva que describa los diferentes tipos de respuesta. En este caso se utilizaron las categorías Respuesta hablada; No sigue el contorno y Respeta el contorno.

Las categorías elegidas son acordes con los trabajos previos (Dowling, 1994). Sin embargo en trabajos futuros podrían analizarse más exhaustivamente en términos de las curvas que describen los contornos tal como lo ha hecho Huron (1996).

Para la variable Adecuación Tonal las sub-variables y categorías siguientes

- Estabilidad tonal incluye algunas categorías que aluden a comportamientos descriptos en estudios previos, aunque insuficientemente exhaustivas y $\sin$ conformar una estructura jerárquica. Dichas categorías son Centro tonal ausente, Centro tonal parcialmente presente, Centro tonal por frase, Centro tonal estable insuficiente, Centro tonal estable suficiente. Los estudios previos aluden a algunos de los comportamientos descriptos en estas categorías aunque 
no los conforman como una estructura exhaustiva que contenga y tipifique los diferentes niveles de respuesta.

En trabajos previos se ha aludido frecuentemente al problema de la ausencia de la configuración tonal en las respuestas infantiles (Snyder, 2000; Moog, 2006). En este trabajo dicha característica ha sido abierta en categorías intermedias centradas en el principio de estabilidad a lo largo del todo o por partes.

Respecto de la inestabilidad de las respuestas de la muestra, conclusiones similares describió Tafuri (2009) y en cuanto al desarrollo por “mesetas" los resultados acuerdan con lo descripto por Davidson (1994).

- Apareamiento de la altura muestra la distinción en las respuestas al analizar del grado de acuerdo entre la altura de emisión y la altura de la banda grabada. Contiene las categorías Altura de comienzo y Altura de cierre. El estudio de ambas y la comparación entre las mismas se denominó Vinculaciones entre las alturas de comienzo y cierre y se fundamenta en la concepción de que ambas delimitan las fronteras de la tonalidad y del ámbito de la canción, asuntos que no constan como tales en estudios previos. Las categorías diseñadas para analizar tales relaciones son: Alturas absolutas: Respuesta que acuerda con las alturas reales de la banda grabada. Alturas transpuestas: Respuesta que desacuerda con la altura impuesta por la banda y que respeta las relaciones interválicas. Alturas erróneas: Respuesta que no atiende a la altura impuesta ni a las relaciones interválicas.

Las categorías construidas no constan en estudios previos. En tal sentido la categoría alturas transpuestas daría cuenta de la adopción de un centro tonal configurado "per se" pero no acorde al de la banda grabada, esto es, no concordante con 


\section{CANTAR CANCIONES ENTRE LOS CUARENTA Y CINCUENTA MESES 141}

la tonalidad de la banda. Este tipo de respuestas muestran las dos vertientes del desempeño en la tonalidad: entonar consistentemente de acuerdo a una tonalidad "interna" o hacerlo de acuerdo a una tonalidad impuesta externamente (por la banda). Dicha distinción marca una frontera entre la tonalidad como marco de relaciones y la tonalidad como emplazamiento de la altura en términos absolutos.

Para la variable Continuidad Temporal las sub-variables siguientes

- Ajuste en el tempo Correspondencia entre el tempo de la banda y el tempo de la emisión

- Réplica del texto literario. Sucesión literal de las palabras del texto

La memoria del texto de ambas canciones corroboró lo descripto por Dowling, (1994), Davidson (1994), Welch (1996), Mang (2000), Moore et al. (2008) y Mónaco (2008).

No constan antecedentes en estudios previos del análisis de ambos comportamientos en términos de su continuidad en el tiempo. Las dos categorías precedentes pertenecen a Continuidad Temporal bajo el supuesto que la articulación de las palabras se despliega en el tiempo acorde con lo que Parncutt (1984) llama "tren de pulsos" impuesto -en este caso por la canción-, que contribuye a la mejor organización, distribución y memorización del texto.

\subsubsection{Algunos interrogantes de interés para investigaciones futuras}

El estudio acerca de la reproducción del contorno deja un interrogante sin contestar: ¿cuál contorno resulta más fácil de resolver, el de direccionalidad ascendente o descendente? Investigaciones futuras podrían medir las respuestas a canciones con 
dificultad equivalente. Las seleccionadas para este estudio poseen diseños iniciales de diferente dificultad por su encuadre tonal, por lo tanto no permitirían dar una respuesta unívoca.

Otro interrogante que genera este estudio es el siguiente: ¿se obtendrían similares resultados en las tres áreas de estudio delimitadas si la interpretación de estas canciones fuera a capella? (aunque la enseñanza de las canciones se realizara sobre la banda grabada). Estudios comparativos entre ambos tipos de performances serían de interés. También el indagar si los niños que acoplan con exactitud a la tonomodalidad de la banda grabada lo hacen porque pueden adaptarse a ella o porque han logrado memorizar muscularmente las alturas de la canción en los ensayos; para lo cual sería de utilidad cambiar la tonomodalidad en los diferentes registros grabados.

Resultaría de interés la realización de un estudio longitudinal multidisciplinario que indagara si las habilidades el canto y el habla se desarrollan en paralelo y más aún si "las canciones contribuyen a la adquisición del lenguaje" (Schön, 2008, p. 976) colaborando a superar dificultades suscitadas en el habla a partir de la experiencia del canto.

\subsection{Aportes potenciales}

Los estudios realizados pueden resultar de utilidad para educadores musicales y profesores de Didáctica Musical.

Los niños desarrollan la habilidad de entonar con la ayuda de adultos competentes. Pueden considerarse contribuciones de los maestros realizar acciones tales como

- Ayudar a la Localización de la altura en el rango del canto 
- Rescatar el rol de la imitación para el aprendizaje mostrando el modelo del maestro.

- Incluir prácticas con tarareo para quitar la variable verbal y centrarse en los componentes musicales.

- Utilizar melodías fuertemente tonales que promuevan la conciencia tonal y melódica, para lo cual resulta crucial seleccionar adecuadamente el repertorio. En las primeras etapas, melodías con contornos ascendentes y descendentes "por paso" y aquellas en que los saltos se produzcan más frecuentemente entre la dominante y la tónica.

- Diseñar estrategias para afianzar la tonalidad, como por ejemplo cambiar de tónica en cada repetición usando introducciones fuertemente tonales, reiterando las canciones más sencillas y dominadas por el grupo en diferentes tonalidades, eligiendo la tonalidad vocalmente más cómoda para los niños en lugar de la más cómoda para el maestro o utilizando contraejemplos tales como proponer una tonalidad en el registro grave para que comprueben que no es posible cantar tales alturas.

- Hacer cantar a los niños entonados para que lo hagan "a solo" o en dúos con otros niños, particularmente con aquellos que están transitando las etapas próximas a la emisión en el rango del canto.

- Utilizar el lenguaje de manera apropiada: "recitar" para rimas y retahílas y "cantar" para las canciones.

- Conversar con los niños acerca de lo que se pretende de ellos, poniendo "en palabras" la práctica propuesta "ahora lo vamos a cantar más agudo", “atiendan porque voy a proponerles cambiar de tono" 
- Atender a los componentes fisiológicos implicados en el canto (postura, respiración, emisión del fiato) mostrando la acción corporalmente.

- Hablar con los niños acerca de la tarea, promover el placer por la acción de cantar "per se" elogiar a los niños que muestran progresos en el desarrollo de la habilidad, reiterar el repertorio buscando mejorar la performance en cada repetición, esto es, usar la repetición describiendo muy brevemente el logro que se intenta con la reiteración.

- Ayudar al canto de los niños cantando a dúo con ellos.

- Promover que otros adultos que posean la habilidad de entonar, canten para ellos.

- Evitar tanto el elogiar el canto hablado considerándolo "canto" como demandar el uso de la voz en niveles de sonoridad altos.

- Promover una actitud de re-ensayo de la performance atendiendo a la acción de entonar por encima de la de "recitar" el texto.

- Desarrollar la actitud de cantar como actuación "para los demás" y así contribuir a la pérdida de vergüenza por la acción de cantar.

Estos avances serán aportados en copias reducidas a escuelas de la localidad y en particular a las instituciones y maestros que han colaborado para el trabajo empírico. Como integrante de la cátedra de Educación Musical de la Facultad de Bellas Artes, la autora facilitará el presente material el que será motivo de análisis y discusión con docentes y estudiantes. 


\section{Referencias}

Akoschky, J. (2007). Música en el nivel inicial. En e-Eccleston. Lenguajes artísticosexpresivos en la Educación Inicial, 3 (6). ISPEI "Sara C. de Eccleston” DGES. Ministerio de Educación GCBA. Recuperado de http://ieseccleston.buenosaires.edu.ar/Revista\%20N\%BA\%206_Akoschky.pdfel $10 / 12 / 2010$

Beard, D. (2003). Contour modeling by multiple linear regression of the nineteen piano sonatas by Mozart. (Tesis de doctorado en filosofía, Florida State University). Recuperada de http://etd.lib.fsu.edu/theses/submitted/etd-10302003012714/unrestricted/BeardDDissertation.pdfe 16/11/2009

Bregman, A., y Campbell, I. (1971). Primary auditory stream segregation and a perceptual order in rapid sequences of tones. Journal of Experimental Psychology, 89(2), 244-249.

Buck, P. (1944). Psychology for musicians.USA: Oxford University Press.

Butler, D. (1979). A further study of melodic channeling. Perception and Psychophisycs, 25(4), 264-268.

Carlsen, I. (1981). Some factors which influence melodic expectancy. Recuperado de http://webistem.com/acoustics2008/acoustics2008/cd1/data/articles/001790.pdf el $7 / 2 / 2008$

Chang, H., y Trehub, S. (1977). Infant's perception of temporal grouping in auditory patterns. Child Development, 48(4), 1660-1670.

Cohen, A. J. (2008). Advancing interdisciplinary research in singing through a shared digital repository.En Acoustics'08 Paris, 3177-3182. Recuperada en 
CANTAR CANCIONES ENTRE LOS CUARENTA Y CINCUENTA MESES 146

http://webistem.com/acoustics2008/acoustics2008/cd1/data/articles/001790.pdfel $18 / 10 / 2010$

Cole, M. (1996). Psicología Cultural. Madrid: Morata

Cross, I. (2003). Music and biocultural evolution. En M. Clayton, T. Herbert, y R. Middleton (Eds.), The cultural study of music: A Critical Introduction (pp. 1930).UK: Routledge

Dalla Bella, S., Gigère, J., y Peretz, I. (2007). Singing proficiency in general population.Acoustical Society of America, 121(2), 1182-1189. Recuperado de http://www.ncbi.nlm.nih.gov/pubmed/17348539 el 17/2/2011

Davidson, L. (1994).Songsinging by young and old: a developmental approach to music. En R. Aiello y J. Sloboda (Eds.), Musical Perceptions (pp.99-130). USA: Oxford University Press.

Davidson, L. (1994). Melodic contour in hearing and remembering melodies. En R. Aiello y J. Sloboda (Eds.), Musical Perceptions (pp. 173-189). New York: Oxford University Press.

Davidson, L., y Scarlett, W. (1987). When a song is a song? The development of singing in early childhood. Early Childhood Education Journal, 14(3), 30-31.

Domingo Curto, J. (2005). La Cultura en el laberinto de la mente. Aproximación filosófica a la 'Psicología Cultural' de J. Bruner. Buenos Aires: Miño y Dávila.

Dowling, J. (1984). Developing of musical schemata in children's spontaneous singing. En W. R. Crozier y A. J. Chapman (Eds.), Cognitive process in the perception of art (pp. 145-163).North Holland: Elsevier Science Publishers. 
Dowling, J. (1994). Melodic contour in hearing and remembering melodies. En R. Aiello y J. Sloboda (Eds.), Musical perceptions (pp.173-186).Oxford University Press.

Farnsworth, P. (1968). The social psychology of music (2nd. edition).Ames IA: Iowa State University Press.

Furnó, S. (2004). La canción infantil autoral: una diagnosis del estado del arte en la Argentina. En Actas de las Primeras Jornadas de Investigación en Disciplinas Artísticas y Proyectuales (490-496).La Plata: Universidad Nacional de la Plata.

Furnó, S. (2001) La etapa prepolifónica: un espacio de transición. En F. Delalande, S. Malbrán, El juego de la música siglo XXI. Fichas de Fundamentación Pedagógica. 3ra clínica Latinoamericana de Educación Musical. La Plata: Fundación para la Educación Musical.

Gates, A., y Bradshaw, J. (1977). The role of the cerebral hemispheres in music. BrainLanguage, 4, 403-431.

Gorini, V. (1983).El coro de niños. Como actividad en la escuela primaria.Buenos Aires: Editorial Guadalupe.

Hargreaves, D. (1996). The development of artistic and musical competence. En I. Deliege y J. Sloboda (Eds.), Musical beginnings (pp.145-170).New York: Oxford University Press.

Hemsy de Gainza, V. (1964). La iniciación musical del niño. Buenos Aires: Ricordi. Hevner, K. (1936). Experimental studies of the elements of expression in music. The American Journal of Psychology, 48(2), 246-268.

Hughes, E. (1915). Musical memory in piano playing and piano study. The Musical Quarterly, 1(4),592- 603. 
CANTAR CANCIONES ENTRE LOS CUARENTA Y CINCUENTA MESES 148

Huron, D. (1996). The melodic arch in Western Folksongs. Computing in Musicology,10, 3-23.Recuperado de http://www.humdrum.org/Huron/Publications/huron.arch.text.html el 14/11/2008. Ibarretxe, G. (2010). Fundamentos psicopedagógicos. En M. Díaz y M. E. Riaño (Coord.), Fundamentos Musicales y Didácticos en Educación Infantil (pp.39-54). España: Universidad de Cantabria.

Jeans, I. (1937). Science and Music. London: Cambridge University Press.

Kim, J. (2000). Children`s pitch matching, vocal range, and developmentally appropriate practice. Journal of Research in Childhood Education, 14(2), 152160.

Lerdahl, F., y Jackendoff, R. (2003). Teoría generativa de la música tonal.(J. González Castelao, trad.). Madrid: AKAL.

Lessen, W., Levine, I., y Wendrick, K. (1979). The imitation of pitch in infants. Infant Behavior, 2, 93-99.

Levitin, D., y Tirovolas, A. (2009). Current Advances in the Cognitive Neuroscience of Music. En The Year in Cognitive Neuroscience 2009 (pp.211-231). New York Academy of Sciences.

Licklitterm, R., Honeycutt, H., y Bahrick L. (2001). Intersensory redundancy facilitates prenatal auditory learning in bobwhite quail chicks. Recuperado de http://www.infantlab.fiv.edu/posters/SRCD\% 2001\%quails\%20posters.docel $18 / 8 / 2010$.

López Cano, R. (2004).Elementos para el estudio semiótico de la cognición musical. Teorías cognitivas, esquemas, tipos cognitivos y procesos de categorización. 
Texto para el curso on-line Géneros, estilo y competencia en la semiótica musical cognitiva actual. Escuela Universitaria de Música, Uruguay.

Malbrán, S, y Furnó, S. (1987).Objective test for songs. Council for Research in Music Education, 91, 110-118

Malbrán, S. (Dir.), y Furnó, S. (Codir.). (1989/1994).Proyecto: Aplicación y análisis de resultados de un Instrumento Objetivo para determinar la dificultad de melodías y canciones. Trabajo seleccionado por la Comisión de Investigaciones Científica y Tecnológicas, Programa de Promoción Preferencial de Formación de Recursos Humanos en Investigación Científica, Universidad Nacional de La Plata, La Plata. Malbrán, S. (1991). El aprendizaje musical de los niños. Buenos Aires: Actilibro S. A. Malbrán, S. (1992). Ese es otro cantar. Vocación. Nivel Inicial, 48.

Malbrán, S., Martínez I., y Segalerba M.G. (1994). Audiolibro 1. La Plata: Las Musas Ediciones Musicales.

Malbrán, S., y Mónaco, M. (2002). Canto espontáneo y ejecución sincrónica como habilidades en gestación. En Actas del Encuentro de investigación en arte y Diseño-ENIAD 2002 (pp.41-43).La Plata: Universidad Nacional de la Plata.

Malbrán, S. (2007) El oído de la mente. Teoría musical y cognición. Madrid: AKAL.

Malbrán, S., y García Malbrán, E. (2010). Lenguaje musical y su didáctica: melodía y estructura musical. En M. Díaz y M. E. Riaño (Coord.), Fundamentos Musicales y Didácticos en Educación Infantil (pp.157-184). España: Universidad de Cantabria.

Malbrán, S. (2012).Los comportamientos musicales y su vinculación con las teorías y modelos psicológicos. Manuscrito en prensa, Departamento de Artes, Universidad de Buenos Aires, Buenos Aires, Argentina. 
Mang, E. (2000). Intermediate vocalizations: an investigation of the boundary between speech and songs in young children's vocalizations. Bulletin of the Council for Research in Music Education, 147, 116-121.

Martínez, I. (2008). La composición temporal del habla, el canto y el movimiento en la musicalidad de las interacciones tempranas adulto-infante. En M. P. Jacquier y A. Pereyra Ghiena (Eds), Actas de la Séptima Reunión Anual de SACCoM. Objetividad-Subjetividad y Música(pp.73-82). Rosario: Universidad Nacional de Rosario.

Marty, G. (1992).Teoría de esquemas en psicología. Palma de Mallorca: Prensa Universitaria.

Massen, C., y Prinz, W. (2009). Movements, actions and tool-use actions: an ideomotor approach to imitation. Philosophical Transactions of the Royal Society of London - Series B: Biological Sciences, 364(1528), 2349-2358.

Meltzoff, A., y Moore, M. (1977).Imitation of facial and manual gestures by human neonates. Science, 198, 75-78.

Meltzoff, A., y Gopnik (1993).The role of imitation in understanding persons and developing a theory of mind. En S. Baron-Cohen, H., Tager-Flusberg y D. J., Cohen (Eds.), Understanding other minds. Perspectives from Autism (335-366) Oxford: Oxford University Press.

Meltzoff, A. (1995). Understanding the intentions of others: re-enactment of intended acts by 18-months- old children. Developmental Psychology, 31(5), 838-850.

Meltzoff, A. (2007). 'Like me': a foundation for social cognition. Developmental Science, 10(1), 126-134. 
Meyer, L. (1956). Emotion and meaning in music. Chicago: University of Chicago Press.

Miyamoto, K. (2007). Musical characteristics of preschool-age students: a review of literature. Recuperado de http://upd.sagepub.com/subscriptionsel 11/2/2011

Mónaco, M. (1998a). La tesitura vocal en el canto espontáneo de niños y adultos no músicos. En Actas de la 1ra. Conferencia Iberoamericana de Investigación Musical (pp.50-53). Argentina: Universidad Nacional de Lanús.

Mónaco, M. (1998b). Tonalidad de las canciones y canto infantil. Algunos interrogantes sobre las prácticas docentes. En Actas de la IIa. Conferencia Iberoamericana de Investigación Musical (pp.47-50). Argentina: Universidad Nacional de Lanús.

Mónaco, M. (1999a). Himno Nacional Argentino y tonalidad impuesta. En Orpehotron (pp.43-52). Argentina: Conservatorio Provincial Alberto Ginastera.

Mónaco, M. (1999b) Desarrollo vocal infantil y estrategias de canto en el Jardín de Infantes. En Actas del 2do Encuentro Latinoamericano de Educación Musical. Sociedad Venezolana de Educación Musical (pp.24-25).Venezuela: Fundación V Centenario.

Mónaco, M. (2000). Un estudio acerca de la reproducción del contorno melódico en niños de tres años. En Actas de la IIIra Conferencia Iberoamericana de Investigación Musical (pp.93-96). Mar del Plata: Fundación para la Educación Musical.

Mónaco, M. (2001). La tesitura espontánea del canto en niños de 3 y 4 años. En F. Shifres (Ed.) Actas de la 1ra Reunión Anual de la Sociedad Argentina para las Ciencias Cognitivas de la Música. Buenos Aires: SACCoM. CD-ROM 
Mónaco, M. (2003). Un estudio comparado entre niños argentinos y cantoneses acerca de la tesitura vocal a los tres años. En Actas del 4to Encuentro de Investigación en Arte y Diseño-ENIAD 2003(pp.222-224). La Plata: Universidad Nacional de La Plata.

Mónaco, M. (2008). La pericia en el canto a los tres años. Incidencias tonomodales y constructivas. En M. P. Jacquier y A. Pereyra Ghiena (Eds.), Actas de la Séptima Reunión Anual de SACCoM: Objetividad - Subjetividad y Música (pp.125-130). Rosario: Universidad Nacional de Rosario.

Moore, R., Chen, H. y Feng, X. (2008). Investigation of new song acquisition by six year olds in China, Taiwan and the United States. En Proceeding of the $28^{\text {th }}$ ISME Conference in Bologna, Italy.20-25 July 2008.

Nadel J. (2002). Imitation and imitation recognition: Functional use in preverbal infants and nonverbal children with autism. En A. N. Meltzoff y W. Prinz (Eds.), The imitative mind development, evolution and brain bases (pp.63-73). Cambridge:Cambridge University Press.

Papouseck, M. (1996).Intuitive parenting. En I.Deliege, y J. Sloboda (Eds.), Musical beginnings. Origins and a development of musical competence (pp.88-112). Oxford: Oxford University Press.

Parncutt, R. (1994). Pulse salience and metrical accent. Music Perception, 11(4), 409464. University of California.

Patel, A. (2004). A new approach to cognitive neuroscience of melody. En I. Peretz y R. Zatorre (Eds.), The Cognitive Neuroscience of Music (325-346). Oxford: Oxford University Press. 
CANTAR CANCIONES ENTRE LOS CUARENTA Y CINCUENTA MESES 153

Pfederer, M. (1964).The responses of children to musical tasks embodying Piaget's principles of conservation. Journal of Research in Music Education,12(4), 251268.

Reiko Hata (1987) Japanese children’s singing ability and songs used as teaching materials. En Jack Dobbs (Ed.) Intenational Music Education ISME Yearbook, 14. Papers of the $20^{\text {th }}$ Intenational Conference of The International Society for Music Education (75-79).

Reybrouck, M. (2005). Body, mind and music: musical semantics between experiential cognition and cognitive economy. Revista Transcultural de Música 9.

Rivière, A. (1991). Orígenes históricos de la Ciencia Cognitiva: paradigma simbólico y procesamiento de la información. Anuario de Psicología, 51,129-155.

Rizzolatti, G. y Sinigaglia, C. (2007). Las neuronas espejo y los mecanismos de empatía emocional. Anuario de Psicología, 38(2), 321-323. Barcelona:Universidad de Barcelona

Rutkowski, J. (1994). The measurement and evaluation of children's singing voice development. En R. Colwell (Ed), The Quarterly, 1(1-2), 81-95.

Schön, D., Boyer, M., Moreno, S., Besson, M., Peretz, I., y Kolinsky, R. (2008).Songs as an aid for language acquisition. Cognition, 106, 975-983. Recuperado de www.elsevier.com/locate/COGNITel 4/11/2010.

Segalerba, M. G. (2005). Métalangage Et Représentation Graphique Comme Manifestations De La Représentation Mentale De La Musique. Tesis de doctorado inédita, Université Paris IV-Sorbonne.

Sergeant, D. (2009).Book Review: Susan Hallam, Ian Cross and Michael Thaut, Oxford Handbook of Music Psychology. [Reseña del libro Oxford Handbook of Music 
Psychology, de S.Hallam, I. Cross., y M.Thaut].Psychology of Music,37(4), 498504.

Sloboda, J. (1978). Perception of contour in music reading. Perception, 6, 323-331.

Sloboda, J. (1994). Music performance: Expression and the development of excellence. En R. Aiello y J. A. Sloboda (Eds.), Musical Perceptions (152-169). New York: Oxford University Press.

Sloboda, J. (2005). Exploring the musical mind. Oxford: Oxford University Press.

Snyder, B. (2000). Music and memory. London: MIT Press

Stadler-Elmer, S. (2009). How do children develop their vocal musical expression?

Recuperado de http://members.lycos.fr/musicand/BASIC/RESEARCH/STADLERe.htmel 22/12/2009.

Swanwick, K. (1991). Música, pensamiento y educación. Madrid: Morata.

Tafuri, J. (2009). Infants musicality. New research for educators and parents. Traducido al inglés por Elizabeth Hawkins UK: Ashgate.

Tan, N., Aiello, R.,y Bever, Y. G. (1981). Harmonic structure as a determinant of melodic organization. Memory and Cognition, 9, 533-539.

Ward, W. (1963). Absolute Pitch. Part 1.Sound, 2, 14-21.

Welch,G. (1991). A developmental continuum of singing ability: evidence from a study of five-year-old developing singers. Early child development and care, 69, 107119.United Kingdom: Gordon and Breach Science Publishers S.A.

Welch, G. (1996).A developmental view of children’s singing. British Journal of Music Education, 3(3), 295-303. 
CANTAR CANCIONES ENTRE LOS CUARENTA Y CINCUENTA MESES 155

Welch, G. (1998). El desarrollo musical en la temprana infancia. Boletín de Investigación Educativo Musical, 5(14). Buenos Aires: CIEM.

Welch, G. (1999). El desarrollo del canto en el niño. En S. Malbrán (Ed.), Actas de la Ira Conferencia Iberoamericana de Investigación musical (pp.10-19). Buenos Aires: Universidad Nacional de Lanús.

Welch, G., Segeant, D., y White, P. (2000). The role of linguistic dominance in the acquisition of song. En Research Studies in Music Education, 10. Recuperado de: http://rsm.sagepub.com/content/10/1/67.short 28/11/2010

Welch, G. (2004).El canto como modo de comunicación. Traducción de Isabel Martínez. En G. Gonzalo y M. E. de Chazal (Eds.) Actas de la 4ta Reunión Anual de SACCoM. Tucumán Argentina: SACCoM. CD-ROM

Welch, G. (2006).Singing and vocal development. En G. M. McPherson (Ed.), The Child as Musician (311-329). New York: Oxford University Press.

Welch, G., Saunders, J., Papageorgi, I., Rinta, T., Preti, C., Stewart, C., Lani, J., Vraka, M., y Hill, J. (2008). Researching the first year of the National Singing Programme in England. Graham Welch and Evangeline Himonides (Eds).Institute of Education. University of London.

Welch, G., Himonides, E., Saunders, J., Papageorgi, I., Rinta, T., Preti, C., Stewart, C., Lani, J., y Hill, J. (2009). Researching the first year of the National Singing Programme in England: an initial impact evaluation. Psychomusicology: Music, Mind and Brain, 21 (1)

Welch, G., Sergeant, D., y White, P. (1997). Age, sex and vocal task as factors in singing "in tune" during the first years of schooling. Bulletin of the Council for Research in Music Education, 133, 153-160. 


\section{CANTAR CANCIONES ENTRE LOS CUARENTA Y CINCUENTA MESES 156}

Willems, E. (1981). El valor humano de la Educación Musical.Buenos Aires: Paidós

Wolf, T. (1976).A cognitive model of music sight-reading. Journal of Psycholinguistic Research ,5, 143-171.

Zenatti, A. (1969). Le développment génétique de la perception musicale. Paris: CNRS.

Zenatti, A. (1990). Aspects du développement de l'enfant dans l'histoire de la psychologie du XX siècle. Les Ciences de l'education 3-4, 21-38. 